\title{
Gravity Concentration in Artisanal Gold Mining
}

\author{
Marcello M. Veiga *(i) and Aaron J. Gunson \\ Norman B. Keevil Institute of Mining Engineering, University of British Columbia, Vancouver, \\ BC V6T 1Z4, Canada; ajgunson@gmail.com \\ * Correspondence: veiga@mining.ubc.ca
}

Received: 21 September 2020; Accepted: 13 November 2020; Published: 18 November 2020

\begin{abstract}
Worldwide there are over 43 million artisanal miners in virtually all developing countries extracting at least 30 different minerals. Gold, due to its increasing value, is the main mineral extracted by at least half of these miners. The large majority use amalgamation either as the final process to extract gold from gravity concentrates or from the whole ore. This latter method has been causing large losses of mercury to the environment and the most relevant world's mercury pollution. For years, international agencies and researchers have been promoting gravity concentration methods as a way to eventually avoid the use of mercury or to reduce the mass of material to be amalgamated. This article reviews typical gravity concentration methods used by artisanal miners in developing countries, based on numerous field trips of the authors to more than 35 countries where artisanal gold mining is common.
\end{abstract}

Keywords: artisanal mining; gold; gravity concentration

\section{Introduction}

Worldwide, there are more than 43 million micro, small, medium, and large artisanal miners extracting at least 30 different minerals in rural regions of developing countries (IGF, 2017) [1]. Approximately 20 million people in more than 70 countries are directly involved in artisanal gold mining (AGM), with an estimated gold production between 380 and 450 tonnes per annum (tpa) (Seccatore et al., 2014 [2], Thomas et al., 2019 [3], Stocklin-Weinberg et al., 2019 [4], UNEP, 2020 [5]).

One of the mistakes commonly used by many researchers and authorities is to categorize "artisanal" and "small" miners in the same group. The term "artisanal" indicates only the elementary mining and processing practices and not the size of the operation (Veiga, 1997) [6]. Often in developing countries impacted by artisanal mining, mining regulations create barriers to formalizing artisanal miners due to the lack of a clear definition of artisanal mining. Frequently, laws categorize miners into awkward subdivisions such as "traditional, subsistence, panners, informal, formal, etc." with different regulations for each category; however, the distinctions between the types of miner are often unclear (Veiga and Marshall, 2019) [7]. The opposite of artisanal mining is "conventional" mining, which refers to the activities of organized companies. Conventional mining operations can be large, medium, or small but typically use the most appropriate technical, legal, and environmental practices to mine and process ores-some small conventional operations responsibly mine less than 20,000 tpa of raw material. On the other hand, some artisanal mines can be large-artisanal operations processing more than 2 million tpa of secondary (weathered or placer) ores are not uncommon. Typically, an artisanal miner works based on instinct, the need to feed his/her family, and pay bills. There are no "classical" geological exploration activities such as drilling and reserve definition or engineering studies undertaken. The concept of survival is constantly the driving force for those miners. However, they are excellent gold prospectors.

One of the main concerns about AGM is the use of mercury to extract gold. AGM is the largest world's anthropogenic mercury pollution with approximately 2000 tpa of mercury lost to the 
environment (UNEP, 2020 [5], ArtisanalMining.org, 2018 [8]). Mercury is used as it forms an amalgam with gold (and most other metals, except iron and platinum), allowing the gold to be more easily concentrated and recovered (Veiga et al., 2014 [9]). According to Pryor (1965) [10] amalgamation, or "the wetting of gold by mercury is not alloying, but a phenomenon of moderately deep sorption, involving some interpenetration of the two elements". In a large number of countries, artisanal miners amalgamate the whole ore either in small ball mills or passing the ground ore on sluices made of copper plates covered with mercury (Figure 1). These procedures are the main causes of large losses of mercury to the environment, but it is hard to change miners' behavior as they believe that gravity concentration methods are inefficient to extract fine particles of gold. However, the amalgamation of whole ore is generally not a good solution to capture fine gold as amalgamation is typically inefficient when mercury is oxidized and gold particles are smaller than $0.05 \mathrm{~mm}$ (Marsden and House, 2006 [11]).

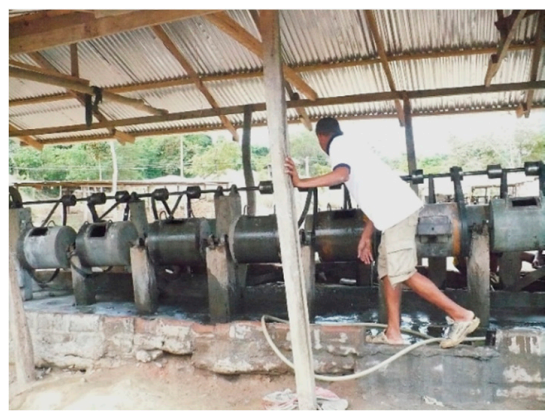

(a)

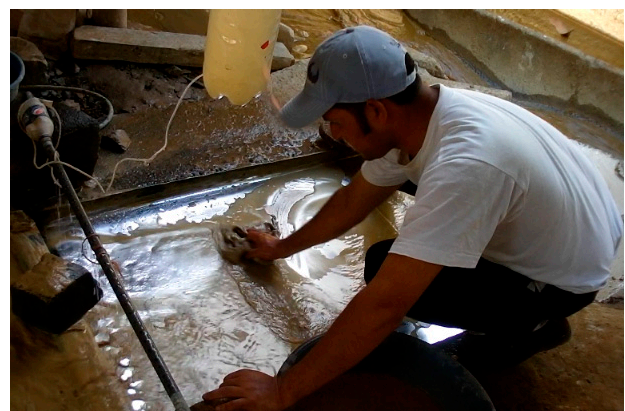

(b)

Figure 1. Whole ore amalgamation in (a) small ball mills in Colombia and (b) in copper-amalgamating sluices in Nicaragua.

When gravity concentrates are amalgamated, mercury losses are drastically reduced but amalgamation-tailings, still with mercury, cannot be discharged into a water stream or recirculated to the grinding circuit or leached with cyanide. In reality, the largest mercury polluters are the processing centers that offer amalgamation services to artisanal miners and retain the mercury-contaminated tailings to leach with cyanide (Veiga et al., 2014 [12]). In this process, mercury forms cyanide complexes that become retained in the final tailings. These mercury-cyanide complexes pollute much more aquatic biota than metallic mercury alone (Drace et al., 2016 [13], Marshall et al., 2020 [14], Seney et al., 2020 [15]). An additional problem is that miners rarely use retorts to condense mercury vapors generated when they burn amalgams in an open pan with a torch. The vapors have been intoxicating millions of individuals directly involved in the gold-processing steps, such as miners and gold buyers, as well as community members in mining towns (Malm, 1998 [16], Hentschel et al., 2002 [17], Hilson et al., 2007 [18], Esdaile and Chalker, 2018 [19], Zolnikov and Ramirez, 2018 [20]).

The ratio $\mathrm{Hg}_{\text {lost }}: \mathrm{Au}_{\text {produced }}$ has been used to assess the efficiency of the amalgamation process and mercury losses can be very low when only gravity concentrates are amalgamated and retorts are used (Table 1). This ratio must be carefully used, as it can cause confusion when just a little gold is produced. For a national or regional assessment of mercury losses, it is a good indicator (Veiga and Baker, 2004) [21].

Table 1. Approximate mercury losses depending on the amalgamation process.

\begin{tabular}{cc}
\hline Amalgamation Method & $\mathbf{H g}_{\text {lost }}: \mathbf{A \mathbf { u } _ { \text { produced } }}$ \\
\hline Whole ore with amalgamating sluices & $\geq 3$ \\
Whole ore in small ball mills & $>6$ \\
Concentrates with no retort & $\sim 1$ \\
Concentrates with retorts & $<0.1$ \\
\hline
\end{tabular}


For more than 40 years, researchers, non-governmental organizations (NGOs), international agencies, companies, etc. have tried to eradicate the use of mercury in AGM, usually demonstrating appropriate processing techniques to concentrate gold. This has been a great challenge, as most artisanal miners do not have the skills and financial resources to change their primitive practices. A better policy would be to reduce first the use of mercury and later eliminate its use.

There are many methods of gold extraction-some, such as panning and sluices, have been used for thousands of years, many others are more recent developments. For instance, Grayson (2007) [22] identified 75 gold separation and leaching methods that do not use mercury or cyanide.

This paper focuses on describing the most common gravity processes used or tested by artisanal miners in various countries, discussing some of the limitations the miners face in adopting these techniques.

\section{Gold Concentration Used by Artisanal Gold Mining (AGM)}

\subsection{General Aspects}

Many gravity concentration methods used by artisanal miners are discontinuous, i.e., miners stop the process to discharge the concentrate after some time of operation. Some miners have the perception that when they see a yellow concentrate, the gold recovery is good, and the equipment works well. This is a common mistake. High gold grade in concentrates does not necessarily mean that the gold recovery is high. Usually, in gravity concentration processes, the grade of gold in a concentrate is antagonistic to the gold recovery (Figure 2) (Veiga et al., 2014 [9]). An interesting perception of most artisanal miners is that the only way to produce more gold is to process more ore. They never think about improving gold recovery by using better concentration methods. They generally do not even know how to assess the gold recovery in their rudimentary processes.

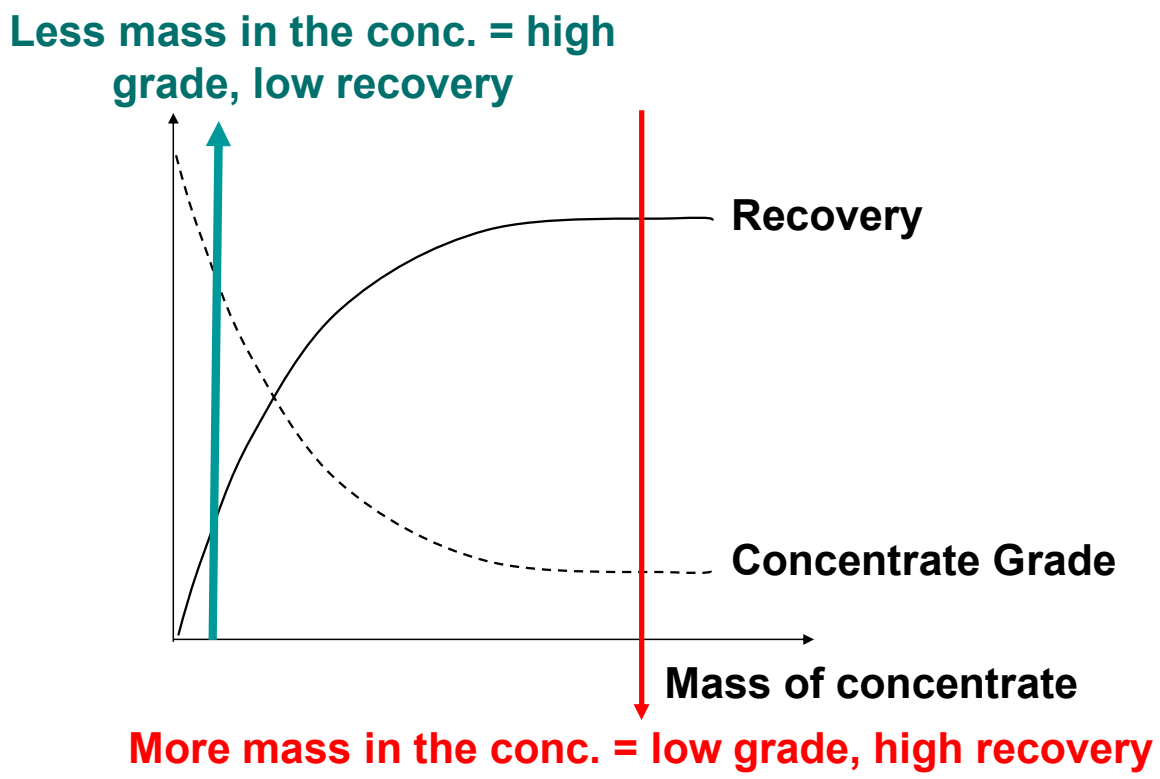

Figure 2. More gold in the concentrate, less Au recovery had the process. Source: Veiga et al. (2014) [9].

Another important point to stress is that chemical analyses of gravity concentrates are usually fraught with imprecision due to the "nugget effect" caused by some gold specks. Analyses of feed and tailings generally provide more accurate gold recovery results than analyses of gravity concentrates.

Most gravity concentration processes consist of a single pass of the feed material through equipment where gold is recovered based on the gravitational force $(G)$ applied to the particles. These methods often do not provide high gold recoveries, particularly with respect to fine gold particles. 
For centuries, gravity methods were gold miners' preferred separation method as there is a large difference between the specific gravity $(\mathrm{sg})$ of gold $(\mathrm{sg} \approx 19.3)$ and common silicate gangue minerals $(\mathrm{sg} \approx 2.7)$ such as quartz sand. The selection of a concentration equipment depends on several variables, such as the mineralogy of the ore, shape of gold particles, pulp density, pulp viscosity, equipment cost, the availability of spare parts, and the grain size of the gold particles. Generally, the applicability of gravity concentration equipment for different gold ores is related to the grain size of the liberated gold particles. As shown in Figure 3, some types of equipment are much more efficient to concentrate fine gold particles than others but most of them are not very efficient for grain sizes finer than $0.074 \mathrm{~mm}$ (200 Tyler mesh). The exception is the centrifugal concentrators, referred to in Figure 3 as "Knelson Centrifuge", which are capable of recovering fine and coarse gold particles.

PARTICLE SIZE OF GOLD (mm)

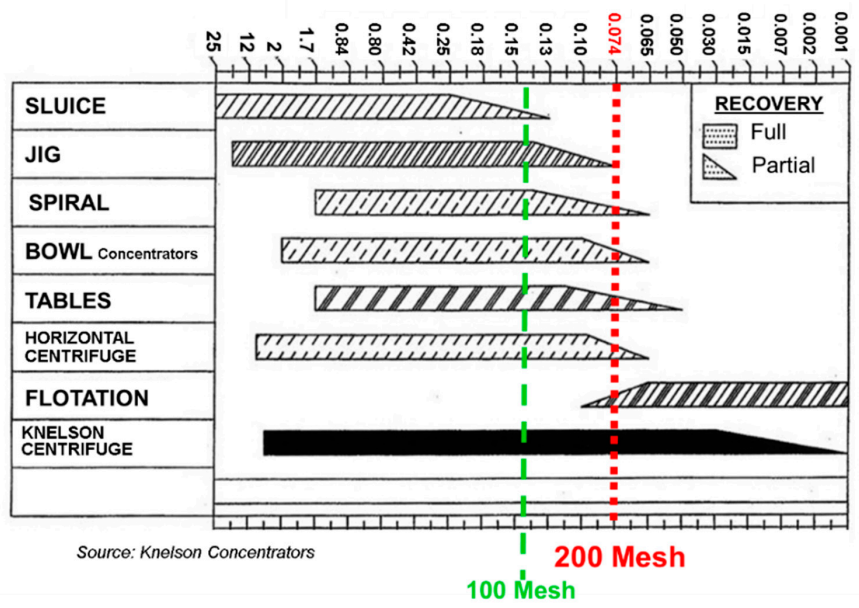

Figure 3. Grain size of gold particle versus the type of gravity concentration equipment (Adapted from Knelson Concentrators' catalog (no longer available) and Sampaio and Tavares, 2005 [23]).

Gravity separation occurs primarily due to weight and size differences between different particles. The size of the particles is an important parameter as a large grain of a gangue mineral (e.g., quartz) behaves like a small grain of gold in a classic gravity separation process. The rate at which a particle settles in a liquid depends on the particle weight and the viscosity of the liquid (in this case the pulp of ore). As a simplification, Gaudin (1939) [24] established an equation to calculate the ratio of diameters of a spherical mineral particle to another, both naturally sinking in a fluid with a certain density under the gravity influence:

$$
\frac{d_{a}}{d_{b}}=\left[\frac{\rho_{b}-\rho_{f}}{\rho_{a}-\rho_{f}}\right]^{n}
$$

where:

$d_{a}$ and $d_{b}=$ diameter of mineral a (light) and $\mathrm{b}$ (heavy)

$\rho_{a}$ and $\rho_{b}=$ specific gravity of the minerals $\mathrm{a}$ and $\mathrm{b}$

$\rho_{f}=$ density of the fluid (or suspension)

$n=$ coefficient ranging from 1 (Newtonian regime) to 0.5 (Stokesian regime), transitional regime between 0.5 and 1

For example, considering a Stokesian regime (very diluted pulps with spherical particles flowing slowly. The drag forces around particles sinking, at low Reynolds number conditions, occur due to the viscosity of the liquid (Sampaio and Tavares, 2005) [23]), the formula above reveals that a particle of quartz of $0.25 \mathrm{~mm}$ should behave in a classical gravity concertation process like a $0.074 \mathrm{~mm}$ particle of gold. Stokesian regime considers spheres falling in a stationary, non-turbulent fluid (low 
Reynolds number, usually below 2000), in which a particle reaches the terminal velocity, $v_{t}$ (zero acceleration) when:

$$
v_{t}=\frac{g \cdot d^{2}\left(\rho_{p}-\rho_{f}\right)}{18 \cdot \mu}
$$

$g=$ gravitational acceleration $\left(9.81 \mathrm{~m} / \mathrm{s}^{2}\right)$

$d=$ particle diameter in meter

$\rho_{p}=$ density of the particle $\left(\mathrm{kg} / \mathrm{m}^{3}\right)$, gold $=19,300$

$\rho_{f}=$ density of the liquid $\left(\mathrm{kg} / \mathrm{m}^{3}\right)$, water $=1000$

$\mu=$ viscosity of the liquid, for example, water at $20^{\circ} \mathrm{C}=1.002 \times 10^{-3}(\mathrm{~Pa} \cdot \mathrm{s})$

While this is a simplification of a complex system, it provides us with a strong reason to believe that size classification (screening or hydrocyclone) of the particles is very important for any type of gravity concentration. Unfortunately, artisanal miners typically do not use size classification, frequently leading to low gold recoveries in gravity concentration processes.

Another important factor is that gold particles can be flaky and can be lost easily to the tailings in laminar concentration systems, such as sluices or tables. In addition, gold is naturally hydrophobic: thin, flat particles tend to "float" on the surface of sluices or tables (Wang and Poling, 1983 [25]). As gold is very malleable, particles can change their morphologies during the comminution process thus affecting gravity concentration, in particular in a laminar system (Ofori-Sarpong and Amankwah, 2011 [26]). Flaky particles can be characterized by their Corey shape factor $(\mathrm{CSF})=\mathrm{C} /(\mathrm{A} . \mathrm{B})^{1 / 2}$, for particles with dimensions: A, B, C such that $\mathrm{A} \geq \mathrm{B} \geq \mathrm{C}$. Small CSFs indicate flattened grains (Figure 4). Particles with a CSF $<0.15$ are very hard to concentrate in laminar regimes (Walsh and Rao, 1988 [27], Wang and Poling, 1983 [25], Gupta and Yan, 2016 [28]). Giusti (1986) [29], studying placer deposits from the North Saskatchewan River, Canada, observed $0.125 \mathrm{~mm}$ gold flakes, with the average CSF of 0.173 , being lost from sluice boxes. The author found in sediments from this river, and in the Athabasca River as well, that as gold particles become flattened their sizes increased. Ofori-Sarpong and Amankwan (2011) [26] highlighted the importance of the grinding process in the recovery of gold as some pieces of equipment, such as hammer mills (very popular in artisanal mining), produce less flaky gold particles (higher CSF) than the ball mill.

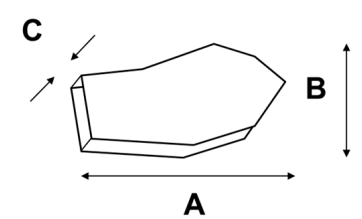

Figure 4. Dimension of a particle to calculate Corey Shape Factor.

The dominant idea held by many researchers and implementers of solutions for artisanal miners, as well as authorities, is that most artisanal miners work only with placer (alluvial) deposits. In fact, artisanal miners often process alluvial, colluvial and eluvial, or secondary, ore deposits until they reach bedrock. However, based on the idea that gold in most alluvial ores is liberated, artisanal miners rarely invest in efficient comminution processes when processing colluvial or eluvial ores. They often use hydraulic monitors to create a slurry and then pump the ore pulp to a gravity concentration process as was common with Californian gold prospectors in the Gold Rush from 1848 to 1855 (Limbaugh, 1999) [30]. With no comminution, their gold recoveries for these secondary types of ores are typically low, usually below 30\%. However, the capital and operating costs for mining (usually dredges and hydraulic monitors) and processing (usually sluice boxes) weathered ores are typically lower than those for primary ores (Figure 5). 


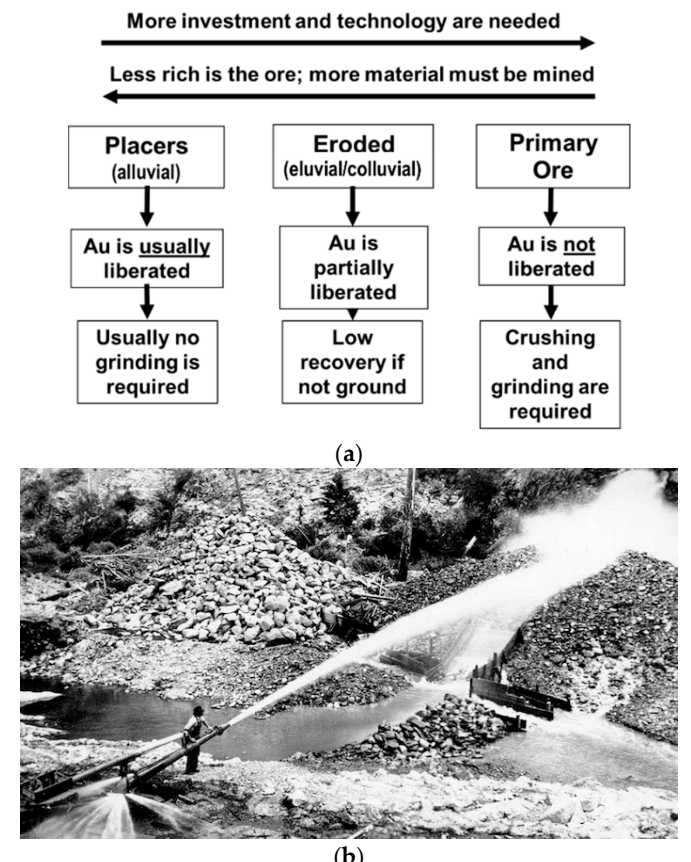

Figure 5. (a) Characteristics of the ores processed by artisanal gold miners (Spiegel and Veiga, 2010) [31]; (b) Photo of an old Californian miner using a hydraulic monitor and sluice box in a placer gold deposit (Hardcore Miner, 2017 [32]).

An interesting observation when analyzing tailings from artisanal miners is a usual U-shape distribution of gold with the grain size analysis (Figure 6) (Andrade-Lima et al., 2008 [33], Veiga et al., 2014 [9]). The gold in the coarse fractions of the tailings is unliberated, associated with the coarse grains of gangue minerals, due to poor comminution processes, while the fine fractions usually have fine gold particles (liberated or not) not recovered due to the rudimentary concentration methods used by the artisanal miners. However, it is important to highlight that in many cases gold does not need to be liberated from a gangue particle to be concentrated (Koppalkar, 2009 [34]). For example, a quartz particle ( $\mathrm{sg}=2.65)$ with an inclusion of $15 \%$ of gold $(\mathrm{sg}=19.3)$ by volume, generates a grain with an $\mathrm{sg}$ of 5.15 , which may be recoverable by gravity processes, especially where there are multiple passes.

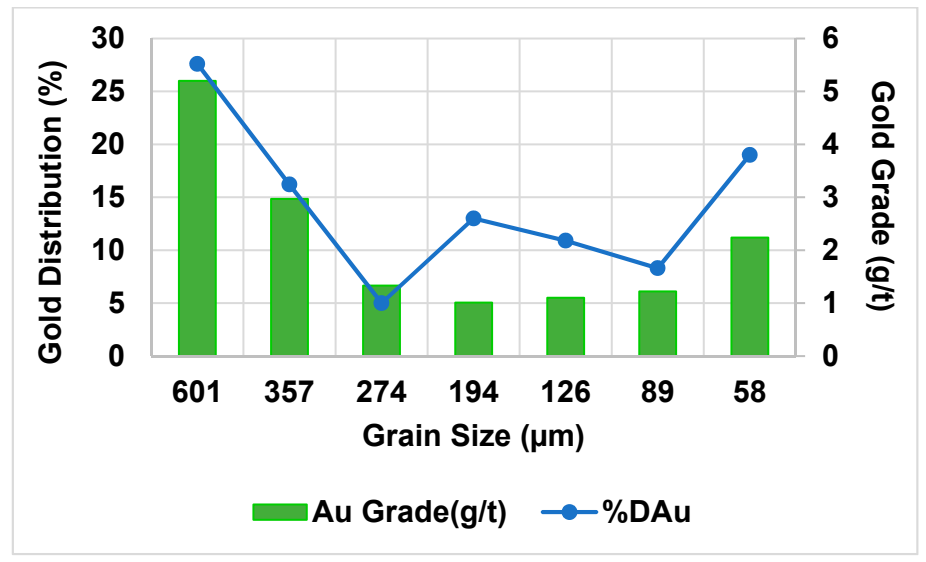

Figure 6. Grain size distribution of gold in artisanal mining tailing from Brazil (Adapted from Andrade-Lima et al., 2008 data) [33].

It is also important to stress that gold is very malleable and usually liberates from the gangue minerals by detachment, as demonstrated by Khalesi et al. (2011) [35]. Therefore, the comminution 
and classification methods play a critical role in the total or partial liberation process of the gold grains (Bode, 2020) [36].

The main gravity concentration processes used by artisanal gold miners worldwide are:

- Panning

- Sluicing

- Jigging

- $\quad$ Tabling

- $\quad$ Centrifuging

\subsection{Panning}

Panning is the most ancient and traditional form of gravity concentration. The movement of water in the pan flushes out the light minerals allowing the heavy minerals to sink. A pan is the main companion of an artisanal miner, either if he/she is prospecting gold or using it as a final concentration tool. For the micro-miners, those processing less than 2 tonnes of ore per day (Veiga et al., 2018) [37], a pan can be the main equipment used for gravity concentration, especially working with alluvial ores.

There are different types of gold pan in the market. In Africa, artisanal miners use gourds, kitchen bowls, or cooking pans to concentrate gold. Wooden and plastic pans have the advantage of buoyancy and of being lighter. In North America, flat bottom plastic or aluminum pans have been used for over 150 years to trap coarse gold specks. These types of pans are 380 to $460 \mathrm{~mm}$ in diameter and 50 to $60 \mathrm{~mm}$ in depth, with sides sloping $30-45^{\circ}$ containing ridges to catch gold (Silva, 1986) [38]. The movement of the flat-bottom pans is usually back and forth, which is easy for experienced operators, (Figure 7).

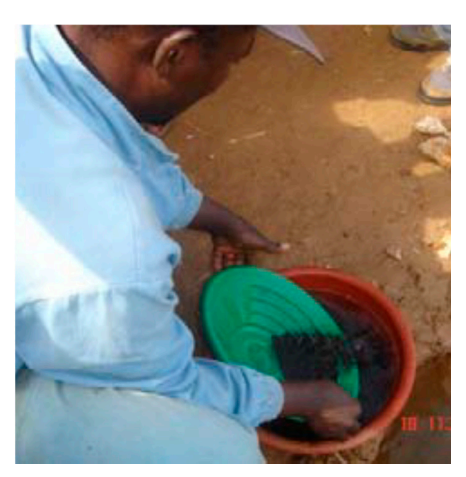

(a)

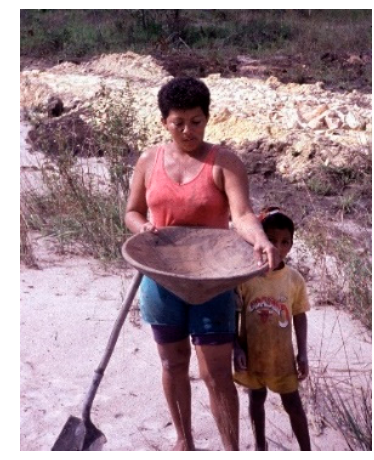

(b)

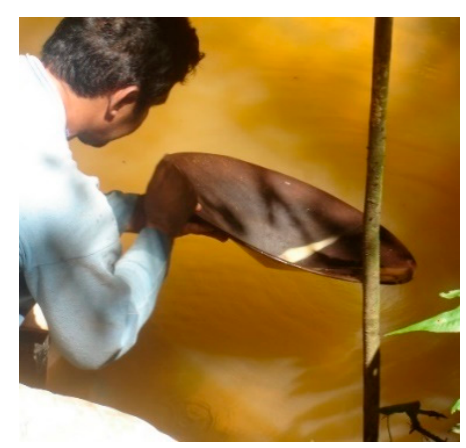

(c)

Figure 7. (a) North American flat bottom pan in Zimbabwe (b) Wooden "batea" in Venezuela (c) Steel "batea" in Indonesia.

In South America and most Asian countries, the main popular panning equipment is the conical "batea", also known as Chinese hat, with a diameter from 0.6 to $1.5 \mathrm{~m}$ and edges with an angle of 
$150^{\circ}$ to $155^{\circ}$. Panning with a "batea" demands experience from the operator and the movements are circular, removing the lighter minerals by overflow.

\subsection{Sluicing}

Sluice boxes are inclined, flat-bottomed troughs, with or without riffles on the surface and usually lined with a carpet to trap the gold particles together with other heavy minerals. Sluices are usually used in alluvial, eluvial, and colluvial ores but many artisanal operations concentrate gold from primary ore ground in hammer mills or Chilean mills. An ore pulp usually with 10-20\% (in mass) of solids is pumped to the sluices and gold and heavy minerals sink to the bottom of the box allowing the lighter particles to pass over and be carried and discharged off at the end of the sluice. Sluices are made in various sizes, from small hand-fed sluices to large sluices found on dredges (Veiga et al., 2006) [39]. With low capital and operating costs, worldwide the artisanal miners prefer the sluices to concentrate gold as they achieve very high ore to concentrate ratio, typically ranging from 10,000:1 to as high as 500,000:1 (Vieira, 2006) [40]. Michaud (2015) [41] described in detail how to make different types of sluice box and provided good tips on how to operate them. Teschner et al. (2017) [42] assessed the gold recovery of an artisanal operation mining alluvial ore in the Guiana region (site not identified) with an average grade of $0.852 \mathrm{Au} g / \mathrm{t}$. After a metallurgical balance of nine samples and microscopic examination, the authors concluded that "more than $90 \%$ of the gold being captured by the sluice is sized between 0.075 and $0.5 \mathrm{~mm}^{\prime \prime}$. Most of the gold particles were liberated.

A well-designed sluice can provide high recoveries for relatively coarse gold particles. The rate of the gold particles settling in the sluice box depends on the gold particle weight, size, and shape. When the ore is naturally classified, which is usually the case with alluvial sand, gold recovery is much higher than unclassified feed, since coarse particles of gangue with low specific gravity can settle at the same velocity as finer gold particles.

\subsubsection{Main Variable in Sluicing}

Some of the main variables affecting the concentration process in a sluice are listed and discussed below (Sivamohan and Forssberg, 1985 [43], Veiga et al., 2006 [39], Lehmann, 2020 [44]):

- Feed rate;

- Water flow;

- $\quad$ Particle size and shape;

- Cleanup period (removal of concentrates);

- $\quad$ Slope angle;

- Riffles and/or carpets lining the sluice;

- Width and length of sluice;

- Pulp density; and,

- Arrangement of the sluices.

The feed rate of material entering a sluice depends on the sluice width, water flow, and pulp density. Most sluices in artisanal mining operations are 1 to $2 \mathrm{~m}$ long, 30 to $50 \mathrm{~cm}$ wide, with walls 10 to $30 \mathrm{~cm}$ high. The relationship between the height of the sluice walls $(\mathrm{H})$ and width $(\mathrm{W})$ is usually $\mathrm{H}=0.3 \mathrm{~W}$ (Lins and Farid, 1992) [45]. The use of screens on top of the sluices is critical to providing a basic size classification of the ore fed into the process. Most sluices in artisanal mining observed in alluvial operations in the Katingan District, Kalimantan, Indonesia, have a feed rate of 10 to 12 tonnes per hour (tph) operating with 15-20\% of solids and producing between 3 to $6 \mathrm{~g}$ of gold after $10 \mathrm{~h}$ of operation (Veiga, 2003) [46].

The water flow, driving pulp density, is an important variable for efficient gold concentration. Silva (1986) [38] highlighted that too much water flow reduces the opportunities for small gold particles to settle and too little water creates a muddy sludge that does not allow the fine gold particles to settle. The adequate water flow for a $60 \mathrm{~cm}$-wide sluice should be around $15 \mathrm{~m}^{3} / \mathrm{min}$ (Sampaio and 
Tavares, 2005) [23]. McCraken (2013) [47] mentioned that in a sluice with riffles, it is not recommended to pass large amounts of water after ore has stopped being fed to the sluice. The author alleged that water flows can remove gold particles already concentrated behind the riffles. Water flow and velocity increase with the sluice slope. Mitchell et al. (1997a) [48] described an operation in Yukon using riffled sluices with slopes of 7 to $12^{\circ}$, a feed rate of $20 \mathrm{~m}^{3} / \mathrm{h}$ of material, and the water flow of $40 \mathrm{~L} / \mathrm{s}$. This operation was designed to recover gold finer than $1 \mathrm{~mm}$. Higher water flows, for example, $80 \mathrm{~L} / \mathrm{s}$, according to the authors, could be used to recover gold specks coarser than $1 \mathrm{~mm}$.

The particle size of gold that is concentrated in a sluice is usually coarser than 200 mesh $(0.074 \mathrm{~mm})$ but the efficiency of the concentration of fine gold particles does not depend only on the size but also on other variables herein discussed, in particular on the particle shape. As discussed above, flaky gold particles can be lost due to the hydrophobicity of the mineral, particularly with laminar flow.

Cleanups to remove the concentrates are necessary, as sluices are batch-type equipment. The gold recovery increases with frequent cleanups, however this decreases the gold grades of the concentrates. The choice of the number of cleanups depends on the grain size of gold, the angle of the sluice (low angles accumulate more material), and the type of minerals associated with the gold. In some operations in Indonesia as well as in Colombia, Guyana, and Suriname, it was observed that miners clean the sluices every $8 \mathrm{~h}$. In Brazil, some miners remove the concentrate from river dredges every 10-15 days. In Portovelo, Ecuador, concentrating fine gold, miners use to clean the low slope angle $\left(5^{\circ}\right)$ wool-carpeted sluices every hour (Gonçalves et al., 2017 [49]). Lehmann (2020) [44] mentioned a placer gold ore study conducted by Russian researchers in which the gold recovery increased from $90 \%$ with cleanups every $12 \mathrm{~h}$ to $94 \%$ with cleanups every $2 \mathrm{~h}$ of operation. The best time of cleanup must be tested for each type of sluice and ore to determine the ideal gold recovery and mass of concentrate generated.

The slope angle of a sluice depends on the type of gold ore being processed. The sluices are usually inclined with angles ranging from $5^{\circ}$ to $15^{\circ}$. The flow velocity of the pulp in a sluice is primarily controlled by the sluice slope. For efficient operation, the flow must be fast enough to assure that the sluice bed is not full and blocked and yet slow enough to allow as much fine gold as possible to settle to the bottom, where it can be trapped. Litvintsev et al. (2012) [50], in an experimental work with sluice boxes using a pulp density of $4 \%$ solids, concluded that the best gold recovery for their placer ore occurred when the slope was $7^{\circ}$. In southern Ecuador, miners concentrate gold coming from Chilean mills in $7 \mathrm{~m}$ long cement sluices operating with an angle of $5^{\circ}$. For an operation with an ore grade of $3 \mathrm{~g} / \mathrm{t} \mathrm{Au}$, the concentrates obtained after one hour was around $17 \mathrm{~g} / \mathrm{t}$. At the end of the process, the Ecuadorian miners have a large mass of concentrate (200-225 kg/day) or $3 \%$ of the original feed (Velasquez et al., 2010) [51]. They then pan this large mass of concentrate, losing significant amounts of gold during panning, and then add mercury to extract gold from the final pan concentrates.

Riffles retard the flow of heavy minerals that are settled on the sluice bed. There are many types of riffle. Hungarian ones promote fluidization of the bed as a "boiling" condition is created that expelled the light particles. Shallow riffles and milder water flow are recommended to trap small gold particles (McCracken, 2013) [47]. Riffles are good for coarse and medium-sized particles and carpets for fine gold. There are many manufacturers of riffled sluices. Keene Engineering (2020a) [52] offers a large selection of sluices with metallic frames, riffles, or expanded metal and carpets (Figure 8). It is common to observe sluices in artisanal plants operating in a very turbulent fashion. This is caused by the presence of riffles on the sluice or by gravels and cobbles as the initial screening is not sufficient to remove coarse particles. Turbulence is one of the reasons for poor gold recoveries as the fine gold particles are often lost. Professor Herman Wotruba, from the University of Aachen, Germany, has demonstrated to the Brazilian artisanal miners the difference in turbulence between carpeted and a riffled sluice (Figure 9). Most North American prospectors concentrating alluvial ores use expanded metal on top of the carpets to trap gold, as they create less turbulence and keep the carpet firmly set at the bottom of the sluice. Hamilton (1988) [53] also recommended expanded metals instead of riffles in conjunction with Nomad carpets to recover placer gold as fine as 150 Mesh $(0.105 \mathrm{~mm})$. 


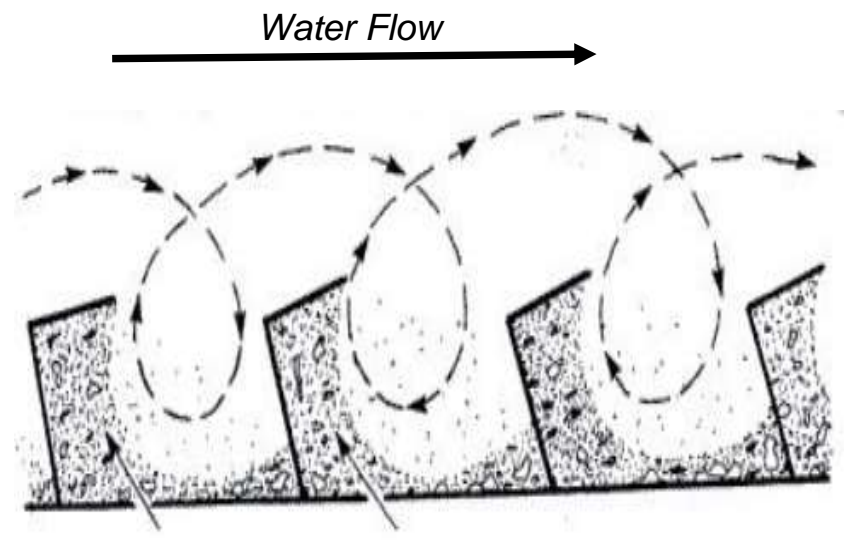

Riffles must operate half full

(a)

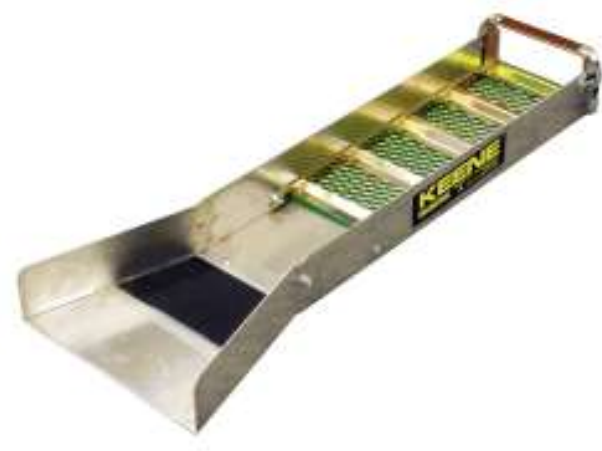

(b)

Figure 8. (a) Hungarian riffles (McCracken, 2013) [47]. (b) Keene sluice with expanded metal on top (Keene Engineering, 2020a [52]).

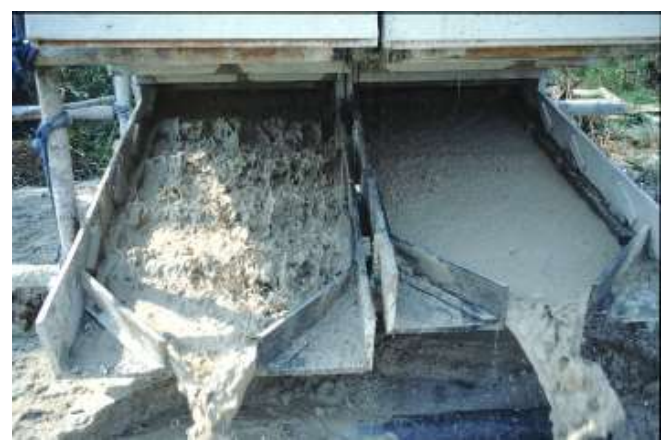

(a)

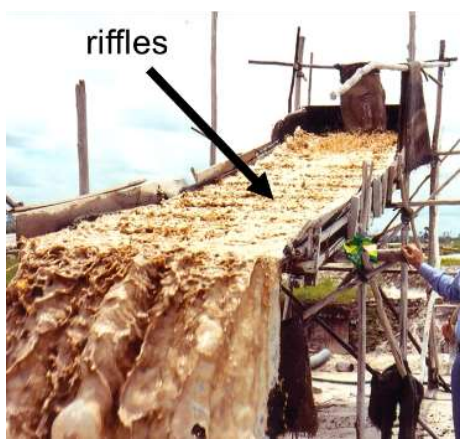

(b)

Figure 9. (a) Sluice box with riffles provokes more turbulence than the one with carpet (photo H.

Wotruba). (b) Riffled sluice with high turbulence in Indonesia.

Carpets are also used to retard the flow of heavy minerals in the sluice. When turbulence is low, the settling process occurs smoothly. In a sluice, there are two types of movement of the particles: rolling and sliding. The rolling velocity increases with the weight of the particle, but the sliding velocity decreases thanks to the friction on the sluice surface. For efficient separation, the friction force must be high. Carpets are ideal for increasing friction and are more suitable for fine gold particles than riffles. In the 1990s, approximately 1 million artisanal miners were distributed in the jungles of South America producing 200 tonnes of gold per year. At that time, the approximately 400,000 Brazilian artisanal gold miners in the Amazon were the world's largest carpet consumers per capita (Feijão and Pinto, 1992 [54], Veiga and Hinton, 2002 [55]).

Artisanal miners use a large variety of carpets to concentrate gold. In Ecuador and Indonesia, miners use wool rags, but the most popular ones in the North of South America are those with grooves (Figures 10 and 11). Brazilian suppliers of equipment for artisanal gold miners sell these carpets for prices ranging from US $\$ 50$ to $70 / \mathrm{m}^{2}$. In laboratory tests with placer ores, Nomad carpets provided excellent recoveries of gold particles as fine as $0.105 \mathrm{~mm}$ (Poling and Hamilton, 1986 [56]). The vinyl loop carpets, similar to the $3 \mathrm{M}$ Nomad ${ }^{\mathrm{TM}}$ mats, have the same price range as the grooved carpets. These mats, used in homes and offices to clean shoes, are very efficient for trapping both coarse and fine gold particles. One of the main problems with a typical vinyl loop mat is that the rubber on the back of the mat makes it difficult to wash out the gold particles entangled in the carpet. In Indonesia, miners were observed burning carpets to recover trapped gold. The Gold Hog (2012) [57] has a series of 
good videos explaining the advantages of different types of carpet. The company Gold Dog (2016) [58] recommends using unbacked Moss vinyl loop carpet (10-12 mm thick) that is set up on top of a felt or grooved rubber carpet (Figure 12). There is a variety of unbacked vinyl loop carpets available for artisanal miners but some of them are of poor quality and tear with little pressure.
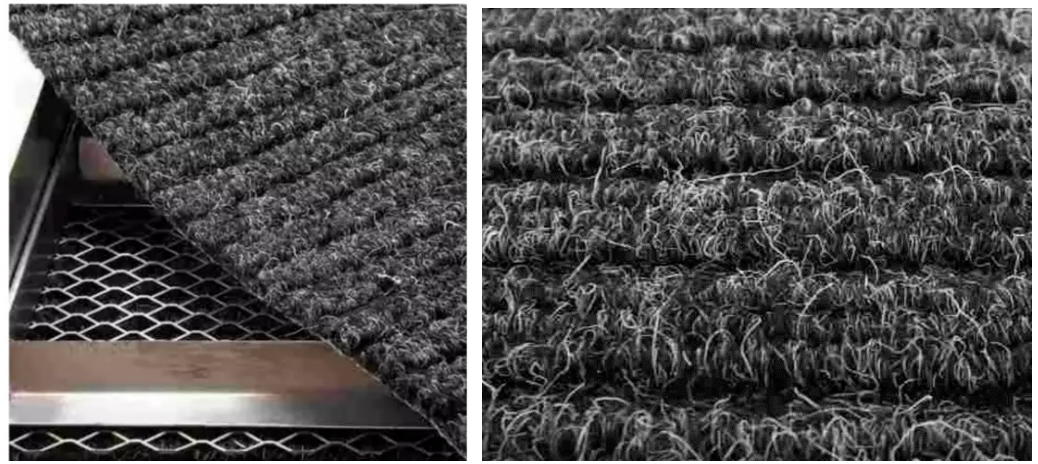

Figure 10. Rubberized carpet used in Brazilian sluices Source: https://www.construvolts.com.br/calhaeclusa-galvanizada-50x185cm-desmontavel-e-mercurio-azougue-100g-para-garimpo-p25277.

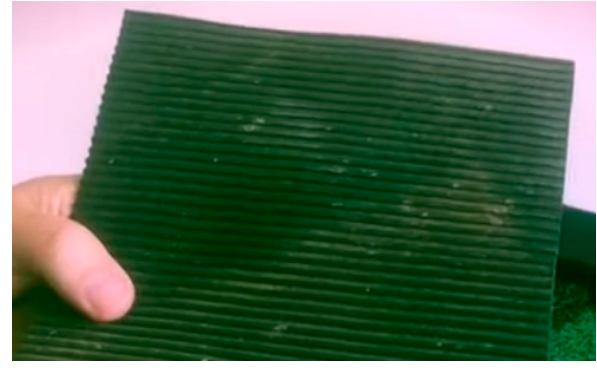

Figure 11. Rubber carpets with grooves.

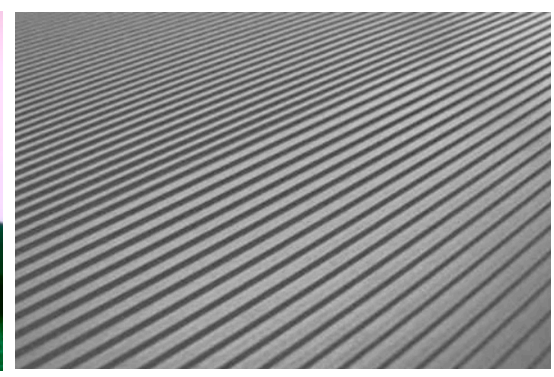

Sources: https://www.youtube.com/watch? vre.com.br/MLB-1202232696-carpete-feltro-pra$\mathrm{v}=$ WyswDAk6iMQ and https://produto.me
garimpo-ouro-fino-verde- $30 \mathrm{~cm}-\mathrm{x}-70 \mathrm{~cm}-\mathrm{JM}$.
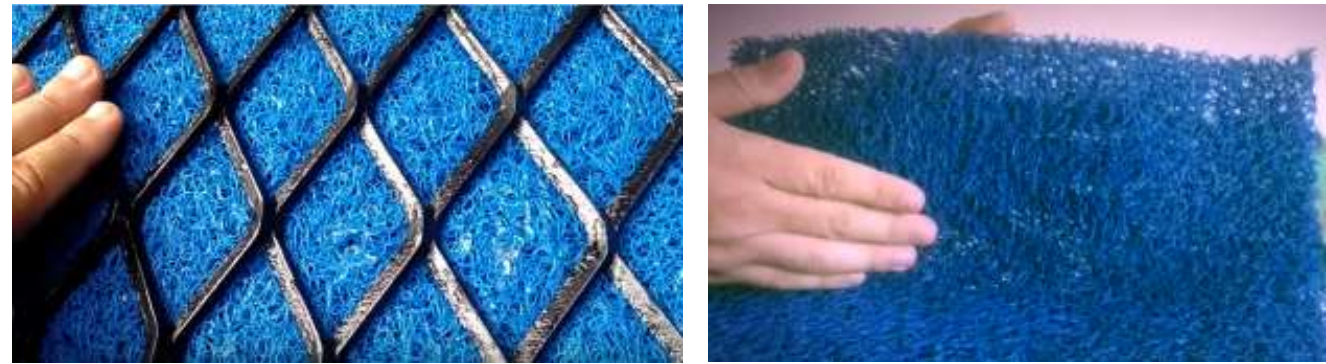

Figure 12. Gold Dog Vinyl loop unbacked MOSS carpet with a metal grid to hold the carpet Sources: https://www.youtube.com/watch?v=lLmNY4mN5SQ, and https://www.youtube.com/watch? $\mathrm{v}=$ WyswDAk6iMQ.

The importance of the width and length of sluices are poorly understood by artisanal miners. It is important to highlight to artisanal miners that the production capacity of a sluice box is given by the width of the sluice and not by the length. Nevertheless, there is a perception among the miners that the longer the sluice, the better it is at capturing fine gold. Sluices with lengths up to $40 \mathrm{~m}$ were observed in many countries. Some old Asian sluices, such as the "Palong", were up to $300 \mathrm{~m}$ long (Sivamohan and Forssberg (1985) [43]. In Brazil, Indonesia, and Sudan artisanal miner built sluices with lengths over $10 \mathrm{~m}$. A simple calculation can reveal the error of the perception that longer is better. For example, let us calculate the final velocity of a sphere rolling down a $3 \mathrm{~m}$-long sluice box with a slope of $15^{\circ}$ with friction, but not considering the drag force of the air (or water): 
Considering the diagram (Figure 13):

$F_{g}=$ gravitational force

$F_{f}=$ frictional force

$\mathrm{N}=$ Normal force

$m=$ mass of the particle

$d=$ sluice length

$\theta=$ slope of the sluice $\left(\theta=15^{\circ}\right)$

$g=$ gravitational acceleration $\left(9.8 \mathrm{~m} / \mathrm{s}^{2}\right)$

$v_{i}=$ initial velocity of the sphere $=$ zero

$v_{f}=$ final velocity of the sphere

$r=$ radius of the sphere

$I=$ momentum of inertia of the sphere at the Center of Mass

$=$ angular acceleration $\left(\mathrm{rad} / \mathrm{s}^{2}\right)$

$a_{C M}=$ acceleration of the sphere at the Center of Mass

$\mathcal{T}=$ Torque

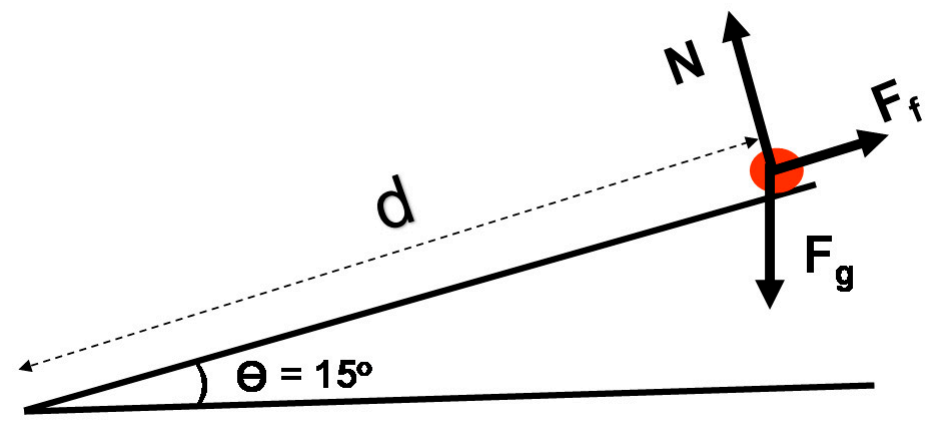

Figure 13. Diagram of a sphere of gold rolling down in a sluice box with carpet (no drag force considered).

Not considering the Drag Force and considering the sphere only rolling:

$\mathcal{T}=r \cdot F_{f}=I \cdot \alpha$ then $\ldots F_{f}=\frac{I \cdot \alpha}{r}$

$a_{C M}=\alpha \cdot r$ then $\ldots \alpha=\frac{a_{C M}}{r}$

Forces at the x-axis:

$F_{g}=m \cdot g \cdot \sin \theta=F_{f}+m \cdot a_{C M}$

$m \cdot g \cdot \sin \theta=\frac{I \cdot a_{C M}}{r^{2}}+m \cdot a_{C M}$

$I($ for sphere $)=\frac{2}{5} \cdot m \cdot r^{2}$

$a_{C M}=\left(\frac{5}{7}\right) \cdot g \cdot \sin \theta$ (rolling)

$v_{f}^{2}=v_{i}^{2}+2 a_{C M} \cdot d$

Then the velocity $\left(v_{f}\right)$ of the sphere with the distance is:

$$
v_{f}=\left(\left(\frac{10}{7}\right) \cdot g \cdot d \cdot \sin \theta\right)^{\frac{1}{2}}
$$

The speed of the sphere in the first meter of the sluice is: $v_{f}$ (in the first $1 \mathrm{~m}$ ) $=1.9 \mathrm{~m} / \mathrm{s}$, in the second meter, is $2.7 \mathrm{~m} / \mathrm{s}$, and in the third meter is $3.3 \mathrm{~m} / \mathrm{s}$. Frictional forces are usually constant in sluice boxes but they depend on the type of sluice bed (carpet or wood). At a certain point, the sphere will reach the terminal velocity when the acceleration is zero. Now, if we think this sphere represents the 
pulp flow, then the speed increases with the distance. Therefore, the fine particles of gold must be concentrated where the flow velocity is slowest, in the first few meters.

Burt (1984) [59] showed that the majority of the gold is recovered in the first meter of a sluice and for most of the coarse $(-2+1 \mathrm{~mm})$, medium $(-1+0.1 \mathrm{~mm})$, and fine gold particles $(-0.1 \mathrm{~mm})$ the cumulative gold recovery essentially flattens after lengths of $2 \mathrm{~m}$. Testing different gold placer ores, Litvintsev et al., (2012) [50] also concluded that approximately $88 \%$ of the gold was recovered within the first meter of the sluice, $10 \%$ in the second meter, and $2 \%$ in the third.

The pulp density (which is the percentage solids in the pulp by mass) of the slurry should be low, in the range of $10 \%$ to $20 \%$ solids, and the thickness of the flow cannot be higher than $3 \mathrm{~cm}$. This allows gold particles to sink to the bottom of the flow to be trapped by the sluice. If aortable digital scale is available, weigh a top-cut Coca-Cola bottle with water and afterward weigh again with pulp coming from the sluice box (Figure 14). The volume of solids plus the volume of water will equal the volume of the bottle (for example $1.5 \mathrm{~L}$ ). The mass of the bottle with pulp will be equal to the mass of the solids plus the mass of the water.

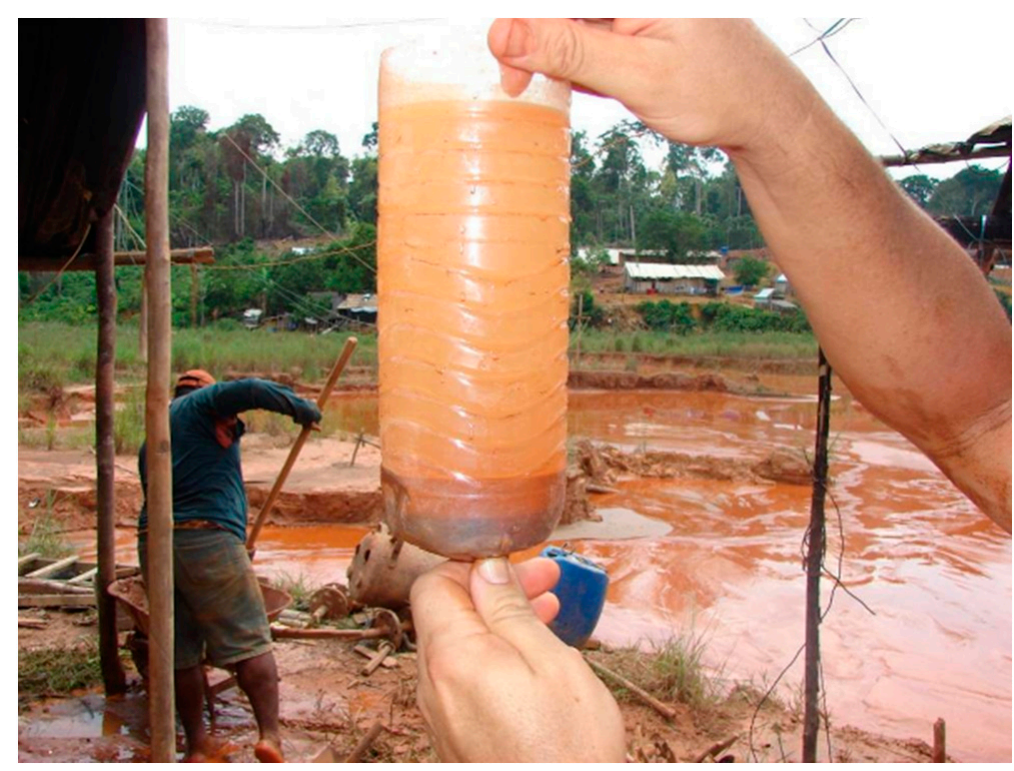

Figure 14. Pulp with solids collected at the discharge of the sluice box.

The specific gravity of the solids, $\mathrm{sg}_{\mathrm{s}}$, can be determined by picnometry using the same bottle or a vial or a beaker. The sg of solids can be calculated using the following formula (picnometry):

$$
s g_{s}=\frac{(M-P)}{(W+(M-P)-S)}
$$

$s g_{s}=$ specific gravity of the ore sample

$P=$ weight of the empty picnometer (a vial or a beaker)

$M=$ weight of solid sample + picnometer

$W=$ weight of pycnometer full of water (full vial or beaker)

$S=$ weight of sample + pycnometer + water (same volume as before)

$W+(M-P)-S=$ weight of water displaced by the solid sample

Usually, the sg of most ores processed by sluices is around 2.7, but it is always useful to obtain it by picnometry. Then the mass of solids in the pulp can be algebraically solved:

$\mathrm{V}_{\mathrm{T}}$ (total volume of the bottle $)=\mathrm{V}_{\text {solids }}+\mathrm{V}_{\text {liquid }}$

$\mathrm{M}_{\mathrm{T}}$ (total mass of the bottle with pulp) $=\mathrm{M}_{\text {solids }}+\mathrm{M}_{\text {liquid }}$ 
The specific gravity of solids, $\mathrm{sg}_{\mathrm{s}}=\mathrm{M}_{\text {solids }} / \mathrm{V}_{\text {solids }}$ or $\mathrm{V}_{\text {solids }}=\mathrm{M}_{\text {solids }} / \mathrm{sg}_{\mathrm{s}}$

As the $\operatorname{sg}_{\mathrm{w}}$ (water specific gravity) is $1, \mathrm{~V}_{\text {liquid }}=\mathrm{M}_{\text {liquid, }}$, then $\ldots \mathrm{V}_{\mathrm{T}}-\mathrm{V}_{\text {solids }}=\mathrm{M}_{\mathrm{T}}-\mathrm{M}_{\text {solids }}$ $\mathrm{M}_{\text {solids }}=\mathrm{V}_{\text {solids }}+\mathrm{M}_{\mathrm{T}}-\mathrm{V}_{\mathrm{T}}=\left(\mathrm{M}_{\text {solids }} / \mathrm{sg}_{\mathrm{s}}\right)-\mathrm{M}_{\mathrm{T}}-\mathrm{V}_{\mathrm{T}}$

$\mathrm{M}_{\text {solids }}\left(1-\frac{1}{\mathrm{sg}_{\mathrm{s}}}\right)=\mathrm{M}_{\mathrm{T}}-\mathrm{V}_{\mathrm{T}}$

$$
\text { Mass of solids }=\frac{\text { Total mass of bottle with pulp }- \text { Total volume of bottle }}{\left(1-\frac{1}{\mathrm{sg}_{s}}\right)}
$$

For example, in a $1.5 \mathrm{~L}$ bottle:

- $\quad$ Mass of the full bottle with pulp $=2.00 \mathrm{~kg}$ (obtained in the scale);

- $\quad$ Total volume $=1.50 \mathrm{~L}$ (measured);

- $\quad$ Specific gravity of solids, $s g_{s}=2.7$ (determined by picnometry);

- Mass of solids $=0.79 \mathrm{~kg}$ (calculated by equation above);

- $\% S(\%$ Mass of solids $)=$ Mass of solids/Mass of the pulp $=0.79 / 2.00=40 \%$;

- Then, this slurry has a pulp density of $40 \%$ solids by mass, too high for sluicing!

In the market, there are scales to determine the pulp density of slurries that are very affordable and easy to operate but the $\mathrm{sg}_{\mathrm{s}}$ is still necessary (Pulp Density Scales, 2011) [60].

The arrangement of the sluice is another important variable for efficient sluicing but is frequently overlooked by artisanal miners. Gold ores usually contain a mixture of coarse and fine-grained gold particles. As fine gold can be lost to the tailings when the pulp flow speed is high, it is always beneficial to have multiple-stage sluices. As most of the gold is recovered in the first meter of a sluice, a way to increase the gold recovery is by using a zigzag arrangement. In this case, the velocity of the flow will be broken every time the direction of flow changes. Zigzag sluices also allow variable flow velocities changing the slope and using different carpets in each deck. In Suriname, zigzag sluices were used for the concentration of gold from both colluvial and alluvial ore. Local miners mentioned that they learned how to make zigzag sluices from Brazilian artisanal miners ("garimpeiros"). In fact, in the Brazilian Amazon, there are sluices with up to four decks arranged in zigzags. In Zaragoza, Colombia, artisanal miners process material from a dry alluvial gold deposit using backhoe excavators to feed a two-deck zigzag sluice (Figure 15). A Colombian engineer mentioned that, unfortunately, some miners add mercury into the lower deck of the sluice box.

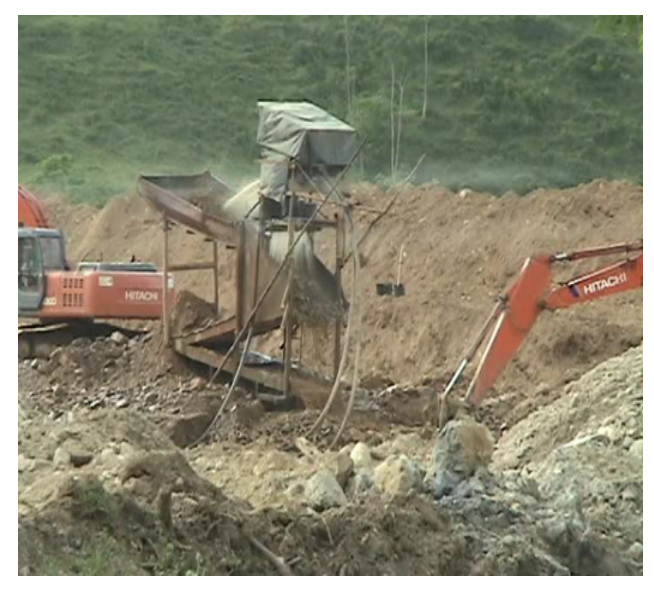

(a)

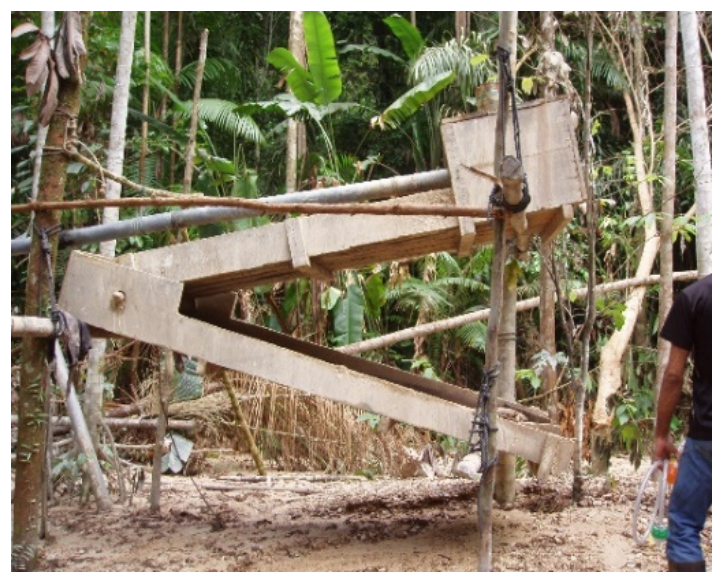

(b)

Figure 15. (a) Zigzag sluice operating dry alluvial gold ore in Zaragoza, Colombia (b) Zigzag sluice in Suriname. 


\subsubsection{Dry Sluices}

A less popular sluice is the dry washers or waterless sluices. These sluices are very useful for regions where water is scarce, for example in the desert in Sudan (Figure 16), but they are not as efficient as the wet sluices. For example, in water, the weight difference between gold and quartz particles is around 11, however, in the air, this difference drops to 7 (911-Metallurgist, 2017) [61]. Dry washers work using pressured air that flows through a perforated bed expelling the light minerals from the sluice bed (Keene Engineering. 2020b) [62]. The main problem with this equipment is the amount of dust generated and most artisanal miners are reluctant to use masks.
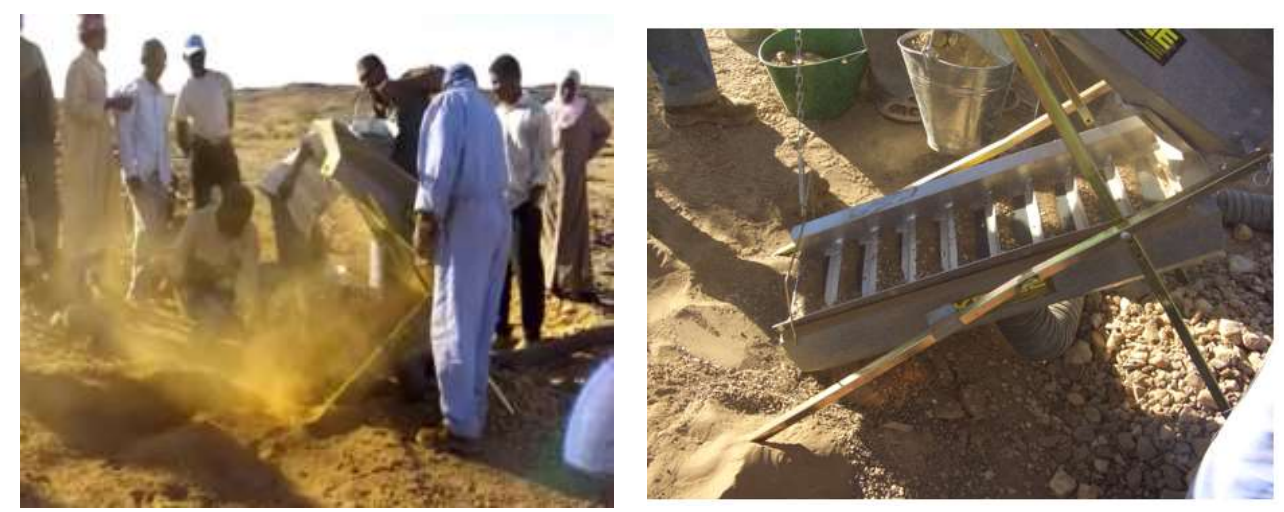

Figure 16. Artisanal miners in Sudan using a waterless sluice.

\subsubsection{Primitive Sluices}

Many primitive sluice boxes have been seen in different countries. In Indonesia, a wooden sluice with no carpet and a low slope is used by artisanal miners to concentrate alluvial cassiterite $\left(\mathrm{SnO}_{2}\right)$ and sometimes gold as well. The amount of sand accumulated in the sluice serves as a carpet to trap the heavy minerals. The calculated $\mathrm{SnO}_{2}$ recovery in operations in Bangka-Belitung was estimated at approximately 12\% (Maia et al., 2019) [63]. Another rudimentary sluice was observed in Uganda, where artisanal miners make sluice boxes carving a tree trunk. Instead of carpets to trap gold particles, those micro-miners use a bed of grass (Figure 17a). In Mozambique, artisanal miners create a sluice to trap gold simply excavating the ground and expecting that the rough surface of the soil traps gold specks from weathered ores. In South Africa, some miners use the same system as in Mozambique but the improvised excavated sluice is lined with wool carpets (Figure 17b).

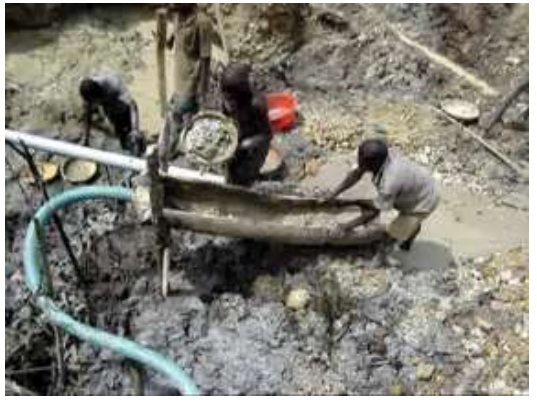

(a)

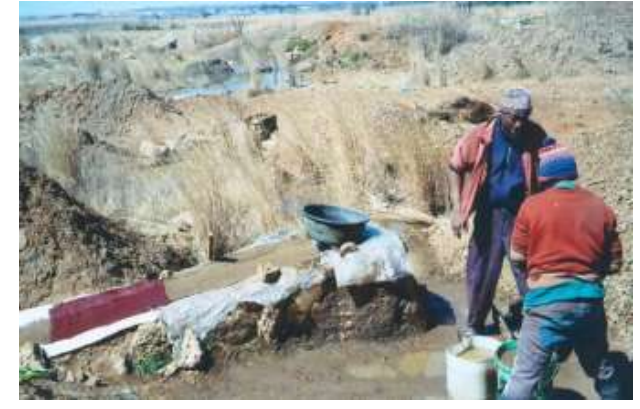

(b)

Figure 17. (a) Small sluice box in Uganda made of a tree trunk (photo: S. Siegel). (b) Ground excavated sluice with carpets in South Africa.

\subsubsection{Amalgamating Sluice}

A common type of sluice used in AGM is the amalgamating sluice, observed in the field in some countries such as Brazil, Chile, Colombia, Costa Rica, Ghana, Guyana, Honduras, Indonesia, Nicaragua, 
Suriname, Venezuela, and Zimbabwe. These are copper plates covered with mercury and set up as a sluice after a grinding process, either by stamp or hammer or Chilean mills. The plates are not very efficient to trap unliberated gold when the ore is poorly ground, usually below $1 \mathrm{~mm}$ (Figure 18). The flow of pulp must be interrupted and the plates scratched with a blade of steel or plastic card to remove the amalgam formed on the surface (Figure 19). The efficiency of the process is low due to the short time of contact between the liberated gold and mercury. These sluices are 1 or $2 \mathrm{~m}$ long and require about $0.3 \mathrm{~m}^{2}$ of copper plate to treat 1 tonne per day (tpd) of ore for pulps with $20 \%$ solids. The friction between the pulp and the plate surface removes mercury droplets that are lost with the tailings. In Venezuela, tailings were analyzed containing 60 to 100 ppm mercury (Veiga et al., 2005) [64]. As shown in Table 1, the copper-amalgamating sluices are responsible for $\mathrm{Hg}_{\text {lost }}$ : $\mathrm{Au}_{\text {produced }}$ ratios around 3 . These sluices are fabricated by the artisanal miners who buy copper plates (2-5 mm thick) and clean the plate surface with acids to remove copper oxidation before adding a layer of mercury.
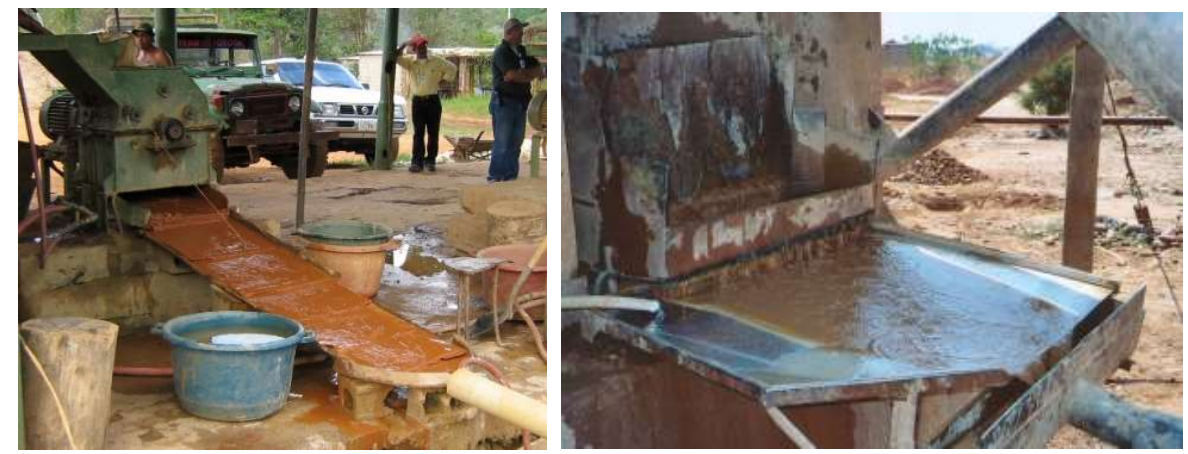

Figure 18. Amalgamating sluices in Venezuela after hammer mills and after stamp mills in Zimbabwe.
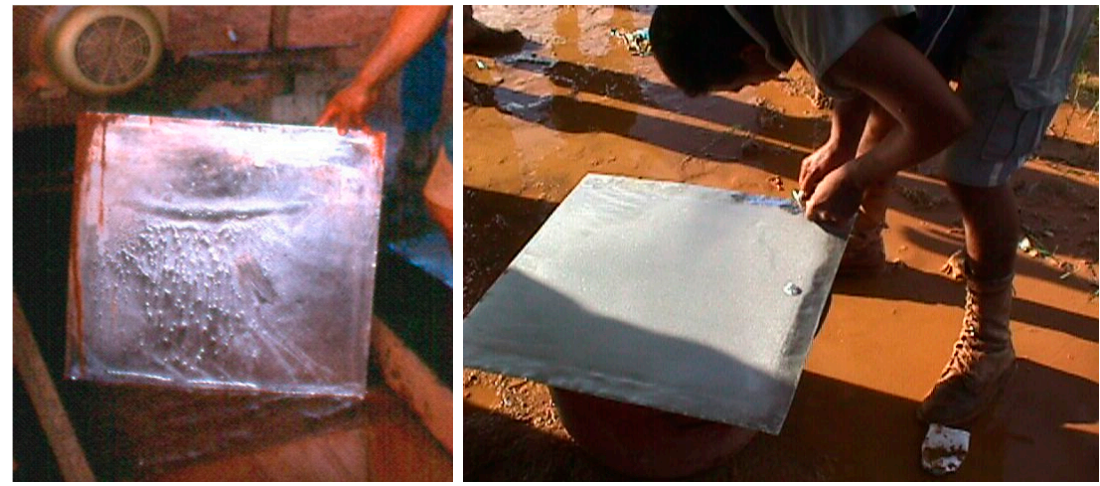

Figure 19. Scratching the surface of the amalgamating plate to remove the amalgam (Brazil and Venezuela).

Amalgamation is a simple and effective way to trap liberated gold particles, usually coarser than $0.074 \mathrm{~mm}$. When the gold particles are too small, the surface tension of the mercury makes it hard for the fine gold particles to form an amalgam. The three main types of gold amalgam are $\mathrm{AuHg}_{2}, \mathrm{Au}_{2} \mathrm{Hg}$, and $\mathrm{Au}_{3} \mathrm{Hg}$ (Taggart, 1945) [65]. The amalgams vary in composition depending on how much force is used to squeeze off the liquid mercury from the amalgam during the filtration process. An amalgam manually squeezed usually contains 40 to $60 \%$ mercury. If a filter is made with a polyvinyl chloride (PVC) tube and a piece of cloth, a Knelson centrifuge can be used, as observed in Venezuela, to remove the excess of mercury from the amalgam. The final amalgam is less than $20 \%$ mercury. An improvised centrifuge (or even a bicycle wheel) can also be locally manufactured for this end. (Figure 20) (Veiga et al., 2006) [39]. 

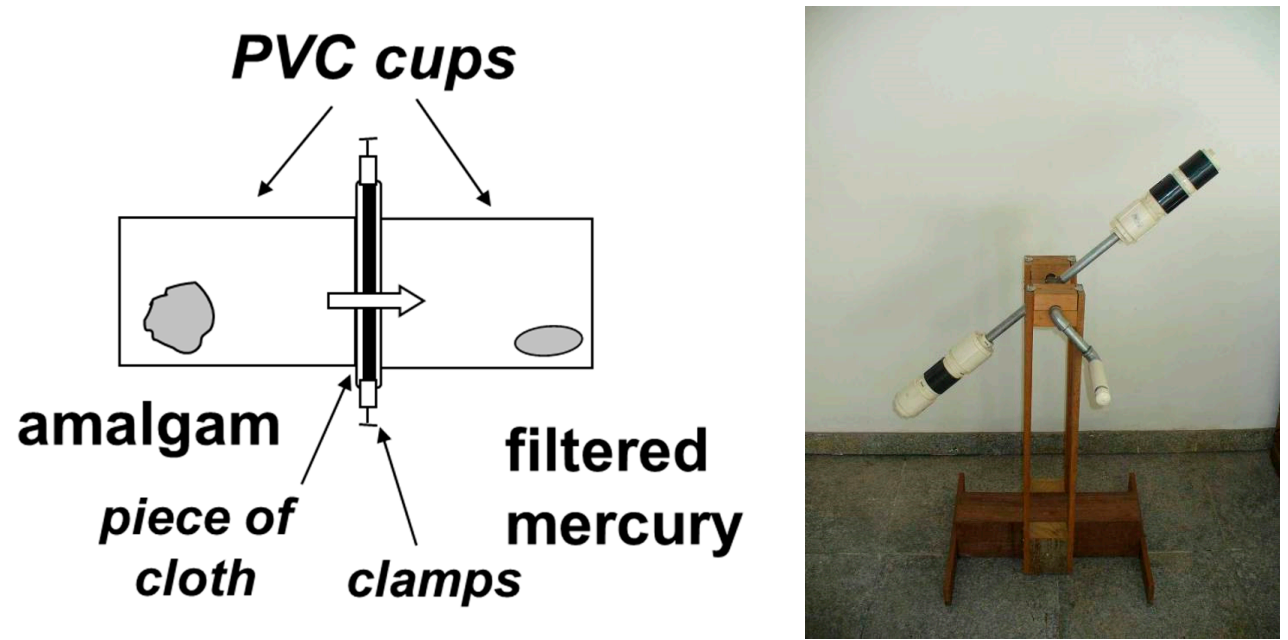

Figure 20. Improvised centrifuge to remove excess mercury from amalgams (devised by Edmundo Veiga).

A major reason for mercury losses to the tailings during the amalgamation process is the oxidation of the copper plate beneath the mercury and oxidation of the mercury layer itself. Some miners, when they observe yellow spots on the surface of the plates, stop the operation and remove the oxidation with a tablet of sodium cyanide or a cyanide solution as observed in Zimbabwe (Veiga et al., 2014 [12], Green et al., 2019 [66]) and Nicaragua. Miners do not take any precautions in handling tablets of cyanide in neutral pH when $\mathrm{HCN}$ (gas) is formed (Figure 21). In Chile, artisanal miners eliminate the yellow spots by rubbing urine on the copper plates, as observed in Andacollo.

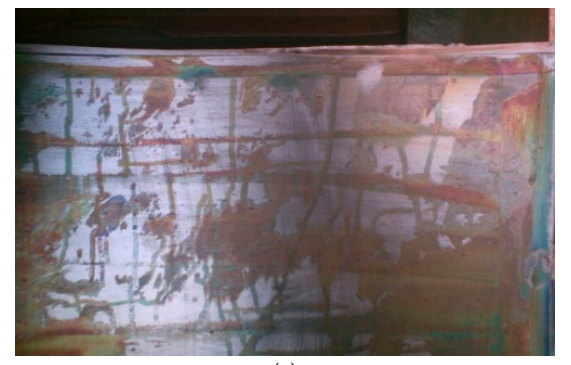

(a)

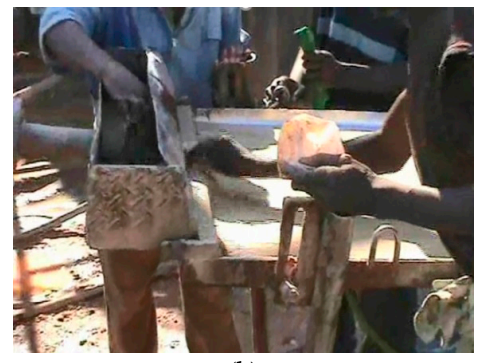

(b)

Figure 21. (a) Copper-amalgamating plate showing oxidation yellow spots (Brazil) (b) Miner using a tablet of sodium cyanide to clean the amalgamating sluice (Zimbabwe).

\subsubsection{Environmental Impacts of Sluicing}

As sluice boxes are the main equipment used by artisanal gold miners, the environmental impacts are remarkable, as many operations are conducted near the water streams. In 1987, the Brundtland Report mentioned that poverty is one of the main causes of environmental problems (WCED, 1987) [67]. Artisanal miners often are not concerned about their impacts on the land and water streams that provide their food nor on their own health. The survival instinct is the main, and sometimes the sole, driving force for their work. Most miners, for example, do not believe in mercury pollution and intoxication, and they see all warnings and awareness campaigns as efforts by governments to stop their activities (Veiga, 2009) [68].

In Ghana, a truck was observed with two sluice boxes set up after two hammer mills. The truck follows the ore deposits that feed the mills using water from a local creek. The system does not use any dam to retain the tailings, which are simply dumped into the rivers or spread on the ground (Figure 22). 


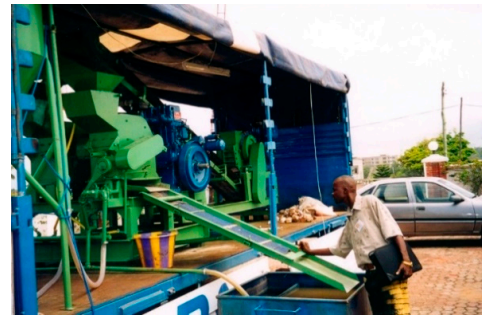

(a)

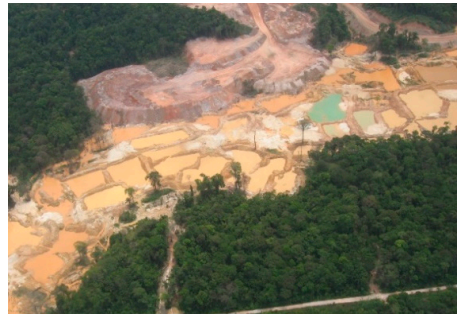

(b)

Figure 22. (a) Sluice boxes on a truck in Ghana, (b) River impacted by artisanal mining in French Guiana.

The use of amalgamating copper-plate sluices has obvious chemical impacts on the operators, due to constant evaporation of mercury, as well as on the environment as droplets of metallic mercury are carried with the tailings. But another invisible impact occurs when miners add mercury into the riffles of the sluice. The friction of the pulp with the liquid metal results in high levels of mercury in the tailings. Some miners throw mercury in an excavated hole with water and colluvial or alluvial ore believing that mercury has a "magic" property to go after the gold. When pumping the ore pulp to the sluices, free gold particles meet the mercury trapped on the riffles, generating the impression that mercury found the gold specks on the ground. Artisanal miners in Suriname, Venezuela, and some places in Indonesia are still using this primitive method. The environmental pollution is noteworthy as not all mercury spread out on the ground is recovered when the pulp is processed in the sluice boxes.

The systematic releases of tailings, sometimes with mercury, into the local rivers in the Brazilian Amazon have been creating problems for the communities downstream that have fish as their main staple food. For example, from 3 to 6 million tpa of tailings from sluices dumped into an affluent of the Tapajós River, the second most important river in the Amazon region, the pulp of tailings flow over $150 \mathrm{~km}$ downstream (Figure 23). Telmer et al. (2006) [69] highlighted that "mining-induced sediment plumes have been a source of sediment to the Tapajós River system for decades".
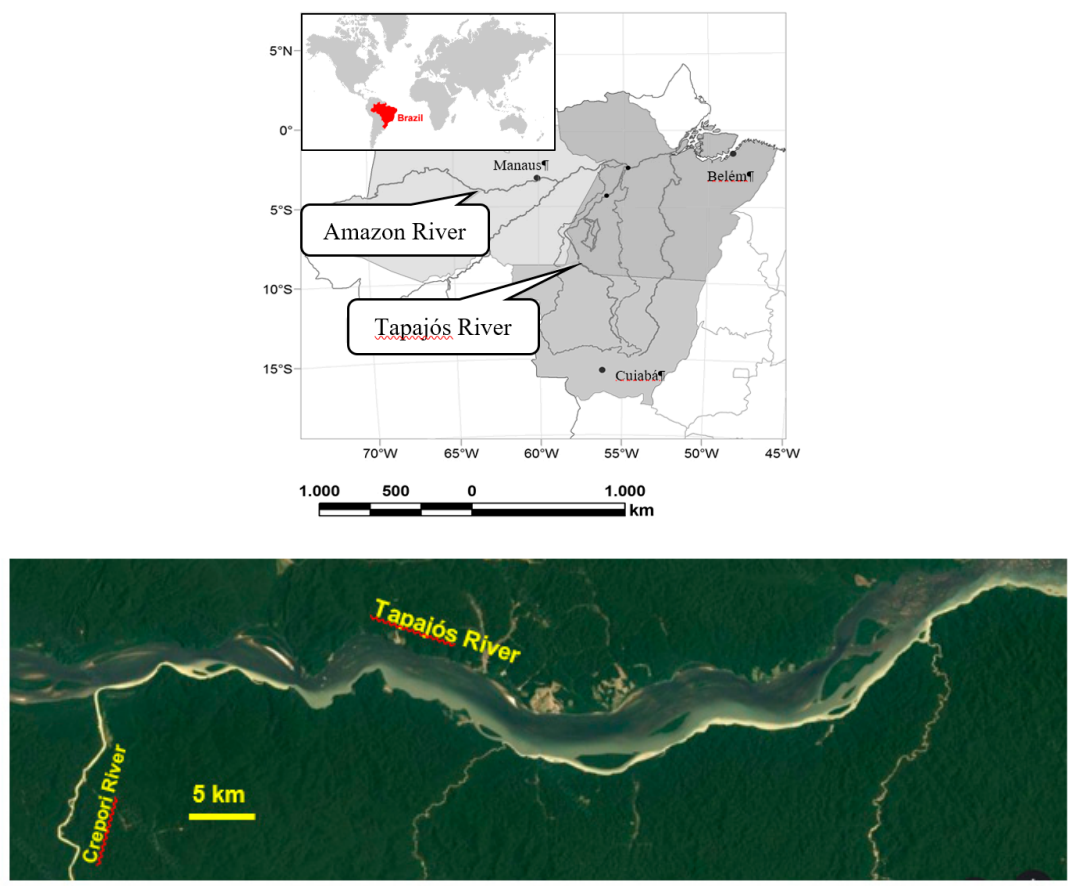

Figure 23. Tailings from the Crepori River pass to the Tapajós River and goes more than $150 \mathrm{~km}$ downstream. (Image obtained from Google Earth, 2020).

The GEF/UNDP/UNIDO Global Mercury Project assessed the volume of 20 abandoned open pits that ranged from $10,000 \mathrm{~m}^{3}$ to $50,000 \mathrm{~m}^{3}$. Every year up to 600 new pits are opened in the 
Tapajós region. When miners reach depths of $10 \mathrm{~m}$, they move their equipment (pumps and sluices) to another pit. The project used these old pits to receive sluice tailings that were dumped into the Crepori River. A straw barrier was used to "filter" the pulp recirculating the water. After the pits were filled, organic soil was generated planting legumes on the top of the reclaimed pits (Figure 24) (Sousa and Veiga, 2009) [70].
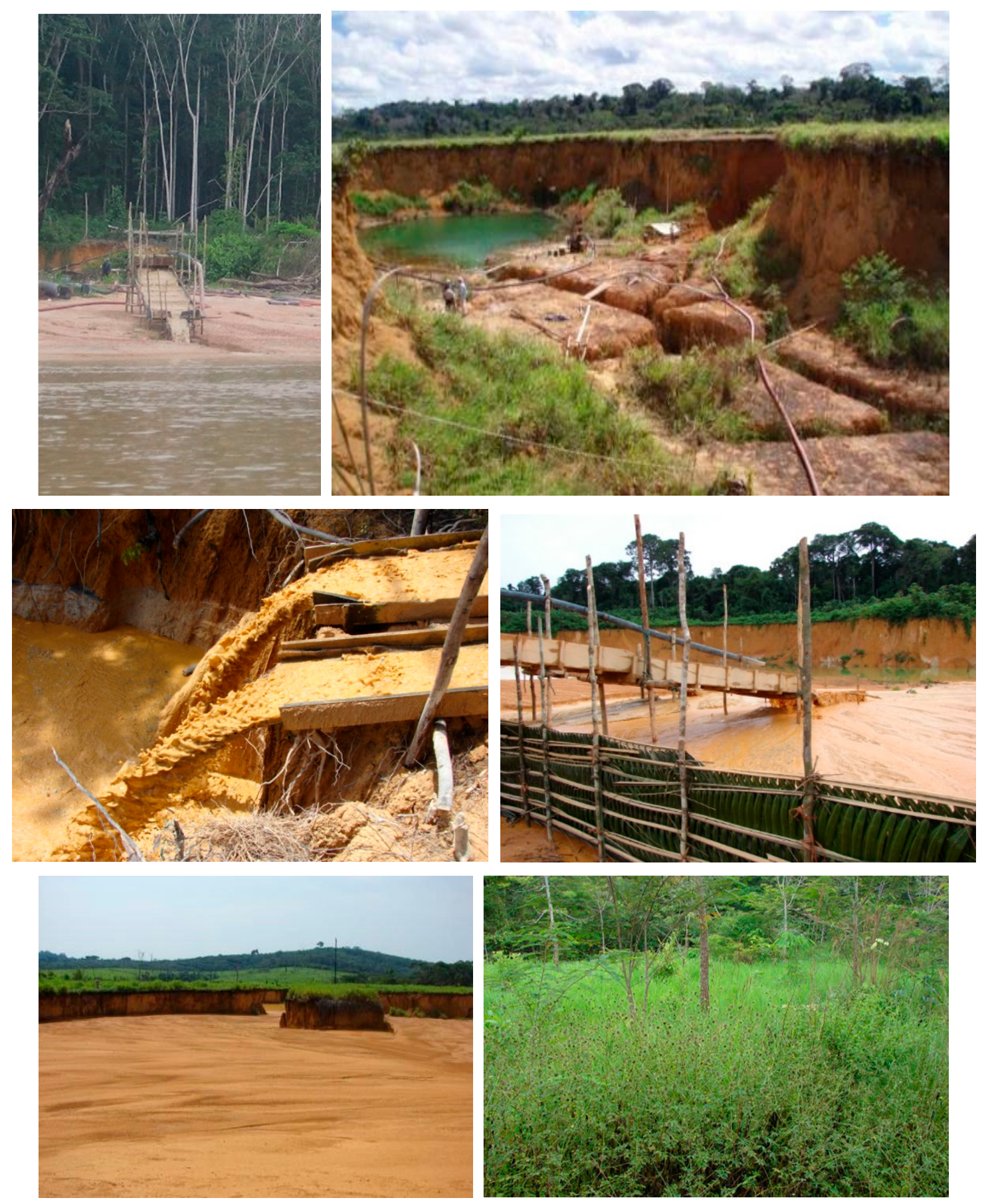

Figure 24. Instead of dumping tailings from sluices into the Crepori River, the tailings were conducted to open pits, filtered with a barrier of straw, and reclaimed (Sousa and Veiga, 2009) [70]. 


\subsubsection{Sluicing-Summary}

Sluice boxes are a very adequate technology for artisanal miners and can be very efficient if well designed and operated. The main points related to sluicing are listed as follows:

- Large amounts of water are needed: $10-15 \mathrm{~m}^{3} / \mathrm{min}$ for a typical $60-\mathrm{cm}$ wide sluice; the water is rarely recycled;

- Artisanal miners do not use an efficient size classification of the sluice box feed. They only remove the large cobbles with a grizzly screen. This provokes turbulence removing the fine gold particles from the bed, reducing the recovery;

- Riffles are not good for fine gold particles, only for large gold specks, as high riffles can create turbulence and fine gold particles are lost;

- Miners often work with high amounts of solids in the pulp (e.g., 30-40\% in mass). This makes it difficult for gold to sink in the sluice to be concentrated; $10-20 \%$ of solids in the pulp would be more adequate;

- Miners use long sluices hoping to catch fine gold but this is not effective. Most gold is concentrated within the first $2 \mathrm{~m}$ of the sluice;

- Fine gold is concentrated where the pulp flow speed is slower, i.e., at the beginning of the sluice. Zigzag sluicing, with multiple decks, is a good way to break the flow velocity and capture more fine gold than a turbulent single-deck sluice;

- Wide sluices can process more material than narrow sluices;

- The carpets cannot be allowed to clog as this stops further gold particles' deposition. In sluices with low angles, the material settles faster. The usual angle of a sluice box is $10-15^{\circ}$. Some miners in Ecuador use $5^{\circ}$ to increase the gold recovery, but they have to clean the carpets every hour, and consequently, the concentrate grade is poor;

- There are a variety of carpets available in the market. The vinyl loop carpets are very efficient, but they must be unbacked, i.e., no rubber at the back, otherwise the gold particles become entrained in the carpet and are hard to dislodge at the end of the operation;

- Flat particles of gold can float on the sluices and are lost; and,

- Spirals or other types of sluice such as pinched sluices or Reichert cones, have not been observed in use in AGM operations. These would bring relevant improvements since the operations do not need to be interrupted to discharge the concentrates. The main reasons for not using these pieces of equipment in AGM are: (1) high price, (2) no local availability, (3) high mass of concentrates to be treated after concentration, and (4) lack of knowledge of the artisanal miners about these technologies.

\subsection{Jigging}

Gravity concentration by jigging has been used in conventional mining operations for more than 100 years (Abols and Grady, 2006 [71]), but they are not common in AGM operations. Jigs have been used for gold concentration since the Old Egyptian times (Sampaio and Tavares, 2005) [23]. Jigging is a continuous gravity concentration process that separates heavy from lighter particles by a pulsating flow of water caused by a piston. This pumps and sucks water, creating a flow that throws the light particles upwards. This process fluidizes the particles, and the heavy particles sink into a bed of steel balls (or pebbles) called "ragging". The ragging is held by a steel screen but during the pulsation, it also moves up and down opening room for the heavy particles to pass through it to be discharged at the bottom of the jig. Wills and Finch (2016) [72] explained the mechanisms involved in a jig, showing that the action of pulsing and suction are responsible for the stratification and, therefore, the concentration of the heavy particles (Figure 25). The smaller and lighter particles are expelled from the jig and the heavier particles, by density or by size, settle down faster. 


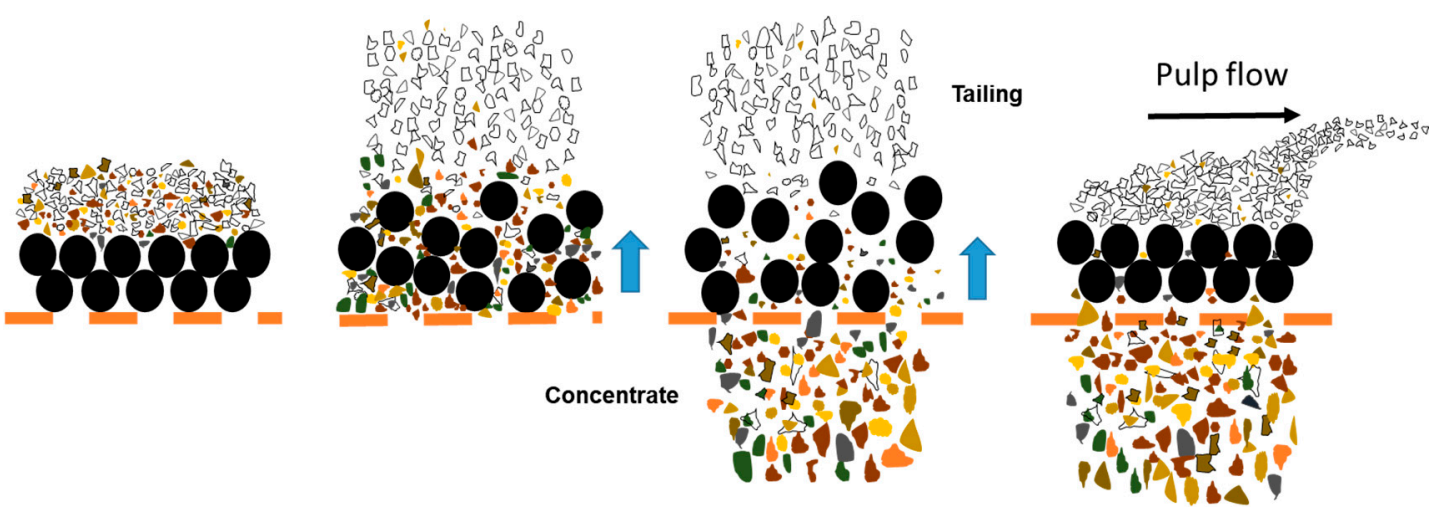

Figure 25. Snapshot of a jig cycle. Water pulses and concentration (adapted from Wills and Finch, 2016) [72].

Priester et al. (1993) [73] showed a jig used by artisanal miners with a manual system that creates a pulsating effect on a bed of minerals to concentrate gold specks at the bottom of the jig. Jigs are very sensitive to particle size and shape and usually are effective to separate particles of gold coarser than 100 mesh (0.15 mm). Mitchell et al. (1997a) [48] reinforce the idea that jigs should process separately screened fractions and highlighted that recovery falls to less than 50\% for gold finer than $0.1 \mathrm{~mm}$. Jigs accept large amounts of ore and can process up to $1000 \mathrm{tph}$ of ore (Wills and Finch, 2016) [72]. Pulp density is usually 10-30\% solids.

In Antioquia, Colombia, many artisanal operations use 8 inch $\times 12$ inch jigs with the capacity to process $0.3-1.5 \mathrm{tph}$, but in many cases processing less than $0.07 \mathrm{tph}$. These jigs have $0.75 \mathrm{~kW}$ electric motors $\mathrm{kW}(1 \mathrm{HP})$, use $2.4 \mathrm{~L} / \mathrm{min}$ of water, and are located at the discharge of the ball mills (Figures 26 and 27). The pulp entering these small jigs, after the addition of water, averaged $25 \%$ solids. The Colombian jigs use a lateral plunger which is an adaptation of the Harz jig. The plunger, located outside the jig, moves vertically and presses down on the water in the jig tank in small, but frequent, pulses (around 100 pulses/min). This moves the water flow against the ragging. New jigs are sold in Colombia for US\$ 2000-5000/unit depending on whether the jig is locally made or imported.
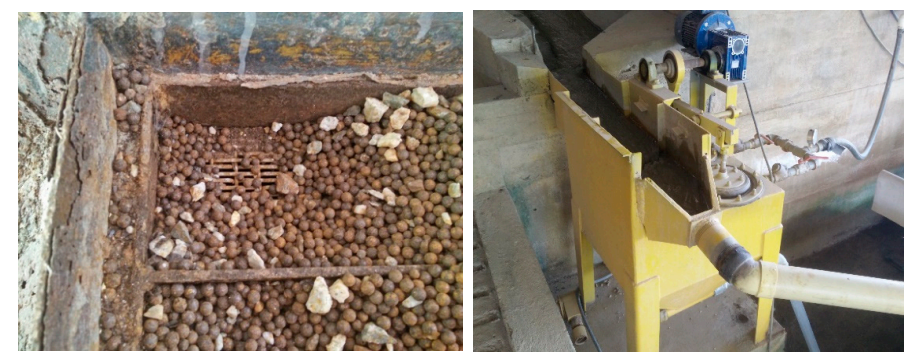

Figure 26. Jig in Colombia uses a bed of small steel balls.

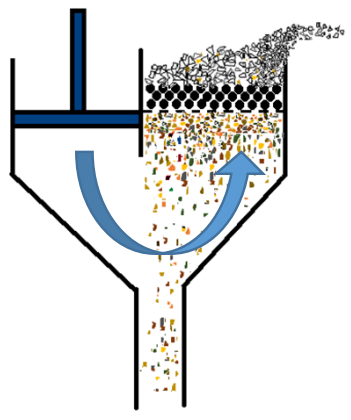

Figure 27. Plunger jig used in Colombia. 
In most Colombian operations visited, the discharge of a ball mill was classified in a trommel with a 1 to $2 \mathrm{~mm}$ screen attached to the ball mill (Figure 28). The coarse particles (+1 $\mathrm{mm}$ ) are returned to the ball mill manually with a shovel. The tailings from the jig are processed in a shaking table without any further classification (Figure 29). As the jig concentrates are not very rich in gold due to large amounts of sulfides and coarse particles of gangue, some miners amalgamate the concentrates in small ball mills or leach with cyanide after re-grinding. This configuration was an initiative of the government that hired a company to implement this design in over 70 formalized operations, without taking into consideration the mineralogical differences among them.
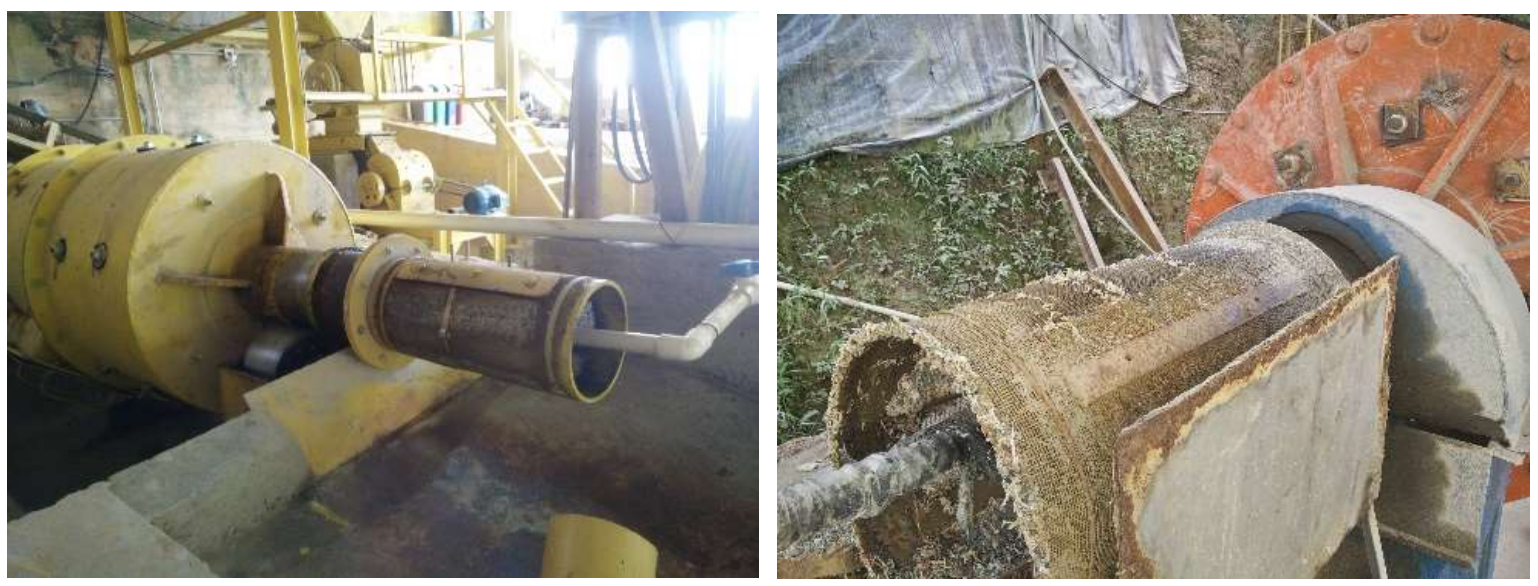

Figure 28. The ground material is screened: the $-1 \mathrm{~mm}$ goes to the jig and $+1 \mathrm{~mm}$ returns to the ball mill.
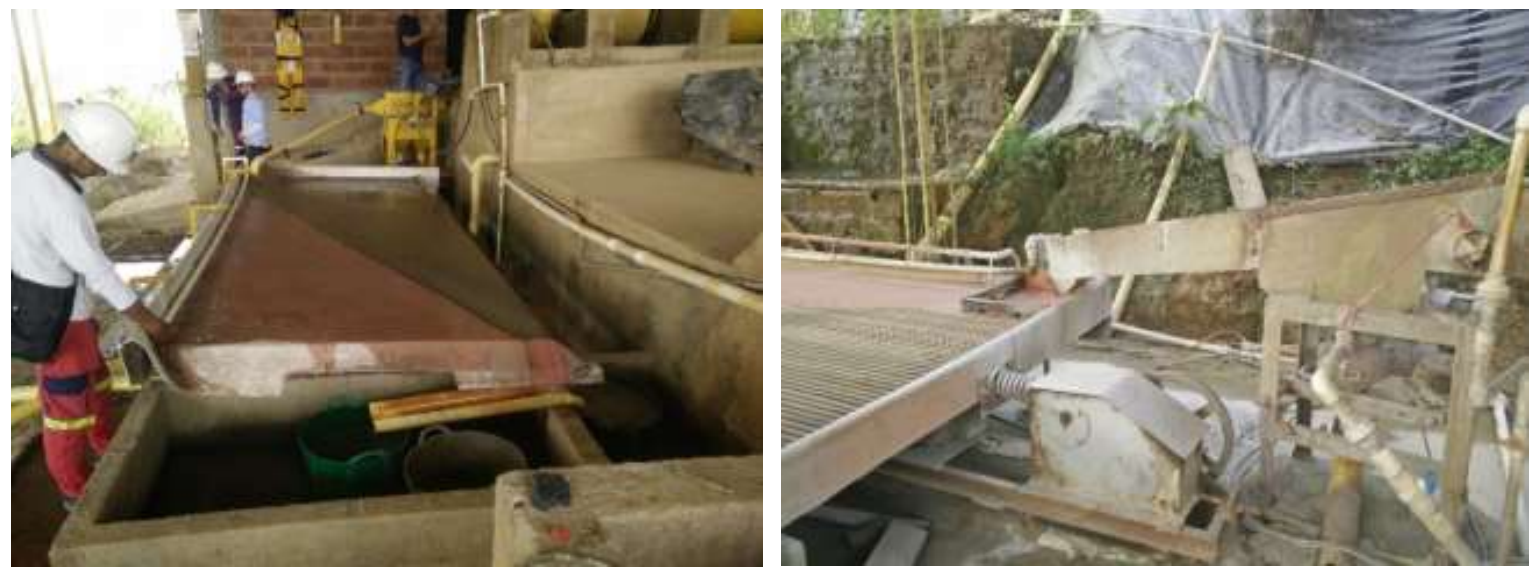

Figure 29. Tailings from the jig are processed by a shaking table (Colombia).

Despite some gold concentration, the Colombian jigs seem to work merely as a size classification device for the shaking tables, since the coarse particles of gangue are reported to the jigs' concentrates together with the heavy minerals. Most local artisanal miners criticize this arrangement as it is not very efficient for gold concentration and the jig provides a low concentration ratio. Most Colombian artisanal plants abandoned this configuration to use a $1 \mathrm{~mm}$ trommel at the ball mill discharge and only the shaking tables.

\section{Jigging-Summary}

The main points related to jigs in AGM are as follows:

- Jigs operate much better with feed classified into narrow particle size ranges. Jigs are sensitive to wide ranges of particle size fractions and without size classification are not efficient as the coarse particles of gangue minerals concentrate together with the heavy minerals; 
- Jigs are not efficient for fine gold particles;

- Jigs require large amounts of water;

- For primary ores, particles ground and screened through $1 \mathrm{~mm}$ sieves rarely contain liberated gold, therefore the gold grade of the concentrates is not high; and

- In Colombian AGM operations, jigs work as size classifiers, basically removing the coarse particles before the shaking table concentration.

\subsection{Tabling}

A shaking table is a riffled inclined deck that shakes horizontally. The most popular is the Wilfley table developed in 1896 (Gupta and Yan, 2016) [28]. The height of the riffles depends on the grain size of the ground ore but is usually 3 to $5 \mathrm{~mm}$. Shaking tables operate in the conventional gold mining sector to obtain the final product for gold smelting after a previous concentration in a centrifuge, for example. The tables are efficient to recover gold grains as fine as 200 mesh $(0.074 \mathrm{~mm})$ but the efficiency depends on the particle size distribution range. The narrower the grain size fraction, the more efficient is the operation. Therefore, classification by screening can improve the gold recovery, which is also applicable for all gravity concentration processes. Shaking tables can process up to 2 tonnes per hour (tph) of ore ground to 1 to $1.5 \mathrm{~mm}$ and $1 \mathrm{tph}$ for ore ground to $0.10 \mathrm{~mm}$ (150 mesh) operating with a pulp of $20-25 \%$ solids by mass. The length of the horizontal movement of the table has a great influence on the gold recovery. Fast speed is useful for fine grain sizes of gold (Wills and Finch, 2016) [72]. Industrial tables usually have decks 2 to $4.5 \mathrm{~m}$ long made of rubber or fiberglass or wood (Silva, 1986) [38].

The operation of shaking tables is not complicated but the two table slopes, ranging from 0 to $6^{\circ}$ (higher in some cases as mentioned by Mitchell et al., 1997b [74]), must be adjusted according to the type of ore and its grain size (Sampaio and Tavares, 2005) [23]. Higher angles of the lateral slope of the table allow more ore to be processed. Lower angles of the frontal slope allow the retention of finer and lighter materials on the table. Heavy particles (coarse and/or dense) are moved along the table's riffles by the throw/stroke (horizontal movement), while small/light particles are washed across the riffles, down into the tailing discharge. The table also discharges the "middling" fraction (with intermediate specific gravity) between the concentrate and the tailings, which is usually composed of unliberated heavy minerals such as iron oxides, sulfides, and gold. Most artisanal miners do not recirculate the middlings to the grinding circuit and submit concentrates plus middlings to amalgamation. As a result, the mercury traps only the liberated gold leaving behind a rich gold and mercury-contaminated tailing.

Operators must find the adequate table slope for the type of ore and the grain size they are processing. Shaking tables are usually inclined in two directions. There are tables specifically designed to process very fine particles of ground ore, also known as "slimes table" (Silva, 1986) [38].

Shaking tables are becoming popular in AGM operations in Latin America. In many operations in Colombia, usually with processing capacity below $30 \mathrm{tpd}$, miners use the shaking table to process tailings from the jig (Figure 29) or just at the discharge of the ball or Chilean mills (Figure 30). Some Colombian plants use a spiral gold panning machine or a homemade elutriator to upgrade the table concentrates. These machines are also used to separate the amalgam from the heavy minerals (Figure 31). Some AGM operators use another shaking table to upgrade the concentrates. Gemeni tables operate with no lateral slope, unlike traditional shaking tables, and with grooves, instead of rifles, following the trapezoidal shape of the table. Gemeni tables have low capacity and can process from $27 \mathrm{~kg} / \mathrm{h}$ to $455 \mathrm{~kg} / \mathrm{h}$ of material (MD Mineral Technologies, 2005) [75]. 

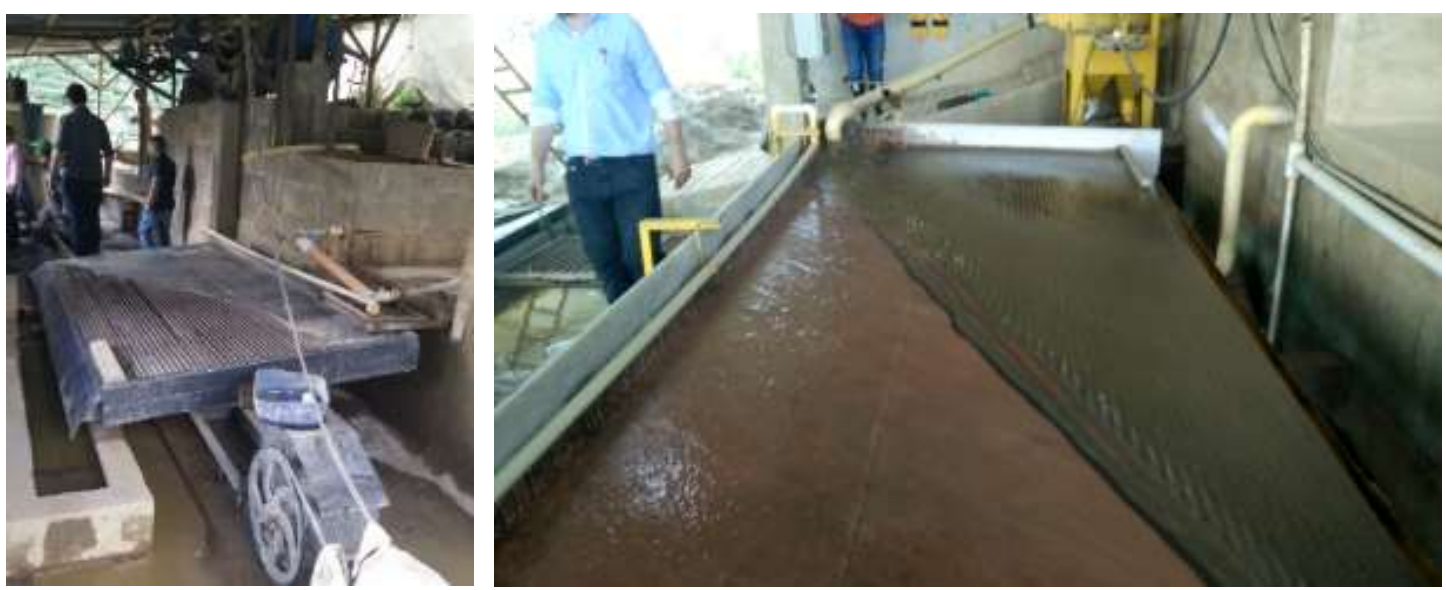

Figure 30. Shaking tales in Colombian artisanal plants in Antioquia.
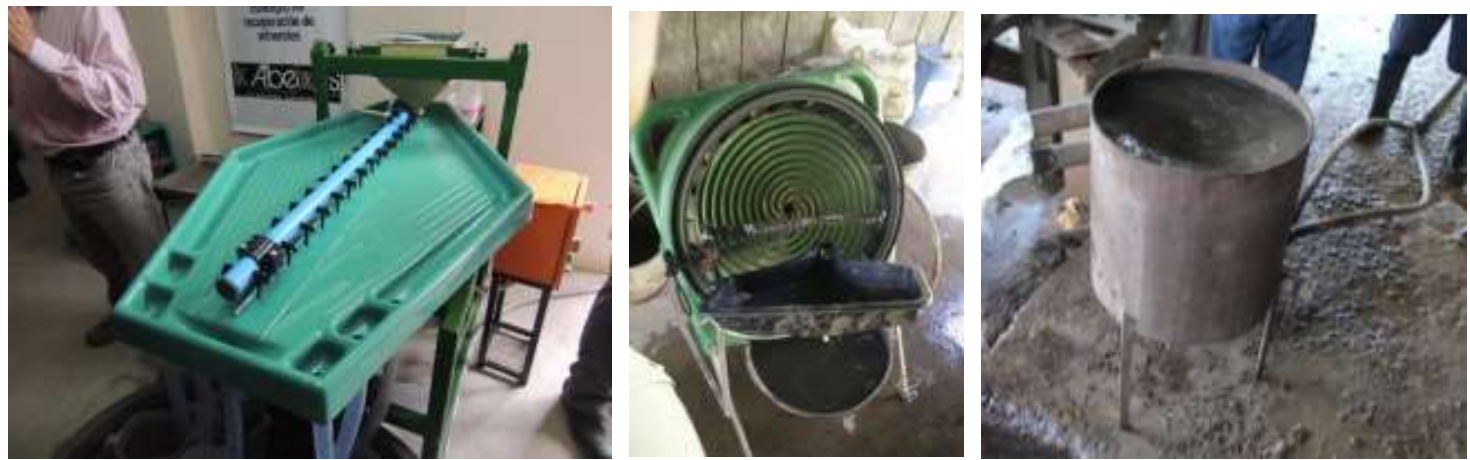

Figure 31. Gemeni table, spiral gold wheel, and elutriator used by Colombian artisanal miners to upgrade table concentrates.

As using one shaking table often does not provide high gold recoveries, several Colombian miners use two or three tables to re-process tailings. There are many different arrangements of these tables working in parallel or in series, and then treating the concentrates through amalgamation and treating the tailings with cyanidation. An example of a Colombian AGM plant processing sulfide-rich gold ores using three tables as rougher, cleaner, and scavengers is shown in Figure 32a. The process of re-grinding concentrates before using amalgamation or even conducting amalgamation in small ball mills, which is popular in many AGM sites, is a result of poor size classification in the primary grinding circuit. The amalgamation of the concentrates and middlings results in tailings rich in mercury that in many cases are leached with cyanide exacerbating the toxicity of the final tailings. The amalgamation is completely unnecessary if the miners upgrade the concentrate from the shaking table $3 a$ in a Gemeni table smelting the concentrate and leaching the middlings and tailings with cyanide. Even with the suggested improvement shown in Figure 32b, the final tailing from the scavenger shaking table $3 b$, might still have a high amount of fine unliberated gold since the trommel screen of $1 \mathrm{~mm}$ at the ball mill discharge is too coarse. If the concentrate from table $2 \mathrm{~b}$ has gold specks above $0.1 \mathrm{~mm}$, it is suggested to remove them in a Gemeni table, upgrading it for a final smelting process with borax. Therefore, more efficient classification methods should be used at the discharge of the ball or Chilean mills. 


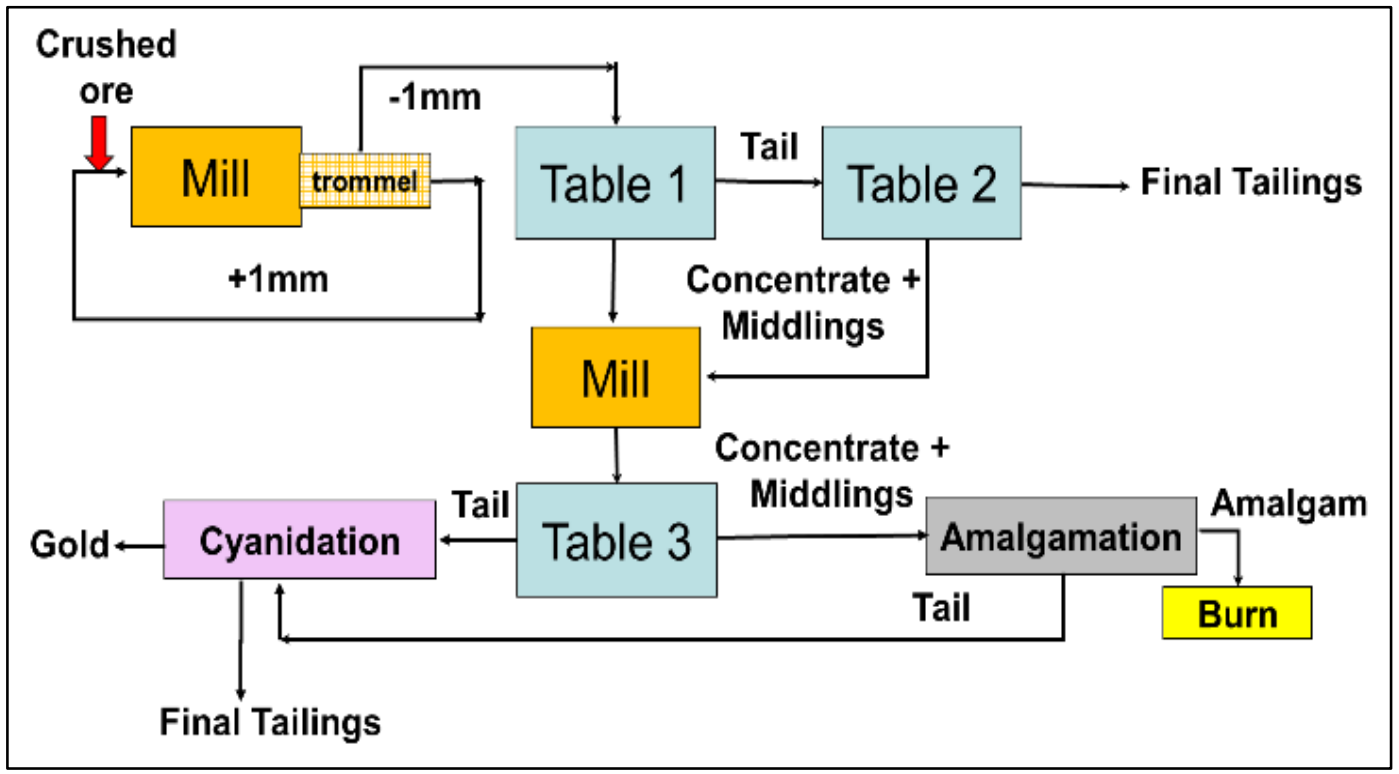

(a)

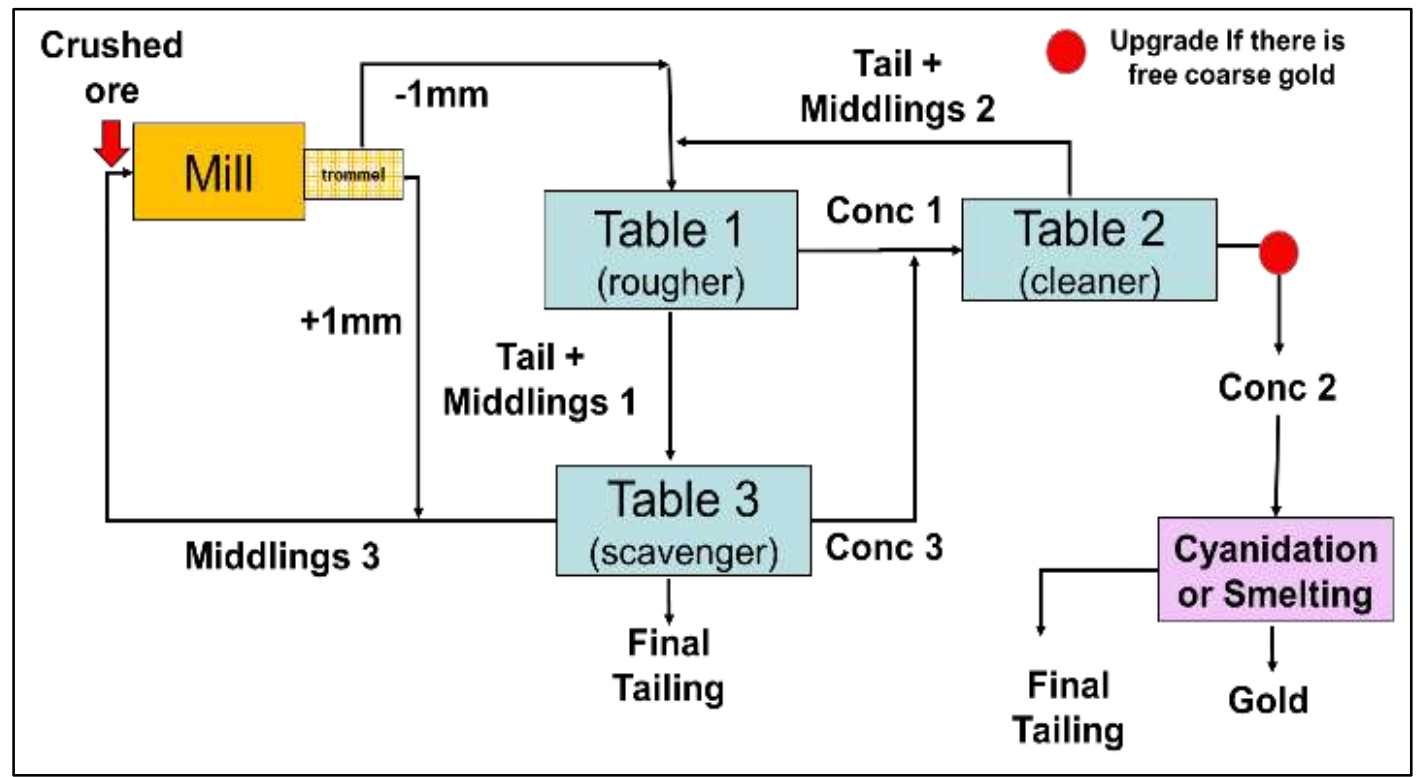

(b)

Figure 32. (a) Example of a gold concentration plant in Colombia (b) Suggested simple improvements in the configuration of the shaking tables.

\subsubsection{Homemade Shaking Tables}

The CICAN (Colleges and Institutes Canada) Project in Colombia (Veiga et al., 2018) [37], was a project sponsored by Global Affairs Canada to provide technical support to artisanal miners in Colombia. The project, led by the CÉGEP from l'Abitibi-Témiscamingue, Rouyn-Noranda, Québec, decided to use inexpensive locally found materials to teach artisanal gold miners and their trainers how to make their own processing equipment. This approach is extremely noble, valuable, and very much in line with what Schumacher (1973) [76] described as "appropriate technology" in his best-seller "Small is Beautiful". This, according to the author of this book, is the basis for the local sustainability of a community. The project built a simple ore impact mill using a steel chain (Figure 33) using the same principle as a hammer mill. The pieces of equipment do not have high capacity and are sufficient for micro-miners producing less than $2 \mathrm{tpd}$. Beyond different types of grinder, the project also developed 
homemade shaking tables and flotation cells and transferred the blueprints to local mechanical shops to make these pieces of equipment at the artisanal mining sites in Colombia. Small shaking tables were built using plywood, plastic buckets, and iron bars. The shaking tables can process $100-200 \mathrm{~kg} / \mathrm{h}$ of ground ore and work either with a $1 \mathrm{HP}$ electric motor to generate the horizontal stroke or by a pedal that shakes the table and provides energy for a pump that recirculates the water. A bucket with water is filled on the top of the table and the ground ore is fed manually (Figure 34). The cost of building this shaking table can range from US\$ 100 to 200 depending on the accessibility of materials and welders. Tests, conducted on a gold ore from Quebec, using the chain mill grinding below 0.5 to $1 \mathrm{~mm}$ followed by the shaking table, resulted in a gold recovery of $88 \%$. Projects in Colombia are demonstrating these techniques to artisanal miners (Veiga and Correa, 2019) [77].
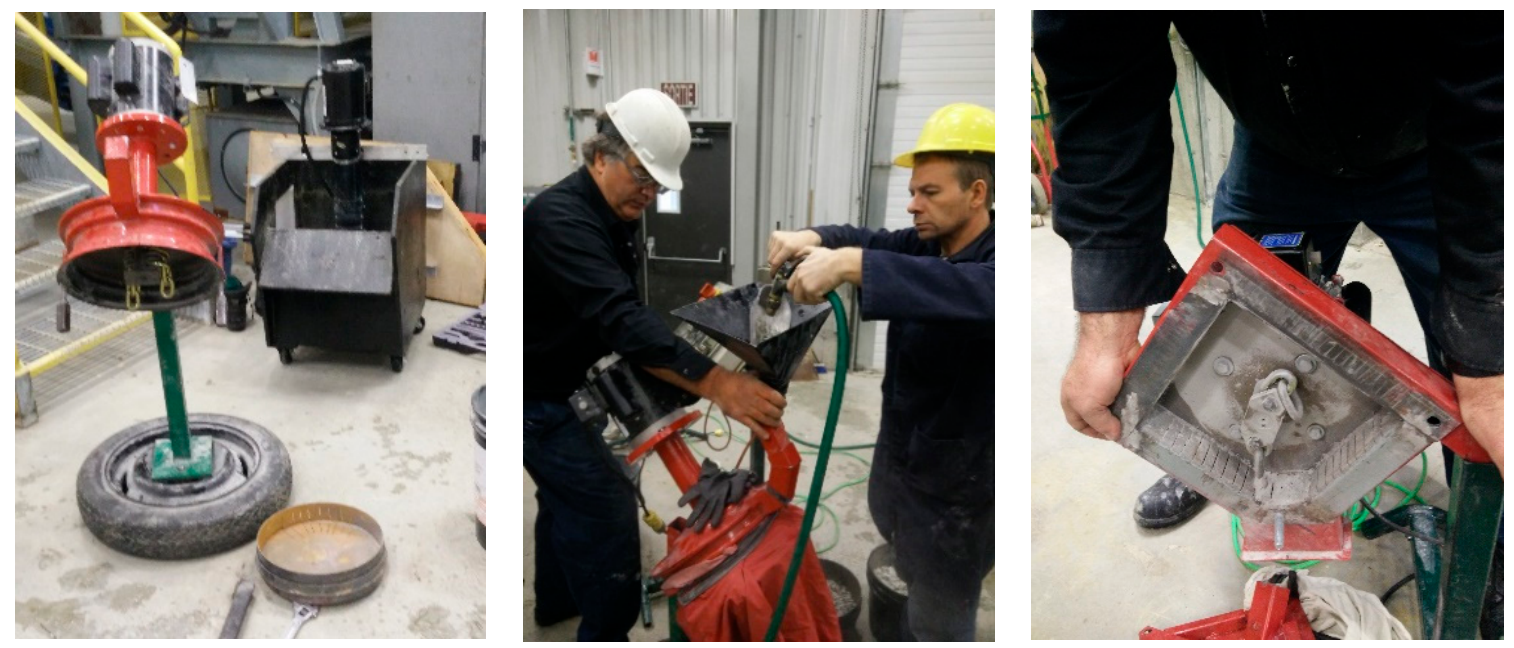

Figure 33. Two different chain mills from the CICAN (Colleges and Institutes Canada) project.
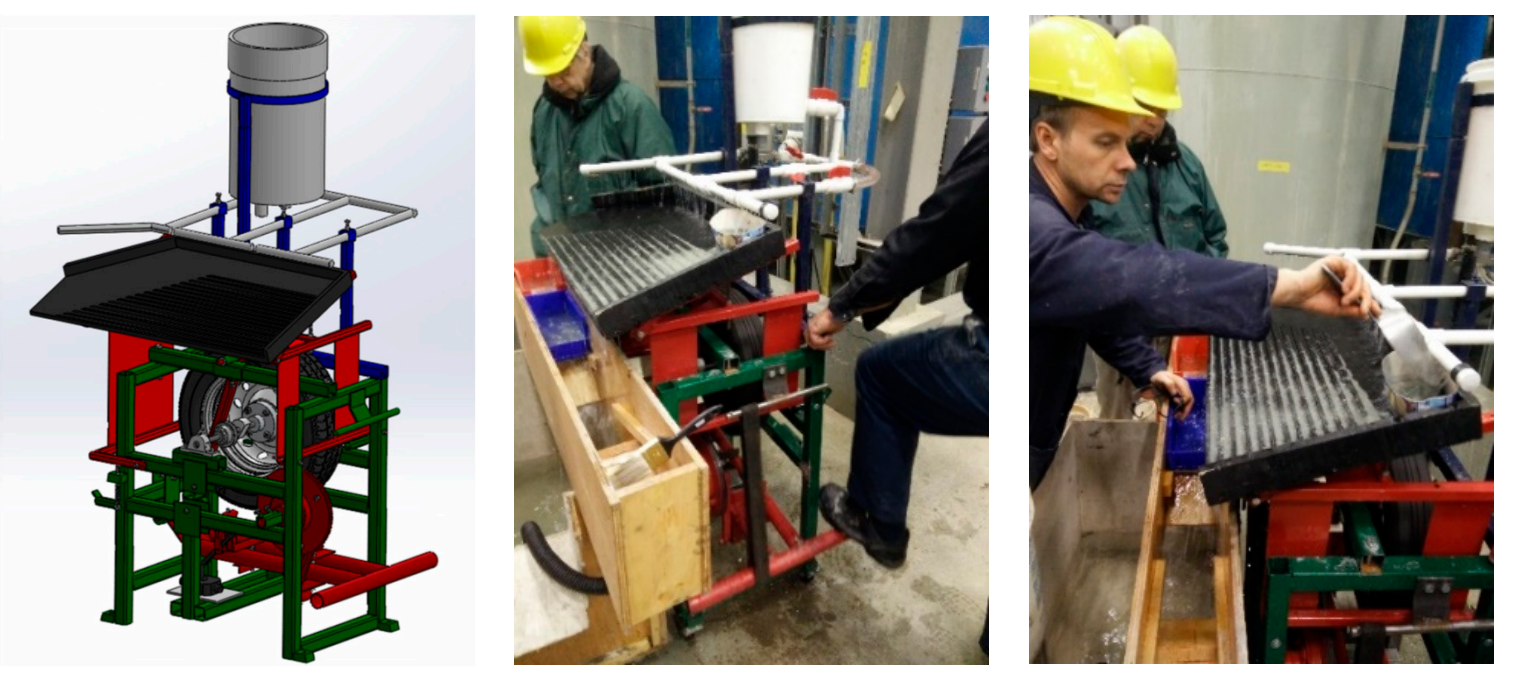

Figure 34. Shaking table operated by a foot-operated lever. (CICAN project).

\subsubsection{Tabling-Summary}

The main aspects related to shaking tables are as follows:

- Shaking tables, when used as primary gravity concentrators, do not provide high production rates, with production usually between 20 to 40 tpd of ores; 
- Ball and Chilean mills usually flatten gold particles, which can lead to the particles floating over the shaking table riffles to be lost with tailings. Gold is naturally hydrophobic and this phenomenon of "floating flaky gold" is commonly observed in laminar gravity separation methods;

- The classification of the ground material (grinding in a closed circuit) is important for an efficient gold concentration. The culture of the artisanal miners in all continents is to introduce re-grinding circuits rather than using closed grinding circuits. It is interesting that artisanal miners usually neglect the classification processes after milling and do not believe in any benefit of creating a circulating load in the grinding circuit. The return of $100-400 \%$ of the ore mass to the mill typically reduces the retention time of the material inside the mill increasing the grinding capacity, improving the energy efficiency, resulting in a more homogenous ground product (Jankovic et al., 2013) [78]. Artisanal miners frequently grind in open circuits with the gravity separation equipment. It is also worth noting that putting gravity recovery equipment in a circuit with a circulating load can improve gold recovery given the inherently low single-pass efficiency of gravity recovery devices;

- Over 50 plants in Colombia were observed using shaking tables as their main gravity concentration step, with gold recoveries rarely above $60 \%$. Gold is mainly lost in coarse grains (unliberated gold) and the fines (not trapped by the table). For ores with fine-sized gold particles and/or high concentration of sulfides, AGM plants combining gravity separation with flotation can obtain gold recoveries above $85 \%$;

- The adjustment of the length of the stroke and the slope of the shaking tables are critical for efficient separation of fine gold particles; and,

- Homemade shaking tables have been proven an affordable solution for micro-miners processing less than 2 tpd.

\subsection{Centrifuging}

Centrifugal concentrators are the most efficient pieces of equipment for gravity separation. The main initial application of the centrifugal concentrators was to recover fine gold (Sampaio and Tavares, 2005) [23]. The principle of gold concentration in centrifugal equipment is the separation of gold from gangue mineral particles based on the difference in the settling velocity (Chen et al., 2020) [79]. When the particles are subjected to the normal gravitational force (G-force $=1)$, like in a jig, a gold particle with a diameter of $0.02 \mathrm{~mm}$ falling in water reaches the same terminal velocity as a quartz particle of $0.07 \mathrm{~mm}$. If a very narrow grain size classification is not previously employed, there is poor selectivity in the separation. Considering that the acceleration of both particles in a centrifuge is 60 or more times higher than the gravitational acceleration, the difference in terminal velocity between the two particles increases, therefore the difference between the sizes of the particles to be separated also increases proportionally. The acceleration of a centrifugal concentrator is expressed as " $G$ ", i.e., how many times the centrifugal acceleration acting on a particle is higher than the gravitational acceleration. The " $G$ " of a centrifugal concentrator is expressed as dividing the centrifugal acceleration $\left(\omega^{2} \mathrm{r}\right)$ by the gravitational acceleration (g) (Sampaio and Tavares, 2005) [23]:

$$
\mathrm{G}=\frac{\omega^{2} \mathrm{r}}{\mathrm{g}}
$$

where: $\omega=$ angular velocity $(\mathrm{rad} / \mathrm{s}), \mathrm{r}=$ radius of the centrifuge, and $\mathrm{g}=$ gravitational acceleration

$$
\mathrm{G}=\frac{\varnothing n}{182}
$$

where: $\varnothing=$ centrifuge diameter $(\mathrm{m})$ and $u=$ rotation frequency $(\mathrm{rpm})$

A centrifugal concentrator operates when a ground ore pulp is introduced at the bottom of the equipment and particles in the slurry flow upward and outward due to the centrifugal force. When the particles are trapped in a V-shape bowl with rings of riffles, these particles can or cannot 
find counter-flow water that fluidizes the bed, expelling the light particles and retaining the heavy ones. It is important to stress that a centrifugal concentrator works in an exchange process where a light trapped particle leaves the bed to open room for a heavy one. In this process, the volume of concentrate (which is the volume of the space between rings) remains constant. The counter-flow water pressure helps in this process. The discharge of the trapped concentrate can occur intermittently or continuously through an automatic diaphragm. More water pressure is needed when the centrifuge operates with coarse or high specific gravity particles. The centrifuge with fluidizing water was first patented by McNicol in Australia in 1935 (Sampaio and Tavares, 2005) [23].

As centrifuges operate at high G-Forces, they are less sensitive to gold particle shape than other gravity concentration equipment and accept larger variations of particle size than other concentrators. The maximum feed grain size is $6 \mathrm{~mm}$ but it is recommended to only feed particles smaller than $2 \mathrm{~mm}$. Some centrifuges can operate with extremely small particles, as fine as $3 \mu \mathrm{m}$ (Sepro, 2019) [80]. Unliberated particles can also be concentrated depending on the proportion of gold in the gangue particle. However, centrifugal concentration is sensitive to the proportion of clay minerals in the pulp as clay minerals lead to an increase in pulp viscosity, thus, decreasing gold recovery (Agorhom and Owusu, 2020) [81]. Conventional mines typically place centrifuges in closed-loop grinding circuits, either at the discharge of the mills or the underflow of cyclones to remove coarser gold grains from the circuit before the ore enters the flotation and/or cyanidation circuits. The percentage of solids in the feed pulp is usually from $20 \%$ to $40 \%$ and for fine materials, this ranges from $10 \%$ to $20 \%$ solids. In a discontinuous centrifuging system, which is the one used by some artisanal miners, after a certain time of operation the centrifuge stops and the concentrate is washed out, usually manually, from the rings. According to Figure 2, large amounts of concentrate (which is obtained when the discharging cycles are shorter) produce high gold recoveries but low gold grades. The operators must assess the concentrate discharging cycle for each type of ore. In many cases, the rinse cycle occurs between 20 and 120 min of operation. The mass of concentrate in a centrifuge is typically much less than $0.1 \%$ of the original feed. It was observed in the field, in an artisanal operation in Ecuador, that by feeding 2 tph of ore with $4 \mathrm{~g}$ $\mathrm{Au} / \mathrm{t}$ in a centrifuge, in $30 \mathrm{~min}$ of operation, $1 \mathrm{~kg}$ of concentrate analyzed $3000 \mathrm{gAu} / \mathrm{t}$.

The sizes of commercial centrifugal concentrators vary considerably and can process up to 1000 tph of ore. There are many different types of centrifugal concentrators in the market. Some are from Chinese, South African, Brazilian, etc. manufacturers, but the most popular ones are the Knelson, by FLSmidth, and the Falcon, by Sepro, both developed separately in British Columbia, Canada. They produce the main centrifuges used in conventional mining operations. The main differences between a Knelson concentrator and a Sepro centrifuge are the design of the bowls and the " $\mathrm{G}$ " $(\mathrm{G}=60-150$ for Knelson and G is variable up to 200 for Sepro) (FLSmidth, 2013 [82], Falcon Concentrator, 2019 [83]). The bowl of a Knelson, from bottom to top, has rings with riffles whereas a Sepro centrifuge has a smooth surface where the light minerals move up faster than the heavy minerals. At the top of the bowl, the centrifuge is similar to the Knelson concentrator, with rings and fluidizing water assisting the particles' exchange process. These centrifuges are becoming popular in artisanal mining plants.

The lack of fluidization of the rings that retain concentrates, as seen in the old original centrifuges, resulted in compaction of the riffles and gold losses. Many models of centrifuges without fluidizing water are still available in the market, such as the Knudsen and GoldKacha (Figure 35). They are popular in Africa and have been observed in some artisanal gold operations in Colombia, Ecuador, and Peru. They rotate much slower than the Canadian centrifuges and have a metal scraper that continuously scratches the bed of concentrate trapped in the rings to allow the particles' exchange. To obtain reasonable gold recoveries, the discharge processes must be more frequent than those used by the Canadian centrifuges. They are less expensive than the Canadian centrifuges, simpler, and provide reasonable gold concentration, possibly better than jigs. 


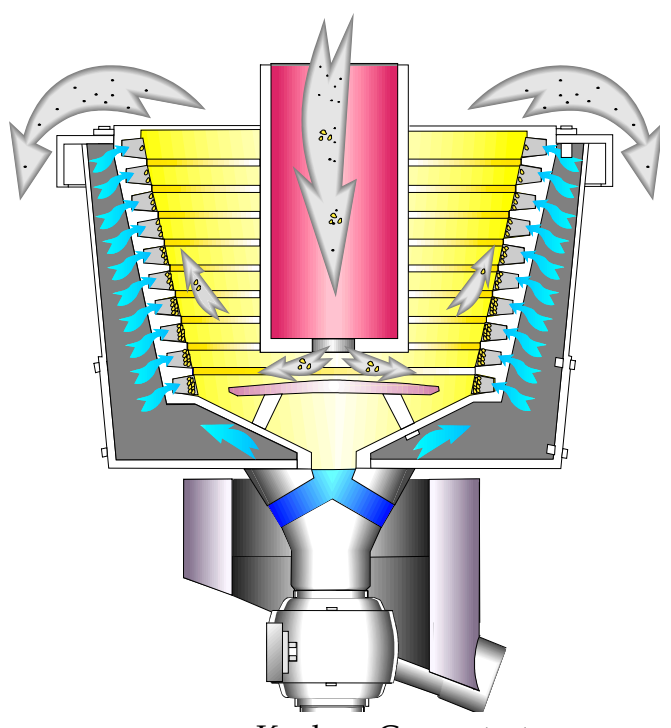

Knelson Concentrator

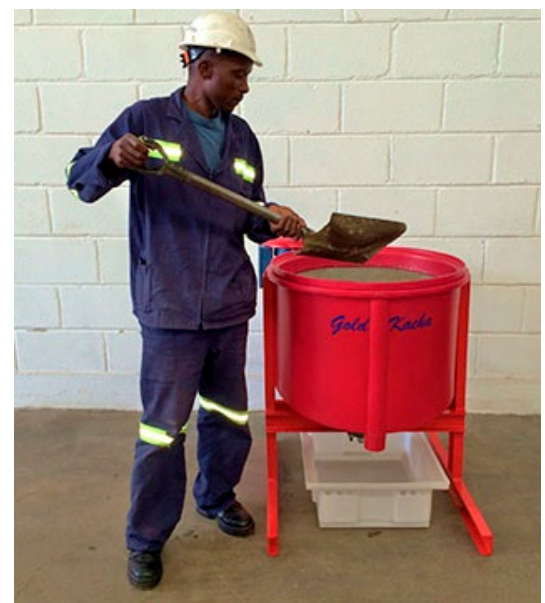

GoldKacha Concentrator

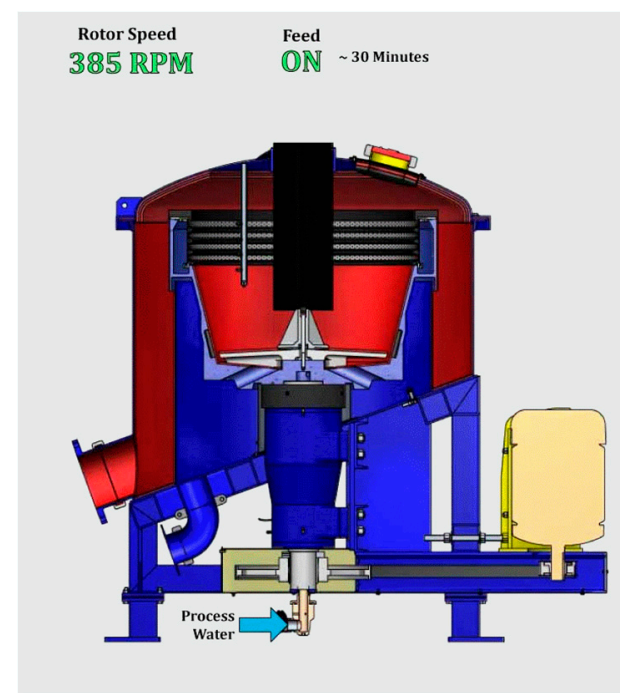

Falcon Concentrator

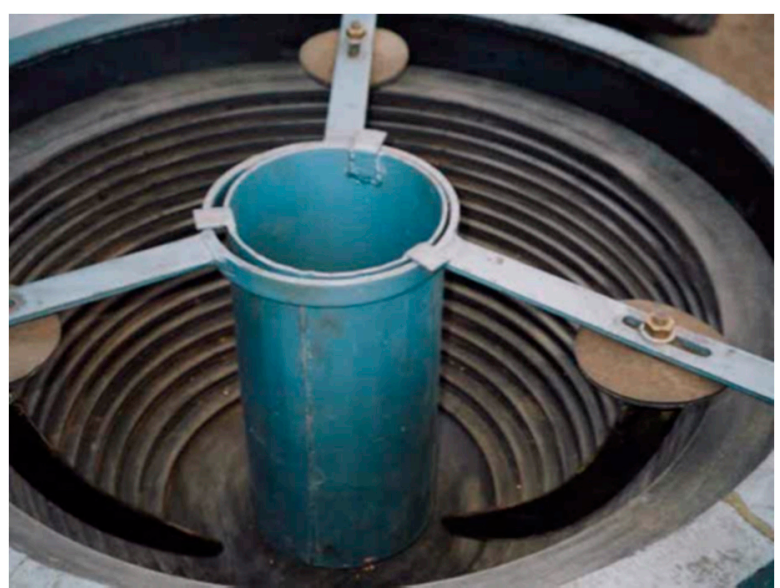

Knudsen Concentrator

Figure 35. Centrifugal concentrators with fluidized bed (on top) and without counter-flow water (down). Sources: http://www.flsmidth.com/en-US/About+FLSmidth/Our+History/Our+ Product+Brands/Knelson, http://www.concentrators.net/ and http://aptprocessing.com/modularmining-equipment/gravity-concentration/gold-concentrator-goldkacha/.

Koppalkar (2009) [34] mentioned that it is impractical to mimic the performance of full-scale centrifuges in a laboratory unit. The author described the gravity recoverable gold (GRG) process developed by Dr. André Laplante in the early 1990s as a useful way to obtain an assessment of the recoverable gold (liberated or not) using a laboratory centrifuge. The procedure consists of a sequential grinding and processing of a 30 to $150 \mathrm{~kg}$ sample (depending on the grade) in a 3 in laboratory Knelson centrifuge. In the first stage, the entire sample is ground below $0.85 \mathrm{~mm}$ and concentrated. The tailings from the first stage are then split and typically $27 \mathrm{~kg}$ is then ground at 45 to $50 \%$ passing $0.075 \mathrm{~mm}$, before being processed through the laboratory unit. In the third step, the tailings from the second stage are ground to $80 \%$ below $0.075 \mathrm{~mm}$ and processed again. Once the adequate size is obtained, a whole sample of the ore is ground at the adequate size and processed to confirm the findings (Laplante, 2000 [84], Laplante and Dunne, 2002 [85], Laplante and Clarke, 2006 [86]).

At the University of British Columbia (UBC), a similar GRG process was also applied to find the adequate particle size to grind an ore before concentrating in a centrifuge. A pulp of ore is ground with 70\% solids for $5 \mathrm{~min}$ in a laboratory ball mill and submitted to centrifugal concentration in a 
laboratory centrifuge. The tailings from the first concentration step are drained and ground with $70 \%$ solids for a further $5 \mathrm{~min}$ to be concentrated again. The procedure is repeated two or more times. In the example shown in Figure 36, the ore ground for 15 min resulted in $92.4 \%$ of gold extraction and a grain size analysis revealed a P80 (80\% of mass below a certain size) of $0.136 \mathrm{~mm}$. A similar procedure has been described by Zhang et al. (2020) [87]. Re-grinding the tailings, these authors determined that the studied ore yielded a gold recovery of $64.7 \%$ when $45 \%$ of the ore particles were ground below 200 mesh.

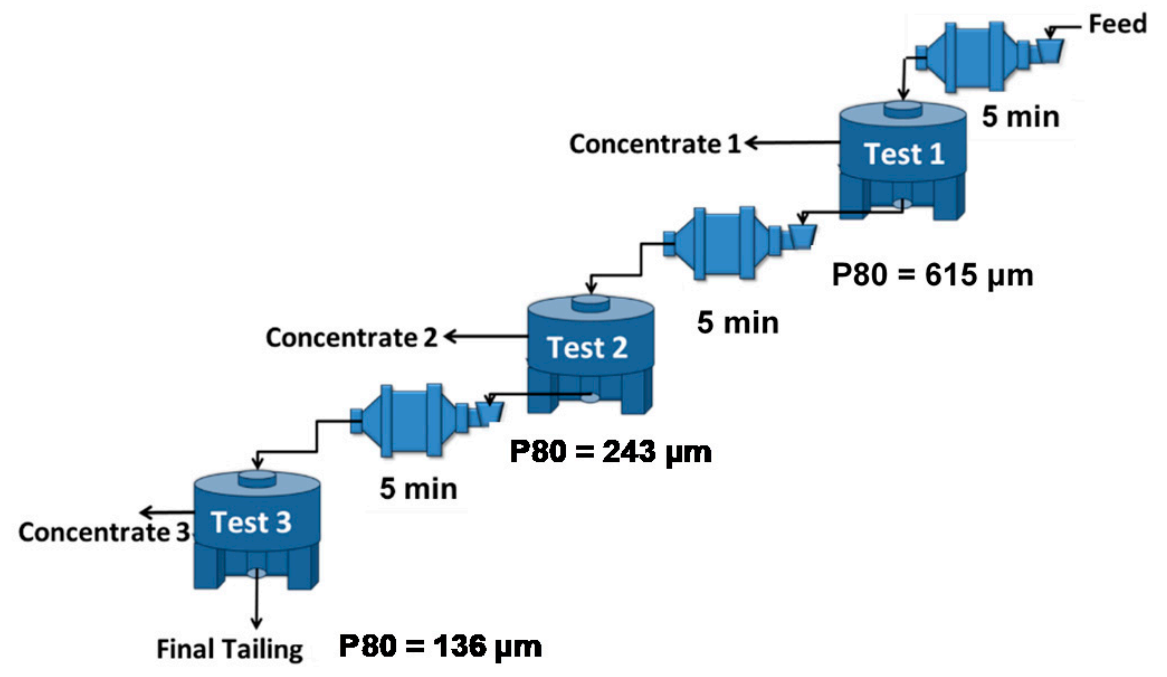

(a)

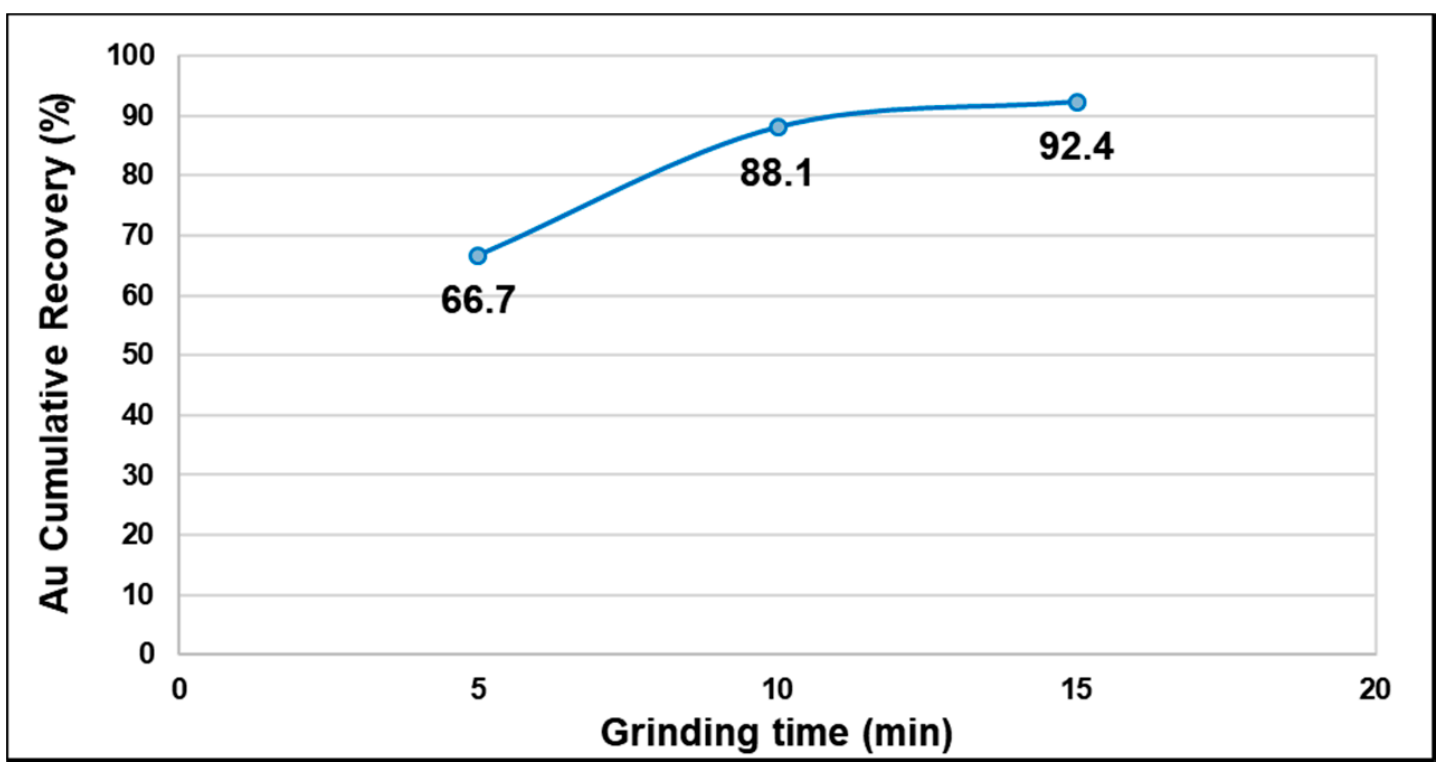

(b)

Figure 36. (a) A simple testing procedure to determine gold recovery vs. particle size in a centrifuge (b) Cumulative gold recovery of three steps of grinding and processing in a laboratory centrifuge.

Sepro developed two types of small centrifuge: the Icon 150 (Figure 37), which can process up to 2 tph of ore, and the Icon 350 with a capacity of $15 \mathrm{tph}$. These have been used in many countries by artisanal and small-scale miners. The main characteristics of an Icon 150 are (Sepro, 2020) [80]: 
- $\quad$ Price in Canada $<$ US $\$ 6000$

- Max solids capacity $=2$ tph

- $2 \mathrm{HP}(1.5 \mathrm{~kW}), 220 \mathrm{~V}, 50$ or $60 \mathrm{~h}$

- $\quad$ Machine weight $=120 \mathrm{~kg}$

- Max particle size $=2 \mathrm{~mm}$

- Water 10 to $30 \mathrm{~L} / \mathrm{min}$

- $\mathrm{G}=120$ to 150 (1100 rpm)

- Fluidization water (water must be clean) pressure $=5$ to $15 \mathrm{psi}$

- $\quad$ Rinse time $=60$ to $90 \mathrm{sec}$

- Generates 0.5 to $1 \mathrm{~kg}$ of concentrate/batch

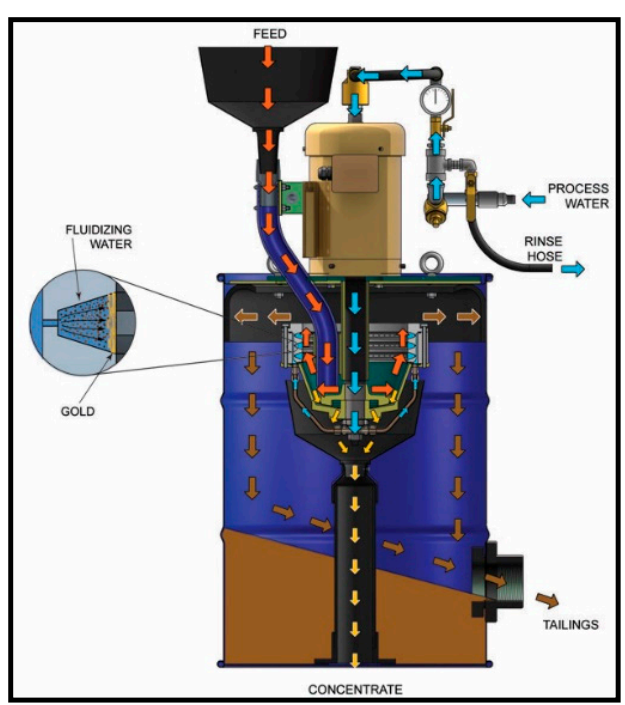

(a)

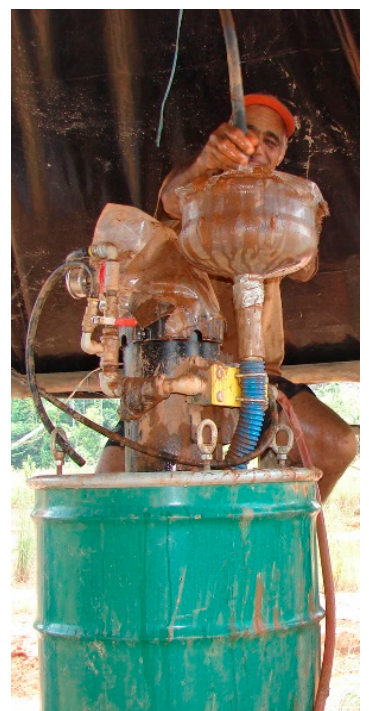

(b)

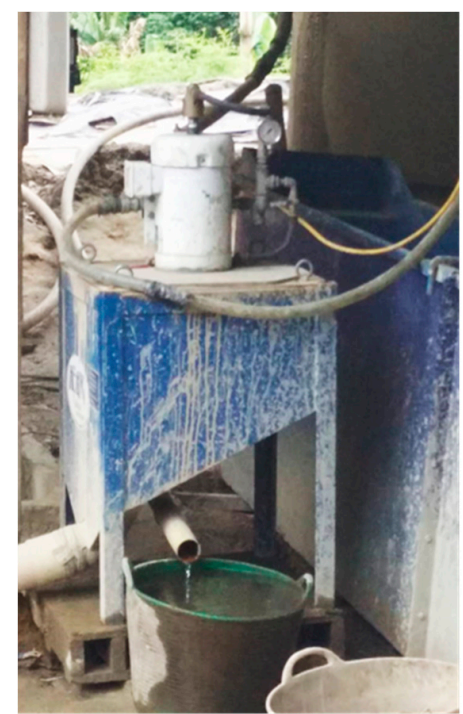

(c)

Figure 37. (a) Scheme of an Icon 150 Centrifuge, (b) Operation in Brazil and (c) in Colombia.

Knelson Concentrators also offers a small version of a centrifuge, the KC-MD 7.5, which is an adequate size for many artisanal miners. This centrifuge can process $0.68 \mathrm{tph}$ of ore with a max particle size of $6 \mathrm{~mm}$. It uses $0.7 \mathrm{~L} / \mathrm{min}$ of water and generates 1 to $1.4 \mathrm{~kg}$ of concentrate per batch. It has a $0.75 \mathrm{HP}$ motor and uses 48 to $68 \mathrm{~L} / \mathrm{min}$ of clean counter-flow fluidizing water (Knelson, 2020) [88].

A single pass of ore in a batch centrifugal concentrator can provide relatively good recoveries for some ores. While conventional mining companies typically use the centrifuge in closed grinding circuits, AGM operations rarely use this type of configuration. In hard rock AGM operations, miners typically grind in an open circuit and the concentrator is located at the discharge of the grinding equipment. To increase gold recovery, some artisanal miners use two or three centrifuges in series instead of using a closed circuit. To demonstrate this approach, a laboratory Knelson Concentrator unit was used to concentrate ore from a group of Colombian artisanal miners. After $15 \mathrm{~min}$ of grinding in a rod mill, $60.6 \%$ gold recovery was achieved with a single pass. When the tailings of the first pass were reprocessed in the same centrifuge without grinding, the gold recovery increased to $76 \%$ and $85 \%$ in the second and third passes, respectively (Figure 38). In closed circuits, when the centrifuge tailings are returned to a ball mill, placing centrifugal concentrators in series is not practiced. It is hard to compare data from laboratory centrifuges testing a few kilograms of ore with a field centrifuge processing tonnes of ore per hour. Sometimes the results are not compatible. A pilot test is always recommended to confirm whether scavenger centrifuges are justifiable. 


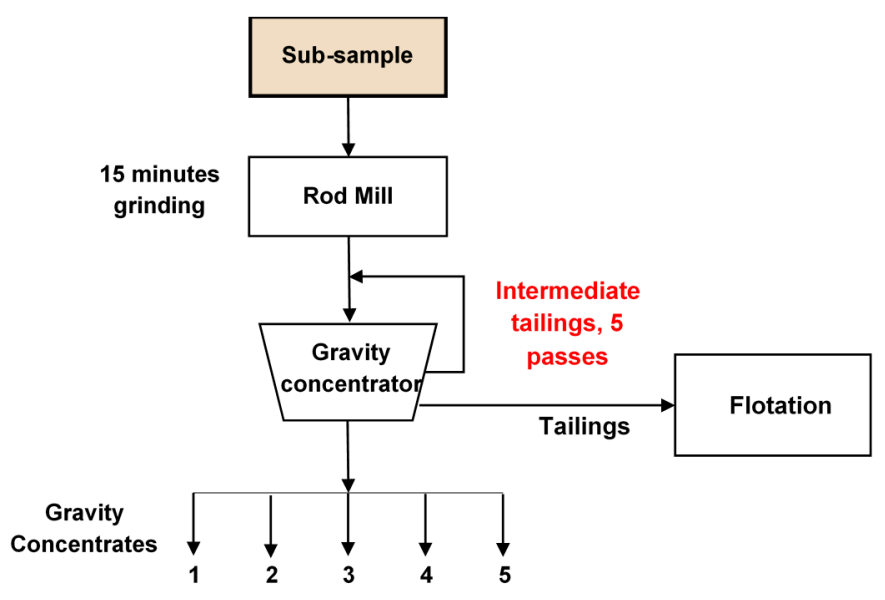

(a)

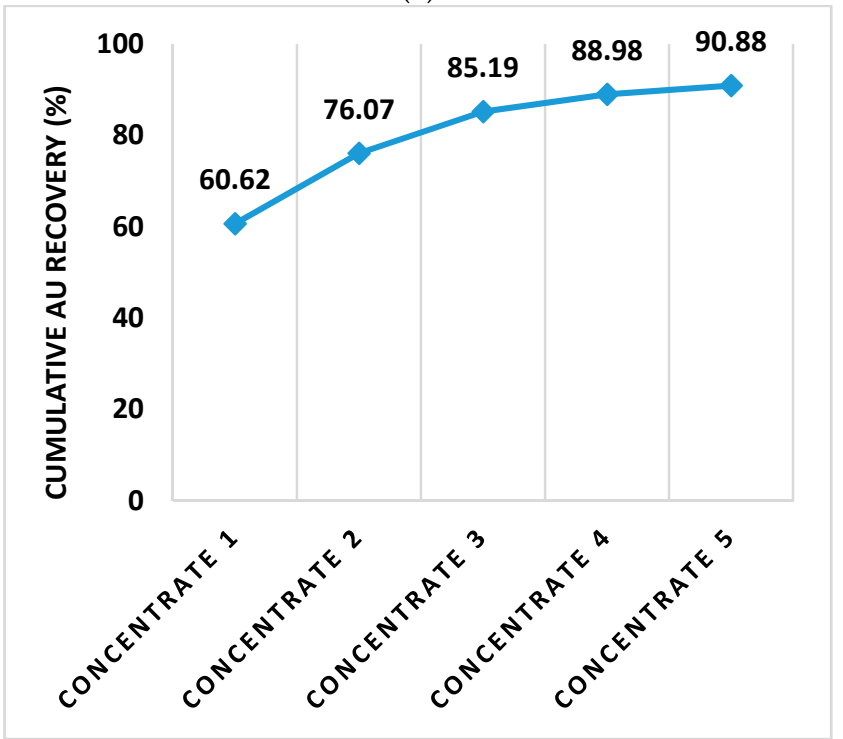

(b)

Figure 38. (a) Laboratory tests with a Colombian ore using five sequential passes in a Knelson Concentrator. (b) Results of gold recovery in 5 passes without re-grinding

Centrifuging-Summary

The main points to highlight for centrifugal concentrators in AGM are:

- Centrifuges are much better gravity concentrators for a feed with a wide particle size range than other gravity concentrators and they can concentrate very fine gold;

- Centrifuges are less sensitive to gold particle shapes, such as flakes;

- Counter-flow fluidizing water must be clear. Often, operators use muddy water, which clogs the centrifuge;

- $\quad$ The counter-flow pressure and the rotating speed are two parameters that must be investigated for a better performance of the equipment. Artisanal miners frequently neglect this;

- High counter-pressure water increases the grade of the concentrate, eliminating more gangue minerals, but this can reduce the recovery of fine gold particles;

- $\quad$ Centrifuges are generally best operated in a closed circuit with a ball mill. The use of centrifuges in series (scavengers), when grinding in an open circuit may increase gold recovery but this involves more capital and operating costs and it is not worthwhile for all types of ore. 
- Operators must find out the adequate discharge time of concentrates. This requires chemical analyses of the products (feed and tailings) and this is not often locally available. Visual assessment by panning the concentrate and tailings can provide useful information; and,

- Skill is needed to properly operate a centrifuge using fluidizing water. Many AGM operators prefer non-fluidized bed centrifuges and, unfortunately, in some cases, they add mercury inside the bowls of the centrifuge, as was observed in Zimbabwe.

\section{Extracting Gold from Gravity Concentrates}

Once the gold is concentrated into a small mass, the challenge is to extract gold from these concentrates. Four methods are discussed below:

1. Direct smelting

2. Amalgamation

3. Leaching

4. Coal-oil agglomeration

\subsection{Direct Smelting}

The concentrates from gravity concentration can be directly melted with borax but this is not a trivial process since the concentrates must have high grades of gold. Borax $\left(\mathrm{Na}_{2} \mathrm{~B}_{4} \mathrm{O}_{7} \cdot 10 \mathrm{H}_{2} \mathrm{O}\right)$ has been used by conventional and artisanal miners for centuries as a flux to melt concentrates and pour gold bars. Appel and Na-Oy, (2011) [89] have been publicizing a "new Borax Method" as a panacea to extract gold from gravity concentrates without the use of mercury or any other leaching processes. Borax reduces the melting point of metals and silicates in the gravity concentrates. However, to bring all gold down to the bottom of a crucible, a large amount of gold must be in the concentrate as the gold particles must coalesce to create enough weight to sink in the molten bath, otherwise, the gold will stay in the viscous slag. These authors have suggested that gold grades in a concentrate must be higher than $30,000 \mathrm{~g} \mathrm{Au} / \mathrm{t}$ (or 3\% Au) to avoid large losses of gold to the slag. As shown in Figure 2, if miners wish to obtain by gravity concentration a very rich (yellow) concentrate, the gold recovery, in most cases, would be poor. The other inconvenience of the direct smelting of concentrates is the presence of sulfides. In tests with a sulfide-rich concentrate, from a centrifuge, with $3300 \mathrm{~g} \mathrm{Au} / \mathrm{t}$ and $1170 \mathrm{~g}$ $\mathrm{Ag} / \mathrm{t}$ from Ecuadorian miners, most gold was lost to the slag (Veiga et al., 2014) [9]. When a mixture of $\mathrm{KNO}_{3}, \mathrm{SiO}_{2}$, and $\mathrm{NaHCO}_{3}$ was used to oxidize the sulfides, gold losses were reduced, but $16 \%$ of the gold still remained in the slag, contained $840 \mathrm{~g} \mathrm{Au} / \mathrm{t}$. The process is not useful for most concentrates from primary ores, however, miners working with alluvial ores have been using borax to pour gold bars from concentrates for many decades. With alluvial ores, the gold is usually liberated, and no sulfides are normally present. An option for artisanal miners to melt concentrates with gold grades below 30,000 ppm is to add more gold or silver to the crucible to collect disperse particles of gold bringing them to the bottom of the melted mixture. This option seems to be hard for the miners to accept, as they want to sell their gold as soon as possible.

\subsection{Amalgamation}

As discussed above, the amalgamation of gravity concentrates, as opposed to whole ore amalgamation, can bring a substantial reduction of mercury use and losses to the tailings. However, this process cannot amalgamate unliberated gold particles. When amalgamation is conducted in small ball mills, mercury pulverizes ("flouring"), forming droplets that do not amalgamate the gold grains. In this process, mercury also oxidizes faster, losing coalescence, i.e., the capacity of the droplets to agglomerate. This is popularly known as the "mercury sickening" effect. Sulfides also contribute to sickening mercury (Beard, 1987) [90]. Around the world, artisanal miners use different reagents to mix with mercury during the amalgamation process to reduce flouring, such as lemon juice, bicarbonate, quicklime, guava leaves, Coca-Cola, brown sugar, toothpaste, urea, detergents, etc. 
The actual effect of these reagents on increasing mercury coalescence is not well understood, but the miners, anecdotally, confirm that they are useful to improve gold amalgamation and avoid droplets formation. Amalgamation must be a gentle process of mixing metallic mercury with the ore to contact it with free gold particles. This can be done in a pan or a mixing barrel without grinding media.

Pantoja and Alvarez (2000) [91] developed an electrolytic process to avoid mercury flouring by forming sodium-amalgam that has better gold amalgamation properties. This simple process consists of making a solution of $10 \%$ of $\mathrm{NaCl}$ (a tablespoon of salt in a glass of water) and then contacting the metallic mercury at the bottom of the glass to the negative pole of a $12 \mathrm{~V}$ motorbike battery or a radio battery. A rod of graphite (extracted from the core of a radio battery) is connected to the positive pole of the battery and stays in the solution for $15 \mathrm{~min}$ (Figure 39). In this process, sodium ions are attracted to the cathode (negative pole) forming a sodium-amalgam that has better gold amalgamation properties than pure mercury. The sodium retained by the mercury slowly reacts with water and forms soluble $\mathrm{NaOH}$. However, the activated mercury (sodium-amalgam) does not last long, likely less than $2 \mathrm{~h}$. Chloride ions are attracted to the anode and form hypochlorite anions. Using potassium chloride to activate the mercury, a potassium-amalgam is formed-interestingly this can also amalgamate platinum, as observed at a placer mining operation in Colombia. The sodium-mercury is brighter, has better coalescence, and amalgamates gold faster than pure mercury.

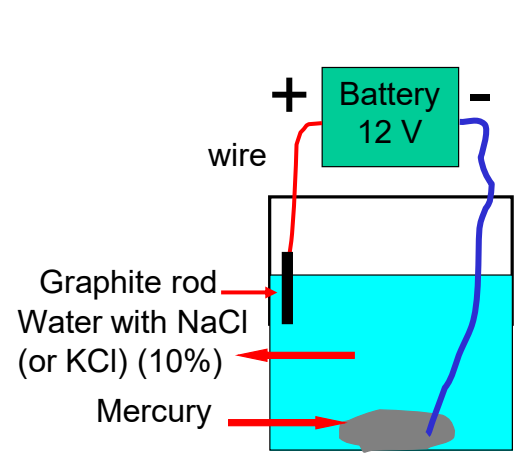

(a)

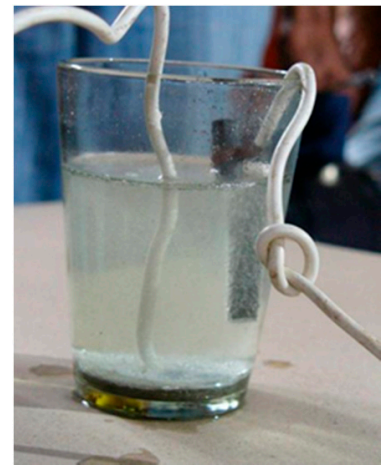

(b)

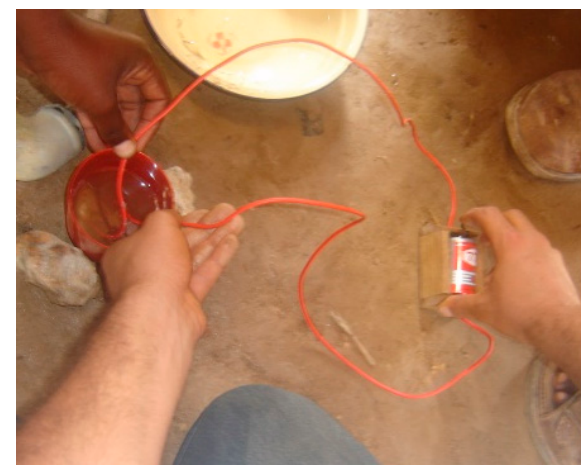

(c)

Figure 39. Pantoja's method being used in Brazil and Mozambique to activate mercury before amalgamation. (a) Scheme of the mercury activation process; (b) Pantoja's method in use generating hypochlorite gas in the anode; (c) Use of a radio battery to activate the mercury.

Once the amalgamation process ends, the heavy mass of the amalgam with excess mercury can easily be separated from the rest of the heavy minerals, by panning or using a spiral or an elutriator. The excess mercury is separated from the solid (paste) gold-silver-amalgam by filtration which is normally conducted by manual squeezing with a piece of fabric or by using a centrifuge as described above in session 2.3.4 (Veiga et al., 2006) [39]. The final method to separate mercury from the gold-silver alloy is a chemical decomposition of the amalgam that can be done by leaching the mercury with a nitric acid solution $(30 \% v / v)$ or by heating the amalgam at temperatures above $400{ }^{\circ} \mathrm{C}$. As observed in Bolivia and Guyana, the dissolved mercury, when $\mathrm{HNO}_{3}$ is used, can be recovered by cementation with a bar of aluminum. Frequently, miners do not want to recover mercury and dump the acidic solution into a river. When decomposing thermally the amalgam, unfortunately, not all artisanal miners use retorts to condense the mercury fumes. They often prefer to burn amalgams in open pans or a shovel, even if simple solutions, such as home-made retorts, have already been demonstrated to them (Veiga et al., 2014b) [39]. The final product is a gold doré with $2 \%$ to $5 \%$ mercury, depending on the temperature of the evaporation process (Veiga and Hinton, 2002 [56]). If the heating temperatures are low or the heating time is insufficient to evaporate all mercury, for example when it is conducted in a bonfire, the final doré can have as much as $20 \%$ mercury (Veiga et al., 2006) [39]. Even a well-burned 
amalgam still carries $2 \%$ to $5 \%$ of mercury, which is then usually evaporated in gold shops when the doré is melted, contaminating the operators and neighbors (Moody et al., 2020) [92].

\subsection{Leaching}

Most conventional gold mining companies use cyanide to extract gold from concentrates or whole ore. Cyanide has been used and misused by artisanal mining in many countries. Since the implementation of processing centers in the early 1990s, the operators of the centers have offered amalgamation for their clients, the miners, and then kept the mercury-contaminated tailings to leach the residual gold with cyanide. This, as mentioned above, can cause significant environmental problems due to the formation of mercury-cyanide complexes and poor management of the cyanidation tailings.

Artisanal cyanidation operations use vat leaching, usually for gravity concentration tailings, or agitated tanks for concentrates or tailings as well. To remove gold from the cyanide solution, some miners use activated carbon, but a large majority precipitate gold with zinc in an adaptation of the Merrill-Crowe process. These plants leach ores, concentrates, or amalgamation tailings for 8 to $12 \mathrm{~h}$, then stop the agitation and wait for about 3 to $6 \mathrm{~h}$ for the material to settle. Then, the gold-rich solution is siphoned to a series of $10 \mathrm{~cm}$-diameter PVC columns filled with zinc shavings where the gold (and eventual part of the mercury) is precipitated, and the solution is recirculated to the agitation tanks to be leached again. This cycle lasts 4 to 6 days. After precipitation, the gold-loaded zinc shavings are transferred to a gas furnace and then the zinc is evaporated in a metallic bucket at temperatures above $950^{\circ} \mathrm{C}$, contaminating with vapors of zinc, and other associated metals, operators and neighbors of the facility (Figure 40). Condensers or filters when evaporating shavings are rarely used.
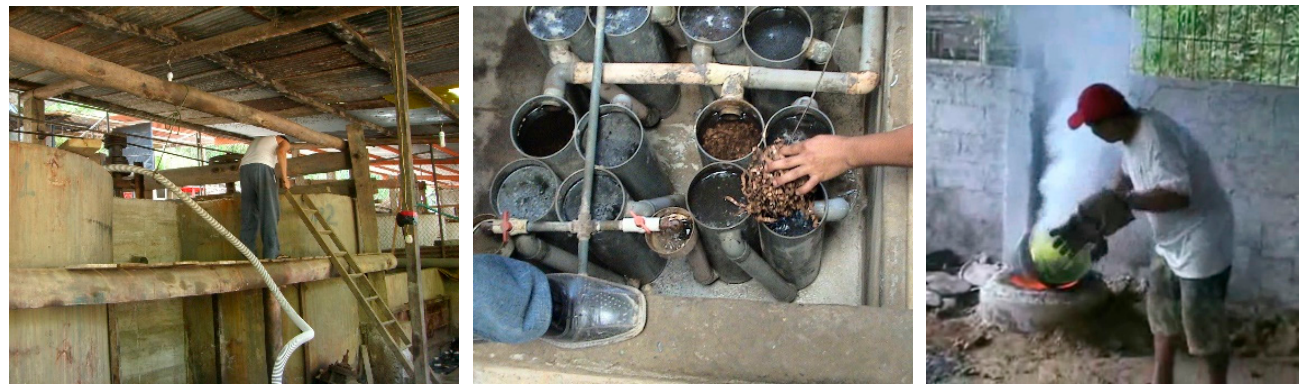

Figure 40. The decanted gold-loaded cyanide solution passed a column of polyvinyl chloride (PVC) tubes with zinc shavings to precipitate the gold. The zinc is later recklessly evaporated to leave behind gold.

The precipitation of gold with zinc (see equations below) should be conducted in a vacuum to avoid the re-dissolution of gold. However, miners typically run the gold-rich solutions through PVC columns at atmosphere and lose around 6\% of the gold in the discharged solution (Velasquez et al., 2011) [93].

$$
\begin{gathered}
4 \mathrm{Au}+8 \mathrm{CN}^{-}+\mathrm{O}_{2}+2 \mathrm{H}_{2} \mathrm{O}=4 \mathrm{Au}(\mathrm{CN})_{2}^{-}+4 \mathrm{OH}^{-} \text {(gold leaching with cyanide) } \\
2 \mathrm{Au}(\mathrm{CN})_{2}^{-}+\mathrm{Zn}=\mathrm{Zn}(\mathrm{CN})_{4}^{2-}+\mathrm{Au} \text { (gold precipitation with zinc) }
\end{gathered}
$$

Hedley and Tabachnick (1968) [94] listed some of the factors affecting cyanidation, such as: dissolved oxygen, $\mathrm{pH}$, the stability of the cyanide solution, cyanide concentration, gold particle size and shape, accessibility of cyanide to gold (exposure), temperature, presence of minerals consuming oxygen, presence of cyanicides, etc. As all these factors also increase the cyanide consumption, AGM operations typically use uncontrollable, and in many cases unnecessary, levels of cyanide in solution, 2 to $6 \mathrm{~g} \mathrm{NaCN} / \mathrm{L}$, to leach tailings. Cyanidation is quite slow for relatively coarse gold particles. In laboratory tests, it was observed that a $0.150 \mathrm{~mm}$ (100 mesh) particle of pure gold needs approximately $44 \mathrm{~h}$ to be dissolved in normal cyanidation conditions. This is a reason why most companies remove the coarse gold specks from the ores with gravity concentration before 
cyanidation (Hedley and Tabachnick, 1968 [94], Marsden and House, 2006 [11], Egan et al., 2016 [95], Chen et al., 2020 [79]).

Cyanide is usually supplied as sodium cyanide $(\mathrm{NaCN})$ or potassium cyanide $(\mathrm{KCN})$. In water, these salts dissociate forming free cyanide and $\mathrm{Na}^{+}$or $\mathrm{K}^{+}$. Free cyanide is a term that refers to $\mathrm{CN}^{-}$or $\mathrm{HCN}(\mathrm{aq})$, in which the predominance of each one of these species depends on the $\mathrm{pH}$ of the solution. Cyanidation is normally conducted at $\mathrm{pH} 10.5-11$ using, in most cases, $\mathrm{Ca}(\mathrm{OH})_{2}$ to adjust the $\mathrm{pH}$. Lower $\mathrm{pH}$ levels favor the formation of $\mathrm{HCN}(\mathrm{aq})$, which reduces the cyanidation kinetics, and it is unstable, generating toxic gaseous $\mathrm{HCN}$. Higher $\mathrm{pH}$ levels decrease the gold leaching reaction kinetics. The main variable to increase the gold dissolution reaction speed is the oxidant that in most cases is oxygen from the air. Excessive oxygen can oxidize the free cyanides and this is not desirable (Marsden and House, 2006 [11]). The level of dissolved oxygen increases when the temperature of the water decreases. For example, at $25^{\circ} \mathrm{C}$, the theoretical concentration of dissolved oxygen in water is $8.6 \mathrm{mg} / \mathrm{L}$ whereas at $5^{\circ} \mathrm{C}$ is $12.8 \mathrm{mg} / \mathrm{L}$ (Higgins, 2013 [96]).

Recently some commercial intensive cyanidation processes have been used by conventional mining companies to leach coarse gold particles using high levels of oxygen in the process. However, when too much oxygen is added, the cyanidation reaction is accelerated but cyanide in solution is also oxidized to cyanate $\left(\mathrm{CNO}^{-}\right)$. Then, more $\mathrm{NaCN}$ must be added to balance the losses. Cyanide concentrations in these processes are usually around 5 to $20 \mathrm{~g} / \mathrm{L}$ of $\mathrm{NaCN}$. Veiga et al. (2009) [68] proposed a method to extract gold from gravity concentrates by adding an oxidizing agent into small ball mills, using the same mills used for whole ore amalgamation. Oxidizing agents such as hydrogen peroxide, or Vanish or Oxiclean, common cloth detergents that have around 16-21\% of $\mathrm{H}_{2} \mathrm{O}_{2}$ in $50-66 \%$ of sodium percarbonate, are suitable to be used in AGM. After about $12 \mathrm{~h}$ of leaching gravity concentrates with 5-10 $\mathrm{g} \mathrm{NaCN} / \mathrm{L}$, the balls are removed and a perforated PVC tube with a porous nylon bag filled with activated charcoal is introduced into the mill for gold adsorption. In tests in Brazil, Colombia, Ecuador, and Indonesia AGM sites, this mill-leaching process extracted more than 92\% of gold from concentrates in less than $24 \mathrm{~h}$ (Sousa et al., 2010 [97], Veiga et al., 2014) [9].

A test was conducted in Portovelo, Ecuador, to convince the local miners that this technique is better than amalgamation to produce more gold. A $240 \mathrm{~kg}$ of a gravity concentrate with $17.3 \mathrm{~g} / \mathrm{t}$ of gold obtained from a Chilean mill and sluice box was split into two subsamples. A $160 \mathrm{~kg}$ portion was given to the miners to conduct amalgamation as they used to do manually in a batea. A smaller $80 \mathrm{~kg}$ portion was used for the mill-leaching technique with the conditions described above. After $8 \mathrm{~h}$ of amalgamation, miners burned the amalgam and obtained a small gold bar with a calculated gold recovery of $26 \%$. The mill-leaching process of the concentrates with $6 \mathrm{~g} \mathrm{NaCN} / \mathrm{L}$ after $8 \mathrm{~h}$ achieved a calculated gold recovery of $95 \%$. The gold was eluted from the activated charcoal using a hot alkaline solution with alcohol and then smelted with borax. Miners could see that the mill-leaching process produced a heavier gold bar from less concentrate processed.

Several other alternatives to cyanidation have been used to leach gold from gravity concentrates, such as the use of sodium hypochlorite and hydrochloric acid developed by MINTEK, in South Africa. The gold in solution is then precipitated with sodium metabisulphate (Mahlatsi and Guest, 2003) [98]. The iGoli process was demonstrated in South Africa, Tanzania, Mozambique, and Peru to artisanal miners, but after training the miners, this mercury-free method was never widely used. Styles et al. (2010) [99] classified the process as technically complicated and expensive. An additional problem is the storage of liquid and unstable solutions of sodium hypochlorite in hot climates (Veiga et al., 2014) [9]. Many methods have been described to leach gold replacing mercury and cyanide (Hilson and Monhemius, 2006 [100], Gökelma et al., 2016 [101]). One example is the American Haber method using undisclosed reagents (Grayson, 2007) [22]. Another example is the patented iodide process promoted by the Canadian company EnviroLeach (2020) [102], which has been used to leach gold from e-waste and concentrates from small gold mines. The sophistication and proprietary characteristics of these technologies are some of the hurdles for the dissemination of these processes in AGM. The use of cyanogenic plants, such as cassava, is also an interesting solution for leaching gold 
from concentrates. On a laboratory scale, this has been studied at the University of British Columbia. In preliminary tests with a Brazilian bitter cassava extract, which generated $300 \mathrm{mg} / \mathrm{L}$ of free $\mathrm{CN}$ when hydrolyzed, $50 \%$ of gold was recovered from an artisanal mining ore with $48 \mathrm{~g} / \mathrm{t}$ of gold in less than $24 \mathrm{~h}$ (Torkaman et al., 2020) [103].

However, any clean and responsible leaching process recommended for AGM should consider higher capital and operating costs as well as the need for skilled operators.

\subsection{Coal-Oil Agglomeration}

The coal-gold agglomeration (CGA) process has its merits for very fine liberated gold particles (below $25 \mu \mathrm{m}$ ) (Sen et al., 2010) [104], as commonly found in alluvial ores. A comparative study in South Africa using synthetic gold ore, where gold particles were mixed with silicates, concluded that the gold recoveries with the CGA process are compatible with amalgamation (Koltze and Petersen, 2000) [105]. This study also mentioned that the presence of sulfides reduces the oleophilicity of gold, thereby reducing its recovery.

The CGA process was tested 26 years ago to replace amalgamation in Brazil by Marciano et al. (1994) [106]. Using a synthetic ore with pure gold particles added and a concentrate from an artisanal mine, the authors tested different types of oil and types of coal. The results showed that diesel oil produced better agglomerates than vegetable oils and kerosene. Like other authors (Mehrotra et al., 1983 [107]; Calvez et al., 1998) [108], this Brazilian study suggested that gold recovery increases with more oil in the coal agglomeration process and that the quality of the coal (e.g., metallurgical coal) has an influence on the quality of the agglomerates.

This technique, being recently brought to the artisanal miners' attention as an environmentally friendly solution to replace mercury and cyanide, seems to be less efficient in recovering gold from concentrates when the quality of the coal is low, the concentrate has high amount of sulfides, the concentrate has clay minerals, and/or the pulp is viscous. The technique works well to recover fine, liberated gold particles (Hilson and Monhemius, 2006 [100]; Otsuki and Yue, 2017 [109]). However, it is important to keep in mind that alluvial deposits have low gold grades and high amounts of ore must be daily processed to pay back the investment in equipment. Other technical and operating difficulties to prepare the coal agglomerates and extract them from the pulp are also hurdles for the broad use of this process. These limitations, in addition to the capital cost required to acquire pelletizers to make the agglomerates and flotation cells, reduce drastically, like the direct smelting process, the number of cases in which this method is applicable in artisanal gold mines.

\subsection{Extracting Gold from Concentrates-Summary}

The main points to highlight are:

- Direct smelting of gold concentrates with borax is not a definitive solution for all types of ore, as the gold grade of the concentrate must be very high $(>30,000 \mathrm{~g} / \mathrm{t} \mathrm{Au})$, otherwise high amounts of gold stay in the slag, leading to a substantial reduction of gold recovered. Direct smelting can be useful for alluvial ores or for recovering free gold from a primary ore before cyanidation; however, sulfides in a concentrate must be previously oxidized before smelting;

- The amalgamation of the concentrates is the quickest, easiest, and cheapest method for artisanal miners to extract gold from concentrates. However, this works only for free gold particles. Oxidation contributes to the reduction of mercury coalescence leading to the formation of fine droplets that lowers the effectiveness of amalgamation. Methods to activate mercury or reduce its surface tension can improve amalgamation, but they will not be useful in trapping unliberated gold particles. Amalgamation is an ancient poisonous process banned by all conventional gold mining companies and it must be also avoided in AGM operations;

- $\quad$ Leaching processes can dissolve unliberated but exposed gold particles. Cyanide is widely used by conventional and artisanal gold miners. The cyanidation of mercury-contaminated tailings 
exacerbates the pollution producing toxic mercury-cyanide complexes that can be bioaccumulated. Although alternative lixiviants exist to replace cyanide, they are not easily available or affordable at most AGM sites;

- The coal-oil agglomeration process is limited to fine, liberated gold particles and the feed concentrate must have low sulfides and clays.

- In many cases, the best option for artisanal miners is to sell their concentrates (or even their ores) to companies with legal and responsible systems of cyanidation. The buyers should pay the miners based on the gold content in the concentrates (Veiga and Fadina, 2020) [110].

\section{Comparing Gravity Concentration Equipment}

New pieces of gravity concentration equipment regularly come frequently to the market and are promoted to gold miners and organizations working with AGM. Most manufacturers of the new equipment claim that they provide better gold recoveries than any other equipment. However, gold recovery is not the only variable to be observed. There are other important parameters to be compared, such as: grade of the concentrate, enrichment factor (grade of the concentrate divided by the grade of the feed), prices, local availability of spare parts, energy consumption, water use (quality and quantity), the durability of the equipment, environmental impacts, etc.

To illustrate the challenge, the following example describes how to evaluate new types of equipment. A type of hypothetical equipment is tested, using the same ore, and compared with some of the traditional concentrators discussed above: sluice with carpets, sluice with riffles, batea, dry sluice, jig, shaking table, and centrifuge. Only based on the gold recovery of $97 \%$ (Figure 41), there is an impression that the new equipment had the best performance. However, if the enrichment factor is used for evaluation, it becomes clear that the new equipment produces concentrates with low grades and a large mass.

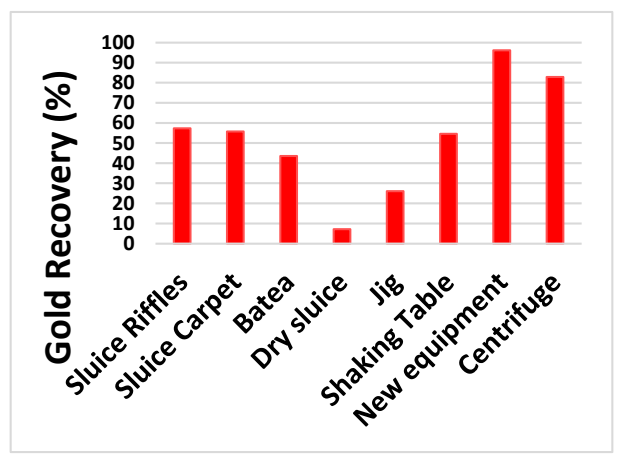

(a)

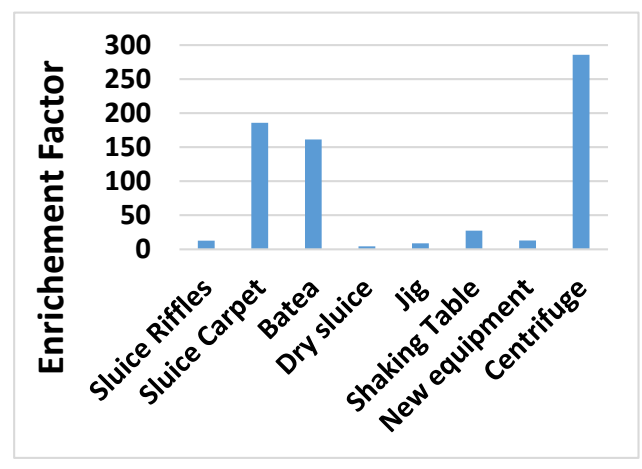

(b)

Figure 41. Comparison of performance of gravity concentration equipment with a hypothetical type of new equipment. (a) Gold recovery using different hypothetical pieces of equipment (b) Enrichment factors using the same pieces of equipment. 
Gravity concentration processes can also be compared through a graph of gold recovery and gold grade. Using data from the previous example, it is clear that the best gravity equipment is the centrifuge, which generated both high gold recovery and a high gold grade in the concentrate (Figure 42).

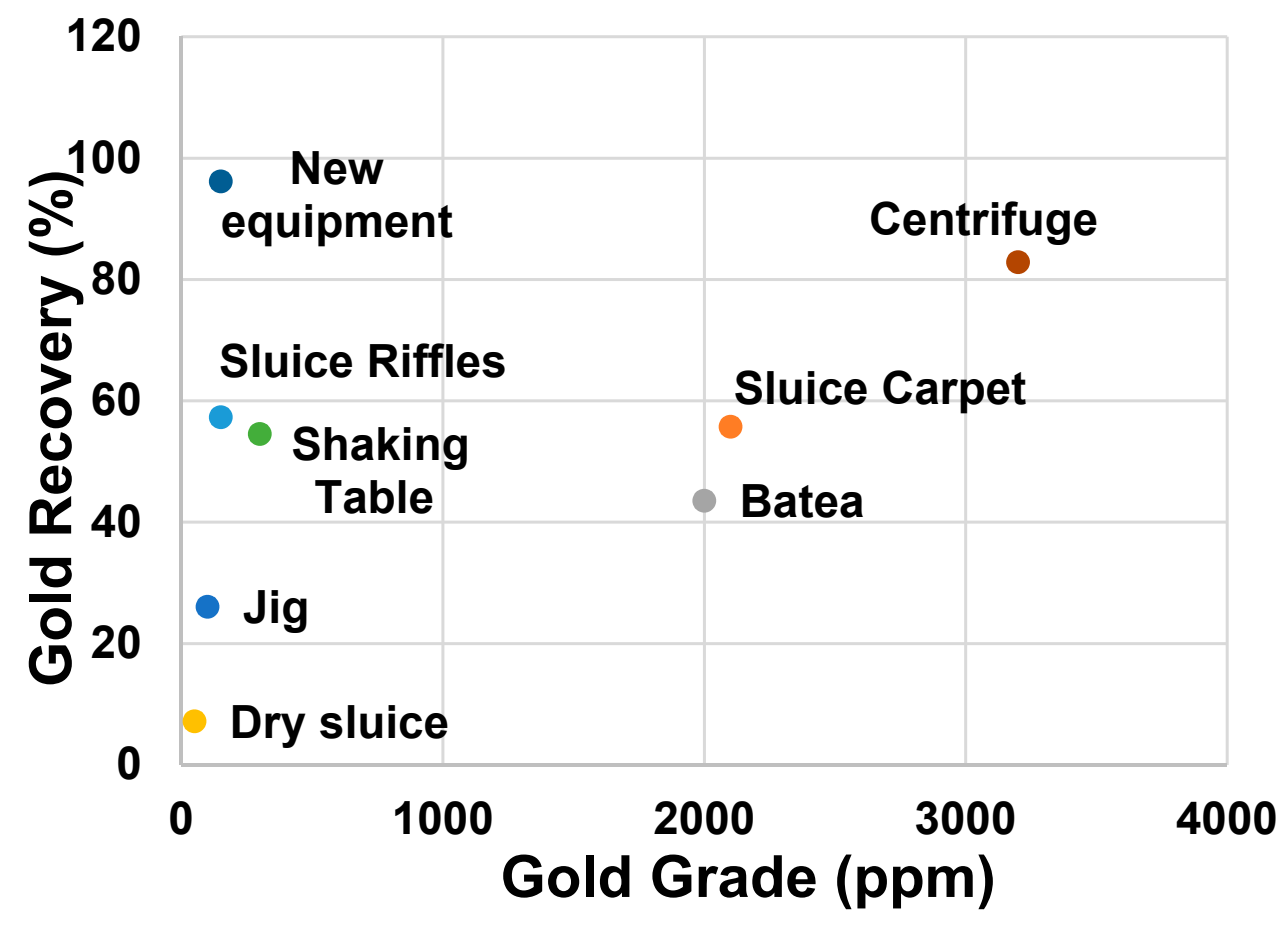

Figure 42. Gold recovery versus gold grade for different types of equipment.

\section{Economic Assessment}

The evolution of AGM is only possible with technical capacity (and technical assistance) for the artisanal miners and more investment. The type of gravity concentration technology available to artisanal miners depends on the technical knowledge of the operators and capital. An exercise was conducted to find out the costs of a complete plant with gravity concentration + flotation (for the fine gold) + cyanidation of concentrates as depicted in Figures 43 and 44 .

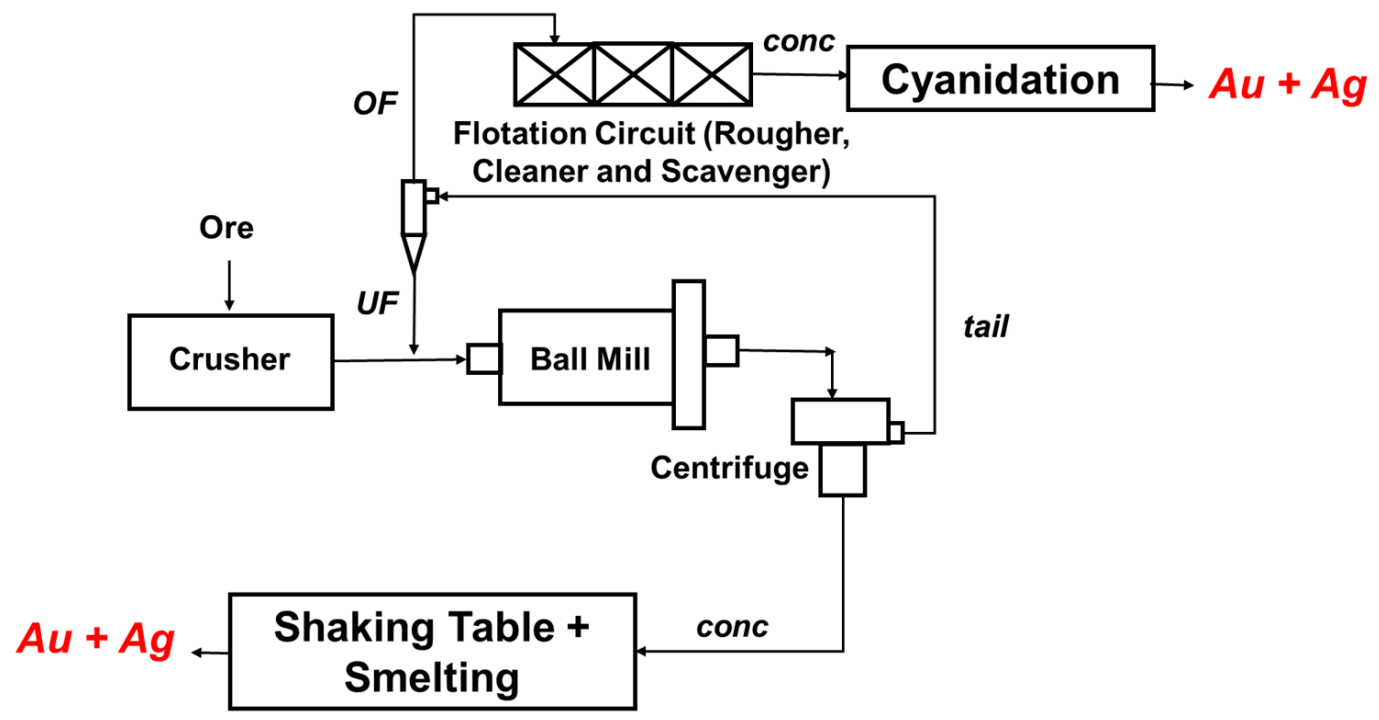

Figure 43. Example of a flowsheet of a small plant to concentrate gold. 


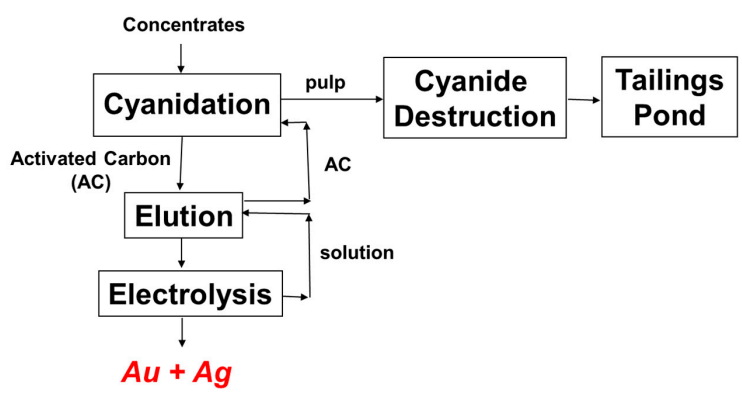

Figure 44. Example of the steps to leach flotation concentrates with cyanide.

This exercise evaluated all pieces of equipment to process from 2 to $200 \mathrm{tpd}$ (tonnes per day) of ore. It also considered all ancillary equipment, as well as water and power distribution systems, tailing dams, infrastructure, labor, reagents, etc., using actual price quotations from suppliers in Colombia. Based on these data, it was possible to obtain the CAPEX (capital cost) and OPEX (operating expenses) (Table 2 and Figure 45). The CAPEX and OPEX per tonne of material being processed and the US\$/tpa (tonnes per annum) revenue becomes more advantageous with a production rate above 50 tpd. A 200 tpd plant operating only with centrifuge + cyanidation will cost around US\$ 3.5 million with an operating cost of $64 \mathrm{US} \$ /$ tpa, considering 300 days per year of operation. If flotation is introduced to recover gold from the gravity circuit tailings, the investment required rises to close to US $\$ 4$ million with an operating cost of 66 US\$/tpa. The highest capital costs are related to comminution equipment. The capital cost can be drastically reduced using second hand and/or locally made equipment.

Table 2. CAPEX (capital cost) and OPEX (operating expenses) for small gold processing plants.

\begin{tabular}{ccccc}
\hline Production Rate (tpd) & CAPEX, US\$ & OPEX, US\$/a & CAPEX (US\$/tpa) & OPEX (US\$/tpa) \\
\hline 200 & $3,946,266$ & 855,091 & 66 & 14 \\
100 & $2,603,565$ & 564,150 & 87 & 19 \\
50 & $1,717,712$ & 372,200 & 115 & 25 \\
25 & $1,133,267$ & 245,560 & 151 & 33 \\
10 & 653,986 & 141,708 & 218 & 47 \\
5 & 431,470 & 93,492 & 288 & 62 \\
2 & 248,993 & 53,953 & 415 & 90 \\
\hline
\end{tabular}

Note: tpa $=$ tonnes per annum of 300 days of operation.

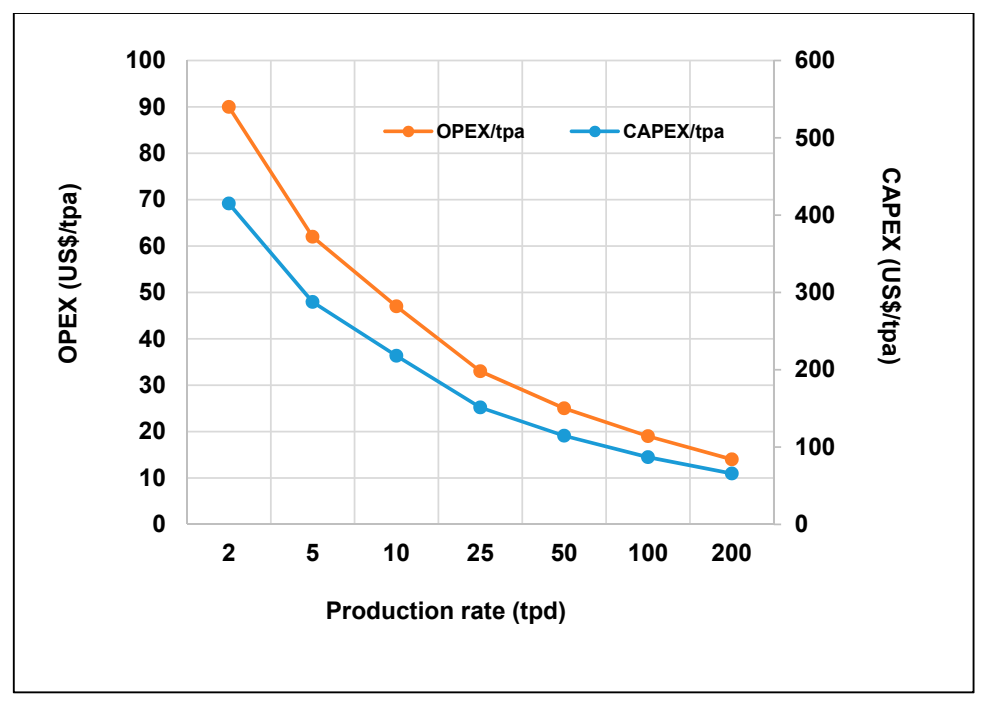

Figure 45. CAPEX and OPEX per tpa of complete small-scale gold plants.

The other economic factor that must be taken into consideration is the minimum ore grade required to operate these plants and to pay back the investment, i.e., to provide a positive net present value 
(NPV). The break-even point characterizes the minimum ore gold grade required to avoid economic losses. For example, according to Figure 46, a processing plant operating with a production rate of $5 \mathrm{tpd}$ and $80 \%$ gold recovery should process ores with no less than $5.21 \mathrm{~g} / \mathrm{t}$ of gold to be profitable.

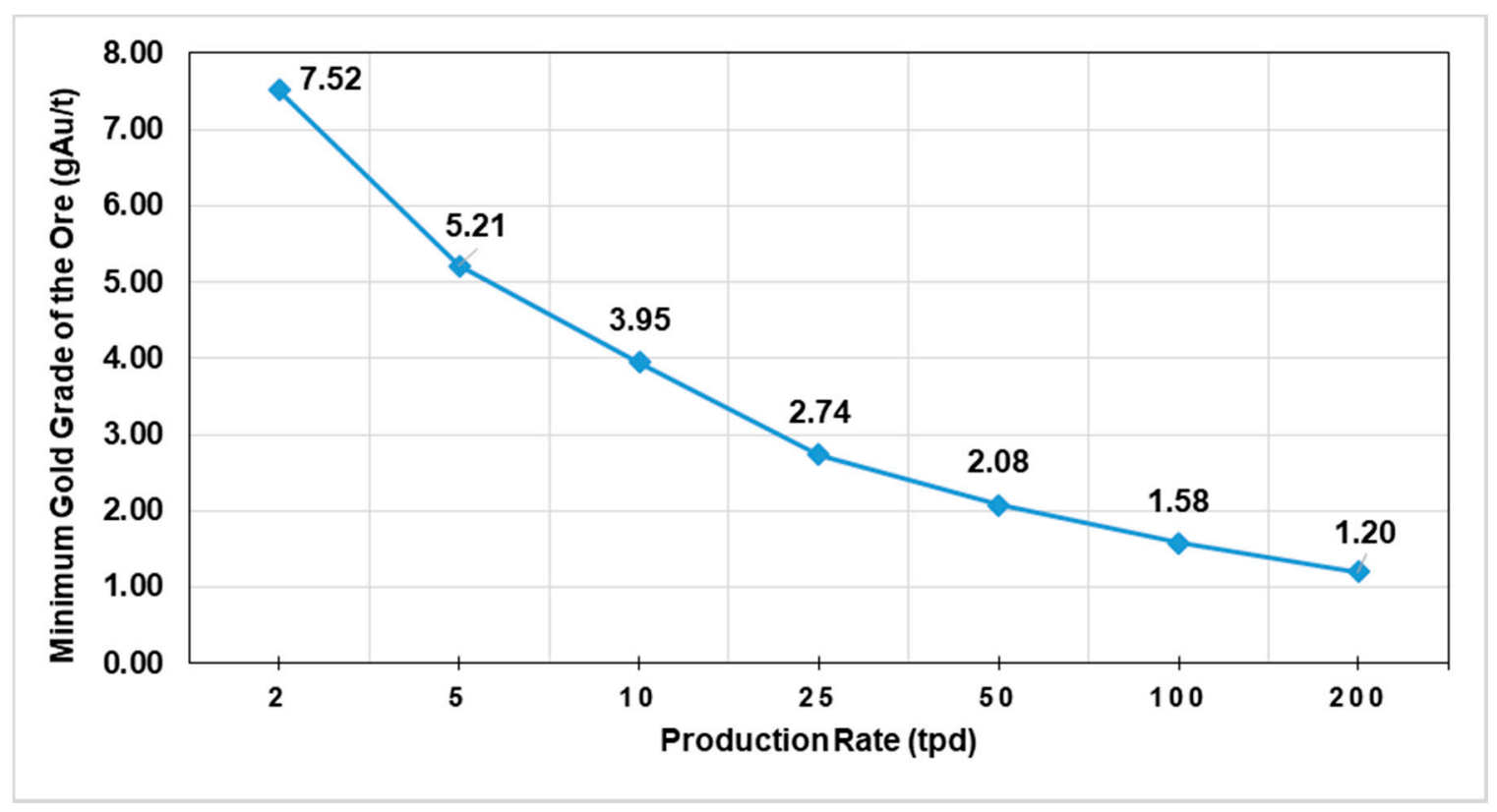

Figure 46. Gold grades that provide break-even point (80\% Au recovery).

For micro-miners producing and processing less than 2 tpd of ore, the economic assessment of homemade pieces of equipment is more favorable than what is offered by the processing centers using amalgamation. The CAPEX and OPEX in Table 3 indicate different levels of production using the chain mills and shaking tables developed by the CICAN project as described above, with a 5-year operation. The OPEX does not contemplate salaries for employees-all miners work in partnership splitting equally the results. The CAPEX calculation assumes that miners will not build their own equipment but will acquire them from a local metal shop. The same occurs for other accessories such as pumps, bins, screens, etc. Based on these assumptions, if the plant has gold recoveries above $50 \%$, they are more profitable at any level of gold grade and production rate than the amalgamation of the whole ore in processing centers recovering $30 \%$ of the gold. However, if they do not have skills or funds to set up a simple cyanidation plant to extract the gold from the concentrates, they must sell the concentrates at a price above $60 \%$ of the gold content, which is the break-even point to pay back the CAPEX and OPEX at any ore grade. If their gold recovery increases to $85 \%$, with a production rate of $1 \mathrm{tpd}$, the miners can make more money than using processing centers if they sell concentrates for more than $35 \%$ of the gold content (Veiga et al., 2018) [37].

Table 3. CAPEX and OPEX for homemade processing plants. (Source: Veiga et al., 2018 [37])

\begin{tabular}{cccc}
\hline Production Rate (tpd) & CAPEX, US\$ & OPEX, US\$/a & OPEX/tpa \\
\hline 0.2 & 2600 & 4500 & 75 \\
0.5 & 4500 & 6259 & 42 \\
1 & 5500 & 8032 & 27 \\
2 & 10,500 & 10,309 & 17 \\
\hline
\end{tabular}

\section{Conclusions}

Gravity separation equipment can concentrate liberated and unliberated gold particles. However, it has been observed that the main losses of gold in AGM occur in the coarse grain size fractions, 
as small gold grains are trapped inside the gangue minerals, and in the fine fractions. Fine gold particles (below 200 mesh $=0.074 \mathrm{~mm}$ ), when liberated, are not concentrated by most typical types of gravity equipment seen at AGM operations. Efficient closed-circuit grinding, size classification, and flotation can increase the gold recoveries to above 80\%, for the large majority of AGM operations.

Many manuals have been published, and are widely available, on how artisanal miners can improve their methods and gold recovery. The pioneers of this educational approach were Priester et al. (1993) [73] with their excellent review of the pros and cons of equipment and techniques used in AGM. Another example is the guide produced by the United Nations Environment Programme (UNEP, 2012) [111] in conjunction with the Artisanal Gold Council. Other manuals have been published by UNIDO (Veiga et al., 2006) [39] and the COMUNICA Project, a Canadian project to demonstrate to artisanal miners cleaner techniques to concentrate gold (Veiga and Correa, 2019) [77]. Despite the merit of bringing simple solutions to eliminate mercury and improve gold recovery, the effectiveness of these toolkits, pamphlets, guides, and manuals, is questionable since miners need permanent technical assistance and capital to sustain the changes in their techniques and behaviors. This is discussed well by Jønsson et al. (2009) [112] and Shandro et al. (2009) [113] when they assess, after some years, the efforts to implement simple retorts to remove mercury safely from amalgams. Rarely did artisanal miners continue using the techniques they learned. The solutions to improve the efficiency and reduce the pollution from AGM operation are not solely related to technology, but also require better participation from governments to simplify laws and mining companies to provide a range of assistance to the miners (Veiga and Marshall, 2019) [7].

There is a common perception from those implementing solutions in AGM that one technique to concentrate and extract gold from concentrates fits all, however, not all ores have the same mineralogical characteristics. This is the most usual mistake observed in the field. It is common to observe agencies looking for "the technical solution" for AGM pollution, focusing on identifying a specific type of equipment to do so. As a result, no sustainable solution has been implemented as miners sooner or later, without technical assistance, return to their rudimentary practices. The idea of demonstrating gold concentration equipment to miners overlooks the following key aspects: (1) the lack of mineralogical information about the ores, (2) the lack of permanent technical assistance, (3) the lack of understanding of the level of miners' skills, (4) the lack of consultation with the miners, (5) the lack of understanding the miners' motivations to change procedures, and, (6) the lack of miners' financial resources to implement and sustain the suggested solutions. This is not an exhaustive list of problems, but just the tip of an iceberg of problems to change the behavior of artisanal miners.

A complete small gravity + flotation (for fine particles) + cyanidation, including all ancillaries and infrastructure as well as tailing dams, can involve a capital cost (CAPEX) from US\$ 60/tpa (tonnes per annum) for a 200 tpd (tonnes per day) plant, to US\$ 415/tpa for a 2 tpd. The operating costs (OPEX) are approximately $\frac{1}{4}$ of the CAPEX, varying from US\$ 14/tpa to US\$ 90/tpa respectively. Homemade solutions can be useful for micro-miners processing less than 2 tonnes of primary ore per day (tpd). The cost for this small plant can be approximately US\$ 11,000 including chain impact mills, gravity concentration, flotation equipment, and cyanidation in small ball mills (Veiga et al., 2018) [37].

From the technical viewpoint, some simple measures can be brought to the attention of the miners to improve their operations. Sluice boxes in a zigzag arrangement operating with good carpets can be very efficient in trapping coarse and fine gold particles. Classifying feed into narrow size fractions would improve substantially the gold recovery with any concentrator, but rarely do miners understand the importance of size classification. Artisanal miners frequently are keen to invest in increasing their production by increasing the mass of ore mined with excavators and trucks instead of improving gold recovery. This increases environmental pollution, as tailing dams are rarely properly designed and managed by artisanal miners. Artisanal gold miners who achieve initial success often later become bankrupted by over-investing in expensive mining equipment, such as excavators and big trucks, rather than investing in improving the efficiency of their concentration plants. 
In the large majority of AGM operations, gold from gravity concentrates or high-grade ores is amalgamated. In the past, many researchers and international agencies promoted the amalgamation of only gravity concentrates, instead of whole ore amalgamation, as the best way to reduce mercury losses. Even without success of reducing mercury use, nowadays all efforts from projects aim at the complete elimination of mercury in AGM by using only gravity concentration; however, this is not practical for the miners if they do not have an affordable and simple method to extract gold from the concentrates. Amalgamating gravity concentrations can reduce drastically the use and loss of mercury, but mercury use cannot be eliminated unless an alternative, such as a leaching process, is used to extract gold from concentrates. The direct smelting of concentrates is typically only practical for some alluvial ores where the gold is mostly liberated from the gangue minerals, allowing the generation of a rich concentrate. If direct smelting is used on low-grade gold concentrates, most gold will end up in the slag. However, if the low-grade concentrate is further concentrated to produce a high gold grade to be directly smelted, a large portion of gold will be lost during the upgrading process. This paradox cannot be easily resolved. Gravity concentration followed by the cyanidation of the concentrates involves capital and skilled operators. It seems that the best practical solution for the AGM operations is to sell their ores for a fair price instead of using processing centers which often exploit the miners, allowing them to only extract the free gold by amalgamation while the centers retain the tailings for processing with cyanide (Veiga and Fadina, 2020) [110].

Artisanal miners frequently use sluice boxes, shaking tables, and jigs for gold concentration, and a few plants are now using centrifuges. Unfortunately, many miners do not have the financial resources to acquire more capital-intensive equipment or do not have the skills to operate more sophisticated equipment efficiently. Without technical assistance, most operators abandon new pieces of equipment when they become frustrated with the additional complexity of the operation, then returning to their previous methods.

Worldwide, the presence of tens of millions of micro-miners panning gold from sediments on the river margins is a problem of poverty and subsistence in rural communities. Micro-miners typically use very small pieces of equipment for gold concentration, such as pans or small sluice boxes, followed by the amalgamation of the concentrate. Bringing more efficient methods to concentrate gold to micro-gold miners will help them produce more gold and temporarily alleviate their poverty problem, but it will not reduce drastically the mercury pollution from this sector. Processing centers recklessly processing tens or hundreds of tonnes of ore daily using mercury and cyanide are the main villains in this scenario of chemical and physical pollution. Therefore, the efforts of governments, NGOs, academics, and international sponsoring agencies must focus on the larger artisanal processing operations, increasing enforcement, educating, and facilitating financial support for the transformation of these polluters into responsible and formalized small gold producers.

Author Contributions: Conceptualization, methodology and writing the original draft were conducted as a team work by M.M.V. and A.J.G. based on their experiences in working with mineral processing and artisanal mining in over 35 countries. All authors have read and agreed to the published version of the manuscript.

Funding: The financial supports from Global Affairs Canada and the Canadian Embassy in Bogotá, as well as the NSERC Discovery Grant, are acknowledged.

Acknowledgments: The authors also recognize the support of the economist Gabriel Jimenez in the economic assessment of this article and the collaboration of the manuscript reviewers to improve the quality of this article.

Conflicts of Interest: The authors declare no conflict of interest.

\section{References}

1. IGF-Intergovernmental Forum on Mining, Mineral, Metals and Sustainable Development. In Global Trends in Artisanal and Small-Scale Mining (ASM): A Review of Key Numbers and Issues; IIED: Winnipeg, MB, Canada, 2017; Available online: https://www.iisd.org/sites/default/files/publications/igf-asm-global-trends.pdf (accessed on 5 November 2020). 
2. Seccatore, J.; Veiga, M.; Origliasso, C.; Marin, T.; De Tomi, G. An estimation of the artisanal small-scale production of gold in the world. Sci. Total Environ. 2014, 496, 662-667. [CrossRef]

3. Thomas, M.J.; Veiga, M.M.; Marshall, B.G.; Dunbar, W.S. Artisanal gold supply chain: Measures from the Ecuadorian Government. Resour. Policy 2019, 64, 101505. [CrossRef]

4. Stocklin-Weinberg, R.; Veiga, M.M.; Marshall, B.G. Training artisanal miners: A proposed framework with performance evaluation indicators. Sci. Total Environ. 2019, 660, 1533-1541. [CrossRef] [PubMed]

5. UNEP-United Nations Environment Programme. Artisanal and Small-Scale Gold Mining; Global Mercury Partnership. 2020. Available online: https://web.unep.org/globalmercurypartnership/our-work/artisanaland-small-scale-gold-mining-asgm (accessed on 5 November 2020).

6. Veiga, M.M. Introducing New Technologies for Abatement of Global Mercury Pollution in Latin America; Pub. UNIDO/UBC/CETEM: Rio de Janeiro, Brazil, 1997; p. 94. Available online: https://www.ais.unwater. org/ais/aiscm/getprojectdoc.php?docid=409 (accessed on 5 November 2020).

7. Veiga, M.M.; Marshall, B.G. The Colombian artisanal mining sector: Formalization is a heavy burden. Extr. Ind. Soc. 2019, 6, 223-228. [CrossRef]

8. ArtisanalMining.org. Inventory of Artisanal Miners. 2018. Available online: http://artisanalmining.org/ Inventory/ (accessed on 5 November 2020).

9. Veiga, M.M.; Angeloci-Santos, G.; Meech, J.A. Review of barriers to reduce mercury use in artisanal gold mining. Extr. Ind. Soc. 2014, 1, 351-361. [CrossRef]

10. Pryor, E. Mineral Processing; Elsevier: New York, NY, USA, 1965; p. 488.

11. Marsden, J.; House, D. The Chemistry of Gold Extraction. Society for Mining; Metallurgy and Exploration Inc.: Littleton, CO, USA, 2006; p. 650.

12. Veiga, M.M.; Angeloci, G.; Hitch, M.; Velasquez-López, P.C. Processing centers in artisanal gold mining. J. Clean. Prod. 2014, 64, 535-544. [CrossRef]

13. Drace, K.; Kiefer, A.M.; Veiga, M.M. Cyanidation of Mercury-contaminated tailings: Potential health effects and environmental justice. Curr. Environ. Health Rep. 2016, 3, 443-449. [CrossRef]

14. Marshall, B.G.; Veiga, M.M.; Da Silva, H.A.M.; Guimarães, J.R.D. Cyanide contamination of the puyango-tumbes river caused by artisanal gold mining in portovelo-zaruma, ecuador. Curr. Environ. Health Rep. 2020, 7, 303-310. [CrossRef]

15. Seney, C.S.; Aljic, S.; Moore, M.E.; Bridges, C.C.; Orr, S.E.; Barnes, M.C.; Mathis, T.N.; McKallip, R.J.; Bellott, B.J.; Drace, K.; et al. Reaction of cyanide with Hgo-contaminated gold mining tailings produces soluble mercuric cyanide complexes. J. Chem. Res. Toxic. 2020. [CrossRef]

16. Malm, O. Gold Mining as a Source of Mercury Exposure in the Brazilian Amazon. Environ. Res. 1998, 77, 73-78. [CrossRef]

17. Hentschel, T.; Hruschka, F.; Priester, M. Global Report on Artisanal \& Small-Scale Mining. Report to MMSD/IIED-International Institute of Environment and Development. 2002, p. 67. Available online: https://www.iied.org/mmsd-final-report (accessed on 5 November 2020).

18. Hilson, G.; Hilson, C.J.; Pardie, S. Improving awareness of mercury pollution in small-scale gold mining communities: Challenges and ways forward in rural Ghana. Environ. Res. 2007, 103, 275-287. [CrossRef] [PubMed]

19. Esdaile, L.J.; Chalker, J.M. The mercury problem in artisanal and small-scale gold mining. Chem. Eur. J. 2018, 24, 6905-6916. [CrossRef]

20. Zolnikov, T.; Ortiz, D.R. A systematic review on the management and treatment of mercury in artisanal gold mining. Sci. Total Environ. 2018, 633, 816-824. [CrossRef]

21. Veiga, M.M.; Baker, R. Protocols for Environmental and Health Assessment of Mercury Released by Artisanal and Small-Scale Gold Miners; Pub. GEF/UNDP/UNIDO Global Mercury Project: Vienna, Austria, 2004; p. 289. Available online: https://iwlearn.net/resolveuid/617e8a7184a7ec1e292a61c2319dc30f (accessed on 5 November 2020).

22. Grayson, R. Fine gold recovery-Alternatives to mercury and cyanide. World Placer J. 2007, 7, 66-161.

23. Sampaio, C.H.; Tavares, L.M.M. Gravity Beneficiation: An Introduction to the Mineral Concentration and Recycling of Materials Based on Specific Gravity; Univ Federal Rio Grande do Sul: Porto Alegre, Brazil, 2005; p. 603. (In Portuguese)

24. Gaudin, A.M. Principles of Mineral Dressing; McGraw-Hill: New York, NY, USA, 1939; p. 543.

25. Wang, W.; Poling, G.W. Methods for recovering fine placer gold. CIM Bull. 1983, 76, 47-56. 
26. Ofori-Sarpong, G.; Amankwah, R. Comminution environment and gold particle morphology: Effects on gravity concentration. Miner. Eng. 2011, 24, 590-592. [CrossRef]

27. Walsh, D.E.; Rao, P.D. A Study of Factors Suspected of Influencing the Settling Velocity of Fine Gold Particles; MLRL Report no. 76; University of Alaska Fairbanks: Fairbanks, AK, USA, 1988; p. 60. Available online: http://dggs.alaska.gov/webpubs/mirl/report_no/text/mirl_n76.pdf (accessed on 5 November 2020).

28. Gupta, A.; Yan, D. Mineral Processing Design and Operations: An Introduction, 2nd ed.; Elsevier: Amsterdam, The Netherlands, 2016; p. 882.

29. Giusti, L. The morphology, mineralogy, and behavior of "fine-grained" gold from placer deposits of Alberta: Sampling and implieations for mineral exploration. Can. J. Earth Sci. 1968, 23, 1662-1672. [CrossRef]

30. Limbaugh, R.H. Making Old Tools Work Better: Pragmatic Adaptation and Innovation in Gold-Rush Technology. Calif. Hist. 1998, 77, 24-51. [CrossRef]

31. Spiegel, S.J.; Veiga, M.M. International guidelines on mercury management in small-scale gold mining. J. Clean. Prod. 2010, 18, 375-385. [CrossRef]

32. Hardcore Miner. The Use of Hydraulic Mining in Gold Country. 2017. Available online: https: //howtofindgoldnuggets.com/the-use-of-hydraulic-mining-in-gold-country/ (accessed on 5 November 2020).

33. Lima, L.D.A.; Bernardez, L.; Barbosa, L. Characterization and treatment of artisanal gold mine tailings. J. Hazard. Mater. 2008, 150, 747-753. [CrossRef]

34. Koppalkar, S. Effect of Operating Variables in Knelson Concentrators: A Pilot-Scale Study. Ph.D. Thesis, Department of Mining and Materials Engineering, McGill University, Montreal, QC, Canada, 2009; p. 167.

35. Khalesi, M.R.; Bazin, C.; Hodouin, D.; Bellec, S. Modelling of the gold mineral associations and size distribution of a grinding mill product. In Proceedings of the World Gold 2011 50th Annual Conference of Metallurgists CIM, MetSoc, Montreal, QC, Canada, 2-5 October 2011; p. 14.

36. Bode, P.; McGrath, T.; Eksteen, J. Characterising the effect of different modes of particle breakage on coarse gangue rejection for an orogenic gold ore. Miner. Process. Extr. Met. 2020, 129, 35-48. [CrossRef]

37. Veiga, M.M.; Masson, P.; Perron, D.; Laflamme, A.-C.; Gagnon, R.; Jimenez, G.; Marshall, B.G.; Mason, P. An affordable solution for micro-miners in Colombia to process gold ores without mercury. J. Clean. Prod. 2018, 205, 995-1005. [CrossRef]

38. Silva, M. Placer Gold Recovery Methods; California Department of Conservation, Division of Mines and Geology: Sacramento, CA, USA, 1986; p. 37, Special Pub. 7. Available online: http://spma-gold.org/pdf/ reports/placerGoldRecoveryMethods_SP87_1986.pdf (accessed on 5 November 2020).

39. Veiga, M.M.; Metcalf, S.; Baker, R.F.; Klein, B.; Davis, G.; Bamber, A.; Siegel, S.; Singo, P. Manual for Training Artisanal and Small-Scale Gold Miners; Pub. GEF/UNDP/UNIDO Global Mercury Project: Vienna, Austria, 2006; p. 144. Available online: https://iwlearn.net/resolveuid/fe84adccc030ee07813d8278fdb4b790 (accessed on 5 November 2020).

40. Vieira, R. Mercury-free gold mining technologies: Possibilities for adoption in the Guianas. J. Clean. Prod. 2006, 14, 448-454. [CrossRef]

41. Michaud, D. How to Size a Sluice Box. 2015. Available online: https://www.911metallurgist.com/blog/howto-size-a-sluice-box (accessed on 5 November 2020).

42. Teschner, B.; Smith, N.M.; Borrillo-Hutter, T.; John, Z.Q.; Wong, T.E. How efficient are they really? A simple testing method of small-scale gold miners' gravity separation systems. Miner. Eng. 2017, 105, 44-51. [CrossRef]

43. Sivamohan, R.; Forssberg, E. Principles of sluicing. Int. J. Miner. Process. 1985, 15, 157-171. [CrossRef]

44. Lehmann, U. Notice to the function of batch-operated sluices. Miner. Eng. 2020, 146, 106144. [CrossRef]

45. Lins, F.F.; Farid, L.H. Gravity Concentration. In Aspectos Diversos da Garimpagem de Ouro; Lins, F.A.F., Ed.; CETEM, Center of Mineral Technoloy: Rio de Janeiro, Brazil, 1992; pp. 31-51. Ser. Tecnologia Mineral, n.54; (In Portuguese)

46. Veiga, M.M. Information about the Project Sites in Indonesia. Report to UNIDO Global Mercury Project; UNIDO: Veinna, Austria, 2003; p. 12. Available online: http://archive.iwlearn.net/globalmercuryproject.org/countries/ indonesia/docs/Indo_site_information.pdf (accessed on 5 November 2020).

47. McCraken, D. True Life Gold Prospecting Adventure. The New 49' ers Inc., 2013. Available online: https://goldgold.com/ (accessed on 5 November 2020). 
48. Mitchell, C.J.; Evans, E.J.; Styles, M.T. Review of Gold Particle-Size and Recovery Methods; Technical Report WC \97\14; Overseas Geology Series; British Geological Survey: Keyworth, Nottingham, UK, 1997; p. 34. Available online: https://core.ac.uk/download/pdf/58474.pdf (accessed on 5 November 2020).

49. Gonçalves, A.O.; Marshall, B.G.; Moreno-Chavez, J.; Veiga, M.M. Mercury and Cyanide Use at Artisanal and Small-scale Gold Processing Centers in Zaruma-Portovelo, Southern Ecuador. J. Clean. Prod. 2017, 165, 836-845. [CrossRef]

50. Litvintsev, V.S.; Pulyaevsky, A.M.; Sas, P.P. Optimization of flushing sluice flow in hydrohoist gold washing machines. J. Min. Sci. 2012, 48, 1054-1057. [CrossRef]

51. Velasquez, P.C.; Veiga, M.M.; Hall, K. Mercury balance in amalgamation in artisanal and small-scale gold mining: Finding ways to reduce environmental pollution in Portovelo-Zaruma, Ecuador. J. Clean. Prod. 2010, 18, 226-232. [CrossRef]

52. Keene Engineering. Sluice Boxes. 2020. Available online: http://www.keeneeng.com/mm5/merchant.mvc? Screen=CTGY\&Category_Code=SB (accessed on 5 November 2020).

53. Hamilton, J.F. A Study of the Fine Gold Recovery of Selected Sluicebox Configurations. Master's Thesis, University British Columbia, Vancouver, BC, Canada, 1988; p. 104. Available online: https://open.library.ubc. ca/cIRcle/collections/ubctheses/831/items/1.0097828 (accessed on 5 November 2020).

54. Feijão, A.J.; Pinto, J.A. Amazon and the Gold Saga of the 20th Century. In Garimpo, Meio Ambiente e Sociedade Indigenas; Barbosa, L., Lobato, A.L., Drummond, J.A., Eds.; University Federal Fluminense: Niteroi, RJ, Brazil, 1992; pp. 18-36. (In Portuguese)

55. Veiga, M.M.; Hinton, J.J. Abandoned artisanal gold mines in the Brazilian Amazon: A legacy of mercury pollution. Nat. Resour. Forum 2002, 26, 15-26. [CrossRef]

56. Poling, G.W.; Hamilton, J.F. Fine Gold Recovery of Selected Sluicebox Configuration; University of British Columbia Report of Program 3, Placer Mining; The University of British Columbia: Vancouver, BC, Canada, 1986; p. 85. Available online: https://www.hecklerfabrication.com/files/fine_gold_recovery_sluiceboxes_Poling.pdf (accessed on 5 November 2020).

57. Gold Hog. Sluice Mats. 2012. Available online: https://youtu.be/U3GeRJ8YPnE or https://youtu.be/kSbx3I_ OrMA (accessed on 5 November 2020).

58. Gold Dog. Carpets for Artisanal Gold Mining. YouTube, 2016. Available online: https://www.youtube.com/ watch?v=WyswDAk6iMQ (accessed on 5 November 2020). (In Portuguese).

59. Burt, R. Gravity concentration technology. In Development of Mineral Processing, 5th ed.; Fuerstenau, D.W., Ed.; Elsevier: New York, NY, USA, 1984; p. 605.

60. Pulp Density Scales. Marcy Pulp Density Scale. 2011. Available online: http://pulpdensityscale.com/ (accessed on 5 November 2020).

61. 911-Metellurgist. Dry Washer Gold Mining. 2017. Available online: https://www.911metallurgist.com/blog/ drywashers-gold-mining (accessed on 5 November 2020).

62. Keene Engineering. Dry Washers. 2020. Available online: http://www.keeneeng.com/mm5/merchant.mvc? Screen=CTGY\&Category_Code=DW (accessed on 5 November 2020).

63. Maia, F.; Veiga, M.M.; Marshall, B.G.; Stocklin-Weinberg, R.; Constanzo, C.; Hariojati, N.; Villegas, C. Need for technological improvements in the Indonesian cassiterite artisanal mining sector. Extr. Ind. Soc. 2019, 6, 1292-1310.

64. Veiga, M.M.; Bermudez, D.; Pacheco-Ferreira, H.; Pedroso, L.R.M.; Gunson, A.J.; Berrios, G.; Vos, L.; Huidobro, P.; Roeser, M. Mercury pollution from artisanal gold mining in block B, El Callao, Bolívar State, Venezuela. In Dynamics of Mercury Pollution on Regional and Global Scales, Atmospheric Processes and Human Exposures around the World; Pirrone, N., Mahaffey, K.R., Eds.; Springer: Norwell, MA, USA, 2005; pp. 421-450. ISBN 0-387-24493-X.

65. Taggart, A.F. Handbook of Ore Dressing; John Wiley \& Sons Inc.: New York, NY, USA, 1945; p. 1905.

66. Green, C.S.; Lewis, P.J.; Wozniak, J.R.; Drevnick, P.E.; Thies, M.L. A comparison of factors affecting the small-scale distribution of mercury from artisanal small-scale gold mining in a Zimbabwean stream system. Sci. Total Environ. 2019, 647, 400-410. [CrossRef] [PubMed]

67. WCED-World Commission on Environment and Development. Our Common Future; Oxford University Press: Oxford, UK, 1987; p. 400.

68. Veiga, M.M. Artisanal gold mining: A trap of poverty and pollution. Geotech. News 2009, 27, 45-47. 
69. Telmer, K.; Costa, M.; Angélica, R.S.; Araujo, E.S.; Maurice, Y. The source and fate of sediment and mercury in the Tapajós River, Pará, Brazilian Amazon: Ground- and space-based evidence. J. Environ. Manag. 2006, 81, 101-113. [CrossRef] [PubMed]

70. Sousa, R.N.; Veiga, M.M. Using performance indicators to evaluate an environmental education program in artisanal gold mining communities in the brazilian amazon. Ambio 2009, 38, 40-46. [CrossRef] [PubMed]

71. Abols, J.A.; Grady, P.M. Maximizing gravity recovery through the application of multiple gravity devices. In Proceedings of the MEI Conference Gravity Concentration, Perth, Australia, 13-14 March 2006. Available online: http://iteseerx.ist.psu.edu/viewdoc/download?doi=10.1.1.492.1408\&rep=rep1\&type=pdf (accessed on 5 November 2020).

72. Wills, B.A.; Finch, J.A. Wills' Mineral Processing Technology, 8th ed.; Elsevier: Amsterdam, The Netherlands, 2016; p. 498.

73. Priester, M.; Hentshcel, T.; Benthin, B. Tools for Mining. German Appropriate Technology Exchange; Friedr. Vieweg \& Sohn Verlagsgesellschaft mbH: Braunschweig, Germany, 1993; p. 537. Available online: http://www. nzdl.org/gsdlmod?e=d-00000-00---off-0hdl--00-0----0-10-0---0---0direct-10---4-------0-11--11-en-50---20about---00-0-1-00-0--4----0-0-11-10-0utfZz-8-00\&cl=CL2.19.7\&d=HASHc096d161f676b196cfad56\&gt=2 (accessed on 17 November 2020).

74. Mitchell, C.J.; Evans, E.J.; Styles, M.T. The Design, Construction and Testing of a Simple Shaking Table for Gold Recovery: Laboratory Testing and Field Trials; Technical Report Survey; British Geological Survey: Keyworth, UK, 1997; p. 51. Available online: https://www.911metallurgist.com/blog/wp-content/uploads/2015/08/GoldShaking-Table-Design.pdf (accessed on 5 November 2020).

75. MD Mineral Technologies. Gemeni Table. 2005. Available online: http://www.gravityrecovery.com/ Introduction.htm (accessed on 5 November 2020).

76. Strange, S.; Schumacher, E.F. Small is beautiful: A study of economics as if people mattered. Int. Aff. 1974, 50, 104. [CrossRef]

77. Veiga, M.M.; Correa, M. Alternative Technologies for Processing Gold in Artisanal Mining; Agriteam and Comunica Project, Ed.; Pub. Canadian Foreign Affairs: Bogotá, Colombia, 2019; p. 89. Available online: https: //comunicacolombia.co/images/recursos/libro_mercurio.pdf (accessed on 5 November 2020). (In Spanish)

78. Jankovic, A.; Valery, W.; Sonm, B. The Benefits of High Classification Efficiency in Closed Ball Mill Circuits. Proc. XV Balkan Mineral Processing Congress, Sozopol, Bulgaria. 2013. Available online: https://www.researchgate.net/publication/283645413_THE_BENEFITS_OF_HIGH_ CLASSIFICATION_EFFICIENCY_IN_CLOSED_BALL_MILL_CIRCUITS (accessed on 5 November 2020).

79. Chen, Q.; Yang, H.-Y.; Tong, L.-L.; Niu, H.-Q.; Zhang, F.-S.; Chen, G.-M. Research and application of a Knelson concentrator: A review. Miner. Eng. 2020, 152, 106339. [CrossRef]

80. Sepro Mineral Systems Corperation. Which Falcon Concentrators Can Recover Gold? 2019. Available online: https://seprosystems.com/which-falcon-concentrators-can-recover-gold/ (accessed on 5 November 2020).

81. Agorhom, E.A.; Owusu, C. The Effects of pulp rheology on gravity gold recovery in free milling gold ore of the Tarkwaian systems of Ghana. Miner. Process. Extr. Met. Rev. 2020, 1-6. [CrossRef]

82. FLSmidth. Knelson Concentrator KC CD12: Specification Sheet. 2013. Available online: https://www.consep. com.au/assets/documents/Knelson\%20KC-CD12\%20rev1.pdf (accessed on 5 November 2020).

83. Falcon Concentrator. Falcon Semi-Batch (SB) Concentrators. 2019. Available online: https://seprosystems. com/wp-content/uploads/2016/08/Falcon_SB_Concentrator_2018.pdf (accessed on 5 November 2020).

84. Laplante, A.R. Testing Requirements and Insight for Gravity Gold Circuit Design. In Proceedings of the Randol Gold \& Silver Forum 2000, Vancouver, BC, Canada, 25 April 2000; p. 11. Available online: http://citeseerx.ist. psu.edu/viewdoc/download?doi=10.1.1.604.25\&rep=rep1\&type=pdf (accessed on 5 November 2020).

85. Laplante, A.R.; Dunne, R.C. The Gravity Recoverable Gold and Flash Flotation. In Proceedings of the 34th Annual Meeting of the Canadian Mineral Processors, Ottawa, ON, Canada, 22-24 January 2002; p. 19. Available online: https://seprosystems.com/wp-content/uploads/2016/09/laplante.pdf (accessed on 5 November 2020).

86. Laplante, A.R.; Clarke, J. A simple gravity-recoverable gold test. In Proceedings of the 38th Annual Meeting of the Canadian Mineral Processors, Ottawa, ON, Canada, 17-19 January 2006; pp. 23-37.

87. Zhang, W.; Cai, M.; Li, G.; Huang, F.; Zhu, X.; Xu, C.; Zhao, J. Research and application of nelson concentrator in beneficiation test of quartz vein type gold ore. IOP Conf. Ser. Earth Environ. Sci. 2020, 546, 052056. [CrossRef] 
88. Knleson Concentrators. Semi-Continuous (Batch) Knelson Concentrator Specifications. 2020. Available online: http://knelsongravity.xplorex.com/sites/knelsongravity/files/Gravity/Semi-Final.pdf (accessed on 5 November 2020).

89. Appel, P.W.U.; Na-Oy, L. The borax method of gold extraction for small-scale miners. J. Health Pollut. 2011, 2, 5-10. [CrossRef]

90. Beard, R.R. Treating Gold Ores by Amalgamation; Department of Mines and Mineral Resources, University of Arizona: Tucson, AZ, USA, 1987; Circular 27. Available online: http://mines.az.gov/Publications/ circ027amalgam.htm (accessed on 5 November 2020).

91. Pantoja, F.; Alvarez, R. Decrease of Pollution by Mercury in Gold Mining in Latin America; Villas Boas, R.C., Barreto, M.L., Eds.; Mine Closure in Iberoamerica; CYTED/IMAAC/UNIDO: Rio de Janeiro, Brazil, 2000; pp. 178-190.

92. Moody, K.H.; Hasan, K.M.; Aljic, S.; Blakeman, V.M.; Hicks, L.P.; Loving, D.C.; Moore, M.E.; Hammett, B.S.; Silva-González, M.; Seney, C.S.; et al. Mercury emissions from Peruvian gold shops: Potential ramifications for Minamata compliance in artisanal and small-scale gold mining communities. Environ. Res. 2020, 182, 109042. [CrossRef] [PubMed]

93. Velasquez, P.C.; Veiga, M.M.; Klein, B.; Shandro, J.; Hall, K. Cyanidation of mercury-rich tailings in artisanal and small-scale gold mining: Identifying strategies to manage environmental risks in southern Ecuador. J. Clean. Prod. 2011, 19, 1125-1133. [CrossRef]

94. Hedley, N.; Tabachnick, H. Chemistry of Cyanidation. Mineral Dressing Notes; American Cyanamid Co.: Bound Brook, NJ, USA, 1968.

95. Egan, J.; Bazin, C.; Hodouin, D. Effect of particle size and grinding time on gold dissolution in cyanide solution. Minerals 2016, 6, 68. [CrossRef]

96. Higgins, P. What is Affecting Your Dissolved Oxygen Measurements? 2013. Available online: https://www.ysi.com/ysi-blog/water-blogged-blog/2013/05/what-is-affecting-your-dissolved-oxygenmeasurements-part-1-of-4 (accessed on 5 November 2020).

97. Sousa, R.N.; Veiga, M.M.; Klein, B.; Telmer, K.; Gunson, A.J.; Bernaudat, L. Strategies for Reducing the Environmental Impact of Reprocessing Mercury-contaminated Tailings in the Artisanal and Small-scale Gold Mining Sector: Insights from Tapajos River Basin, Brazil. J. Clean. Prod. 2010, 18, 1757-1766. [CrossRef]

98. Mahlatsi, S.; Guest, R. The iGoli mercury-free gold extraction process. Urban Health Dev. Bull. 2003, 6, 62-63.

99. Styles, M.; Amankwah, R.; Al Hassan, S.; Nartey, R. The identification and testing of a method for mercury-free gold processing for artisanal and small-scale gold miners in Ghana. Int. J. Environ. Pollut. 2010, 41, 289. [CrossRef]

100. Hilson, G.; Monhemius, A.; Monhemius, A. Alternatives to cyanide in the gold mining industry: What prospects for the future? J. Clean. Prod. 2006, 14, 1158-1167. [CrossRef]

101. Gökelma, M.; Birich, A.; Stopić, S.R.; Friedrich, I.D.H.B. A review on alternative gold recovery re-agents to cyanide. J. Mater. Sci. Chem. Eng. 2016, 4, 8-17. [CrossRef]

102. EnviroLeach Technologies. Eco-Friendly Gold Production. 2020. Available online: https://enviroleach.com/ (accessed on 5 November 2020).

103. Torkaman, P.; Veiga, M.M.; Andrade-Lima, L.R.P.; Oliveira, L.A.; Motta, J.S.; Jesus, J.L.; Lavkulich, L. Leaching gold with cassava: An option for artisanal miners to eliminate mercury use. J. Clean. Prod. 2020. submitted.

104. Sen, S.; Ipekoglu, U.; Cilingir, Y. Flotation of fine gold particles by the assistance of coal-oil agglomerates. Sep. Sci. Technol. 2010, 45, 610-618. [CrossRef]

105. Kotze, W.; Petersen, F.W. Free gold recovery by coal-oil agglomeration. J. S. Afr. Inst. Min. Metal. 2000, 100, 57-62.

106. Marciano, A.; Costa, L.; Lins, F. Utilization of coal-oil agglomerates to recover gold particles. Miner. Eng. 1994, 7, 1401-1409. [CrossRef]

107. Mehrotra, V.; Sastry, K.; Morey, B. Review of oil agglomeration techniques for processing of fine coals. Int. J. Miner. Process. 1983, 11, 175-201. [CrossRef]

108. Calvez, J.; Kim, M.; Wong, P.; Tran, T. Use of coal-oil agglomerates for particulate gold recovery. Miner. Eng. 1998, 11, 803-812. [CrossRef]

109. Otsuki, A.; Yue, C. Coal-oil gold agglomeration assisted flotation to recover gold from refractory ore. J. Physics Conf. Ser. 2017, 879, 012021. [CrossRef] 
110. Veiga, M.M.; Fadina, O. A review of the failed attempts to curb mercury use at artisanal gold mines and a proposed solution. Extr. Ind. Soc. 2020, 7, 1135-1146. [CrossRef]

111. UNEP-United Nations Environment Programme. A Practical Guide on Reducing Mercury Use in Artisanal and Small-Scale Gold Mining. Guide Produced in Conjunction with Artisanal Gold Council. 2012. Available online: https://wedocs.unep.org/bitstream/handle/20.500.11822/11524/reducing_mercury_ artisanal_gold_mining.pdf?sequence=1\&isAllowed=y (accessed on 5 November 2020).

112. Jønsson, J.B.; Appel, P.W.; Chibunda, R.T. A matter of approach: The retort's potential to reduce mercury consumption within small-scale gold mining settlements in Tanzania. J. Clean. Prod. 2009, 17, 77-86. [CrossRef]

113. Shandro, J.A.; Veiga, M.M.; Chouinard, R. Reducing mercury pollution from artisanal gold mining in Munhena, Mozambique. J. Clean. Prod. 2009, 17, 525-532. [CrossRef]

Publisher's Note: MDPI stays neutral with regard to jurisdictional claims in published maps and institutional affiliations.

(C) 2020 by the authors. Licensee MDPI, Basel, Switzerland. This article is an open access article distributed under the terms and conditions of the Creative Commons Attribution (CC BY) license (http://creativecommons.org/licenses/by/4.0/). 